\title{
The International Multidisciplinary Consensus Conference on Multimodality Monitoring in Neurocritical Care: Evidentiary Tables
}

\author{
A Statement for Healthcare Professionals from the Neurocritical Care Society and the \\ European Society of Intensive Care Medicine
}

\begin{abstract}
Peter Le Roux • David K. Menon - Giuseppe Citerio • Paul Vespa • Mary Kay Bader • Gretchen Brophy • Michael N. Diringer $\cdot$ Nino Stocchetti $\cdot$ Walter Videtta $\cdot$ Rocco Armonda $\cdot$ Neeraj Badjatia $\cdot$ Julian Bösel $\cdot$ Randall Chesnut - Sherry Chou · Jan Claassen - Marek Czosnyka • Michael De Georgia • Anthony Figaji Jennifer Fugate $\cdot$ Raimund Helbok $\cdot$ David Horowitz $\cdot$ Peter Hutchinson $\cdot$ Monisha Kumar $\cdot$ Molly McNett Chad Miller • Andrew Naidech • Mauro Oddo • DaiWai Olson • Kristine O'Phelan • J. Javier Provencio • Corinna Puppo $\cdot$ Richard Riker $\cdot$ Claudia Roberson $\cdot$ Michael Schmidt $\cdot$ Fabio Taccone
\end{abstract}

Published online: 22 January 2015

(C) Springer Science+Business Media New York 2015

\begin{abstract}
A variety of technologies have been developed to assist decision-making during the management of patients with acute brain injury who require intensive care.
\end{abstract}

The Neurocritical Care Society affirms the value of this consensus statement as an educational tool for clinicians.

\section{P. Le Roux $(\square)$}

Brain and Spine Center, Suite 370, Medical Science Building, Lankenau Medical Center, 100 East Lancaster Avenue,

Wynnewood, PA 19096, USA

e-mail: lerouxp@mlhs.org

\section{K. Menon}

Neurosciences Critical Care Unit, Division of Anaesthesia,

University of Cambridge, Addenbrooke's Hospital, Box 93,

Cambridge CB2 2QQ, UK

e-mail: dkm13@wbic.cam.ac.uk

\section{G. Citerio}

NeuroIntensive Care Unit, Department of Anesthesia and

Critical Care, Ospedale San Gerardo, Via Pergolesi 33,

20900 Monza, Italy

e-mail: g.citerio@hsgerardo.org

P. Vespa

David Geffen School of Medicine at UCLA, Los Angeles,

CA 90095, USA

e-mail: PVespa@mednet.ucla.edu

M. K. Bader

Neuro/Critical Care CNS, Mission Hospital, Mission Viejo, CA 92691, USA

e-mail: Marykay.Bader@stjoe.org
A large body of research has been generated describing these various technologies. The Neurocritical Care Society (NCS) in collaboration with the European Society of Intensive Care Medicine (ESICM), the Society for Critical Care Medicine (SCCM), and the Latin America Brain

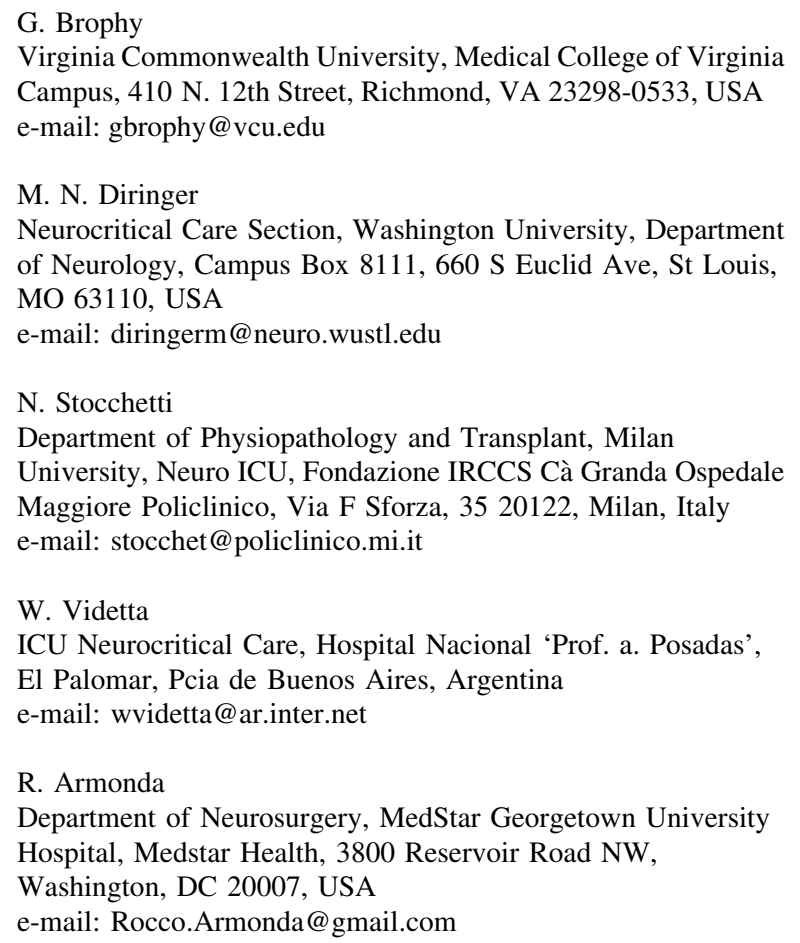


Injury Consortium (LABIC) organized an international, multidisciplinary consensus conference to perform a systematic review of the published literature to help develop evidence-based practice recommendations on bedside physiologic monitoring. This supplement contains a Consensus Summary Statement with recommendations and individual topic reviews on physiologic processes important in the care of acute brain injury. In this article we provide the evidentiary tables for select topics including systemic hemodynamics, intracranial pressure, brain and systemic oxygenation, EEG, brain metabolism, biomarkers, processes of care and monitoring in emerging economies to provide the clinician ready access to evidence that supports recommendations about neuromonitoring.

Keywords Consensus development conference . Grading of Recommendations Assessment Development and Evaluation (GRADE) · Brain metabolism . Brain oxygen - Clinical trials - Intracranial pressure . Microdialysis - Multimodal monitoring · Neuromonitoring · Traumatic brain injury · Brain physiology $\cdot$ Bio-informatics $\cdot$ Biomarkers · Neurocritical care $\cdot$ Clinical guidelines

\footnotetext{
N. Badjatia

Department of Neurology, University of Maryland Medical Center, 22 S Greene St, Baltimore, MD 21201, USA

e-mail: nbadjatia@umm.edu

J. Bösel

Department of Neurology, Ruprect-Karls University, Hospital Heidelberg, Im Neuenheimer Feld 400, 69120 Heidelberg, Germany

e-mail: Julian.Boesel@med.uni-heidelberg.de

\section{R. Chesnut}

Harborview Medical Center, University of Washington,

Mailstop 359766, 325 Ninth Ave, Seattle, WA 98104-2499, USA

e-mail: chesnutr@u.washington.edu

\section{S. Chou}

Department of Neurology, Brigham and Women's Hospital, 75 Francis Street, Boston, MA 02115, USA

e-mail: schou1@partners.org

\section{J. Claassen}

Columbia University College of Physicians \& Surgeons, 177 Fort Washington Avenue, Milstein 8 Center Room 300, New York, NY 10032, USA

e-mail: jc1439@cumc.columbia.edu

\section{Czosnyka}

Department of Neurosurgery, University of Cambridge, Addenbrooke's Hospital, Box 167, Cambridge CB2 0QQ, UK e-mail:mc141@medschl.cam.ac.uk
}

\section{Introduction}

The management of patients admitted to the Neurocritical Care Unit is centered on the early identification and removal of mass lesions and on the detection, prevention, and management of secondary brain injury. This requires careful and repeated assessment and monitoring of clinical and laboratory findings, imaging studies, and bedside physiologic data to target care. The field of neurocritical care has expanded rapidly in the last decade and there is a large and expanding body of literature that describes various bedside techniques used to monitor patients with acute brain injury. Therefore, the Neurocritical Care Society (NCS) in collaboration with the European Society of Intensive Care Medicine (ESICM), the Society for Critical Care Medicine (SCCM), and the Latin America Brain Injury Consortium (LABIC) organized a consensus conference to develop evidence-based recommendations on bedside physiological neuromonitoring. This process required the development of evidentiary tables after a systematic literature review. In this article we provide the evidentiary tables on select topics to assist clinicians in bedside decision making.

M. De Georgia

University Hospital Case Medical Center, Case Western Reserve University School of Medicine, 11100 Euclid Avenue,

Cleveland, OH 44106, USA

e-mail: michael.degeorgia@uhhospitals.org

A. Figaji

University of Cape Town, 617 Institute for Child Health,

Red Cross Children's Hospital, Rondebosch, Cape Town 7700,

South Africa

e-mail: anthony.figaji@uct.ac.za

J. Fugate

Department of Neurology, Mayo Clinic, 200 First Street SW,

Rochester, MN 55905, USA

e-mail: Fugate.Jennifer@mayo.edu

R. Helbok

Department of Neurology, Neurocritical Care Unit, Innsbruck

Medical University, Anichstr.35, 6020 Innsbruck, Austria

e-mail: raimund.helbok@uki.at

D. Horowitz

University of Pennsylvania Health System, 3701 Market Street, Philadelphia, PA 19104, USA

e-mail: david.horowitz@uphs.upenn.edu

P. Hutchinson

Department of Clinical Neurosciences, University of Cambridge,

Box 167 Addenbrooke's Hospital, Cambridge CB2 2QQ, UK

e-mail: pjah2@cam.ac.uk 


\section{Process}

This Supplement contains a consensus summary statement that describes the process used to develop recommendations in detail [1]. Seventeen individual topics were chosen for review and two authors assigned to each topic performed a critical literature review according to the Preferred Reporting Items for Systematic Reviews and Meta-Analyses (PRISMA) statement [2] with the help of a medical librarian. Evidentiary tables were prepared. These tables were used to then facilitate discussion at an international multidisciplinary conference and develop

\section{Kumar}

Department of Neurology, Perelman School of Medicine, University of Pennsylvania, 3 West Gates, 3400 Spruce Street, Philadelphia, PA 19104, USA

e-mail: monisha.kumar@uphs.upenn.edu

\section{McNett}

Nursing Research, The MetroHealth System, 2500 MetroHealth

Drive, Cleveland, OH 44109, USA

e-mail: mmcnett@metrohealth.org

\section{Miller}

Division of Cerebrovascular Diseases and Neurocritical Care, The Ohio State University, 395W. 12th Ave, 7th Floor,

Columbus, OH 43210, USA

e-mail: ChadM.Miller@osumc.edu

\section{A. Naidech}

Department of Neurology, Northwestern University Feinberg, SOM

710, N Lake Shore Drive, 11th Floor, Chicago, IL 60611, USA

e-mail: ANaidech@nmff.org

\section{Oddo}

Department of Intensive Care Medicine, Faculty of Biology and Medicine University of Lausanne, CHUV University Hospital, 08-623 Lausanne, Switzerland

e-mail: Mauro.Oddo@chuv.ch

\section{Olson}

University of Texas Southwestern, 5323 Harry Hines Blvd.,

Dallas, TX 75390-8897, USA

e-mail: daiwai.olson@utsouthwestern.edu

\section{K. O'Phelan}

Department of Neurology, University of Miami, Miller School of Medicine, JMH, 1611 NW 12th Ave, Suite 405, Miami, FL 33136, USA

e-mail:kophelan@med.miami.edu recommendations using the GRADE system [3-5]. In this article we provide the initial evidentiary tables used to help develop recommendations for select topics including: systemic hemodynamics, intracranial pressure, brain and systemic oxygenation, EEG, brain metabolism, biomarkers, processes of care and monitoring in emerging economies.

\section{Evidentiary Tables}

Please refer to individual topic chapters in this supplement for abbreviations and cited literature.

\section{J. Javier Provencio}

Cerebrovascular Center and Neuroinflammation Research

Center, Lerner College of Medicine, Cleveland Clinic, 9500 Euclid Ave, NC30, Cleveland, OH 44195, USA

e-mail: provenj@ccf.org

\section{Puppo}

Intensive Care Unit, Hospital de Clinicas, Universidad de la República, Montevideo, Uruguay

e-mail: coripuppo@gmail.com

\section{R. Riker}

Critical Care Medicine, Maine Medical Center, 22 Bramhall Street, Portland, ME 04102-3175, USA

e-mail: RRiker@cmamaine.com

\section{Roberson}

Department of Neurosurgery, Ben Taub Hospital, Baylor College of Medicine, 1504 Taub Loop, Houston, TX 77030, USA

e-mail: claudiar@bcm.tmc.edu

\section{Schmidt}

Columbia University College of Physicians and Surgeons,

Milstein Hospital 8 Garden South, Suite 331, 177 Fort

Washington Avenue, New York, NY 10032, USA

e-mail: mjs2134@columbia.edu

\section{F. Taccone}

Department of Intensive Care, Laboratoire de Recherche Experimentale, Erasme Hospital, Route de Lennik, 808, 1070 Brussels, Belgium

e-mail: ftaccone@ulb.ac.be 


\section{Systemic Hemodynamics}

Studies that evaluate cardiac function in acute brain injury patients

\begin{tabular}{|c|c|c|c|c|c|c|c|}
\hline Reference & $\begin{array}{l}\text { Patient } \\
\text { number }\end{array}$ & $\begin{array}{l}\text { Study } \\
\text { design }\end{array}$ & Group & $\begin{array}{l}\text { Technique } \\
\text { assessment }\end{array}$ & End-point & Findings & $\begin{array}{l}\text { Quality } \\
\text { of } \\
\text { evidence }\end{array}$ \\
\hline \multicolumn{8}{|c|}{ Incidence of altered cardiac function } \\
\hline $\begin{array}{l}\text { Sandvei et al. } \\
\text { [21] }\end{array}$ & 18 & $\mathrm{P}$ & $\mathrm{SAH}$ & Echography & $\begin{array}{l}\text { To assess the incidence of LV } \\
\text { dysfunction }\end{array}$ & $\begin{array}{l}\text { Systolic function and SV were higher } \\
\text { in patients than in controls } \\
\text { Diastolic function was altered in the } \\
\text { early phase when compared to } \\
\text { controls }\end{array}$ & $\begin{array}{l}\text { Very } \\
\text { low }\end{array}$ \\
\hline $\begin{array}{l}\text { Banki et al. } \\
{[14]}\end{array}$ & 173 & $\mathrm{P}$ & $\mathrm{SAH}$ & Echography & $\begin{array}{l}\text { To assess the incidence and time- } \\
\text { course of LV dysfunction }\end{array}$ & $\begin{array}{l}15 \% \text { had low LVEF } \\
13 \% \text { of patients had RWMA with } \\
\text { normal LVEF } \\
\text { Recovery of LV function observed in } \\
\quad 66 \% \text { of patients }\end{array}$ & Low \\
\hline $\begin{array}{l}\text { Mayer et al. } \\
{[16]}\end{array}$ & 57 & $\mathrm{P}$ & SAH & Echography & $\begin{array}{l}\text { To assess the incidence of LV } \\
\text { dysfunction }\end{array}$ & $\begin{array}{l}8 \% \text { of RWMA, which were } \\
\text { associated with hypotension and PE }\end{array}$ & Low \\
\hline Jung et al. [15] & 42 & $\mathrm{P}$ & SAH & Echography & $\begin{array}{l}\text { To assess the incidence of LV } \\
\text { dysfunction }\end{array}$ & $\begin{array}{l}\text { Only } 1 / 42 \text { patients had LV } \\
\text { dysfunction }\end{array}$ & Low \\
\hline Lee et al. [85] & 24 & $\mathrm{P}$ & SAH & Echography & $\begin{array}{l}\text { To assess the incidence of Tako- } \\
\text { Tsubo cardiopathy among } \\
\text { patients with SAH-induced LV } \\
\text { dysfunction }\end{array}$ & $\begin{array}{l}8 / 24 \text { patients had Tako-Tsubo pattern } \\
\text { All patients recovered LVEF }>40 \%\end{array}$ & $\begin{array}{l}\text { Very } \\
\text { low }\end{array}$ \\
\hline $\begin{array}{l}\text { Khush et al. } \\
{[19]}\end{array}$ & 225 & $\mathrm{P}$ & $\mathrm{SAH}$ & Echography & $\begin{array}{l}\text { To assess the incidence and } \\
\text { predictors of SAH-induced LV } \\
\text { dysfunction }\end{array}$ & $\begin{array}{l}\text { RWMA were found in } 27 \% \text { of } \\
\text { patients } \\
\text { Apical sparing pattern was found in } \\
49 \% \text { of patients } \\
\text { Younger age and anterior aneurysm } \\
\text { position were independent } \\
\text { predictors of this AS pattern }\end{array}$ & Low \\
\hline $\begin{array}{l}\text { Jacobshagen } \\
\text { et al. [86] }\end{array}$ & 200 & $\mathrm{R}$ & $\mathrm{CA}$ & Echography & $\begin{array}{l}\text { To assess the incidence of LV } \\
\text { dysfunction }\end{array}$ & $\begin{array}{l}\text { Significant reduction of LVEF } \\
\quad(32 \pm 6 \%) \text { on admission }\end{array}$ & $\begin{array}{l}\text { Very } \\
\text { low }\end{array}$ \\
\hline $\begin{array}{l}\text { Ruiz-Bailen } \\
\text { et al. [87] }\end{array}$ & 29 & $\mathrm{P}$ & $\mathrm{CA}$ & Echography & $\begin{array}{l}\text { To assess the incidence and time- } \\
\text { course of LV dysfunction }\end{array}$ & $\begin{array}{l}\text { LV dysfunction occurred in } 20 / 29 \\
\text { patients in the early phase after CA } \\
\text { LVEF slowly improved among } \\
\text { survivors }\end{array}$ & $\begin{array}{l}\text { Very } \\
\text { low }\end{array}$ \\
\hline \multicolumn{8}{|c|}{ Role of cardiac function monitoring to explain the mechanisms of brain injury-related cardiopulmonary complications } \\
\hline Miss et al. [88] & 172 & $\mathrm{P}$ & SAH & Echography & $\begin{array}{l}\text { To evaluate the correlation of LV } \\
\text { dysfunction with the type of } \\
\text { aneurysm therapy }\end{array}$ & $\begin{array}{l}\text { No difference in the occurrence of } \\
\text { RWMA or LV dysfunction with } \\
\text { regard of coiling or clipping }\end{array}$ & Low \\
\hline $\begin{array}{l}\text { Frangiskasis } \\
\text { et al. [57] }\end{array}$ & 117 & $\mathrm{P}$ & SAH & Echography & $\begin{array}{l}\text { To evaluate the correlation of LV } \\
\text { dysfunction with ECG } \\
\text { abnormalities }\end{array}$ & Low LVEF associated with VA & Low \\
\hline $\begin{array}{l}\text { Pollick et al. } \\
\text { [17] }\end{array}$ & 13 & $\mathrm{P}$ & SAH & Echography & $\begin{array}{l}\text { To evaluate the correlation of LV } \\
\text { dysfunction with ECG } \\
\text { abnormalities }\end{array}$ & $\begin{array}{l}\text { RWMA in } 4 / 13 \text { patients } \\
\text { RWMA was associated with inverted } \\
\text { T waves }\end{array}$ & $\begin{array}{l}\text { Very } \\
\text { low }\end{array}$ \\
\hline $\begin{array}{l}\text { Kono et al. } \\
{[89]}\end{array}$ & 12 & $\mathrm{P}$ & $\mathrm{SAH}$ & Echography & $\begin{array}{l}\text { To evaluate the correlation of LV } \\
\text { dysfunction with ECG and } \\
\text { coronary angiography } \\
\text { abnormalities }\end{array}$ & $\begin{array}{l}\text { Apical LV hypokinesia was not } \\
\text { associated with coronary stenosis } \\
\text { despite ST elevation on ECG }\end{array}$ & Low \\
\hline $\begin{array}{l}\text { Davies et al. } \\
{[18]}\end{array}$ & 41 & $\mathrm{P}$ & SAH & Echography & $\begin{array}{l}\text { To evaluate the correlation of LV } \\
\text { dysfunction with ECG } \\
\text { abnormalities }\end{array}$ & $\begin{array}{l}\text { RWMA in } 10 \% \text { of patients } \\
\text { RWMA not associated with ECG } \\
\text { alterations }\end{array}$ & Low \\
\hline
\end{tabular}




\begin{tabular}{|c|c|c|c|c|c|c|c|}
\hline Reference & $\begin{array}{l}\text { Patient } \\
\text { number }\end{array}$ & $\begin{array}{l}\text { Study } \\
\text { design }\end{array}$ & Group & $\begin{array}{l}\text { Technique } \\
\text { assessment }\end{array}$ & End-point & Findings & $\begin{array}{l}\text { Quality } \\
\text { of } \\
\text { evidence }\end{array}$ \\
\hline $\begin{array}{l}\text { Bulsara et al. } \\
\text { [13] }\end{array}$ & 350 & $\mathrm{R}$ & SAH & Echography & $\begin{array}{l}\text { To evaluate the correlation of LV } \\
\text { dysfunction with ECG } \\
\text { abnormalities and markers of } \\
\text { heart injury }\end{array}$ & $\begin{array}{l}\text { LVEF }<40 \% \text { in } 3 \% \text { of patients } \\
\text { No association of LV dysfunction } \\
\text { with ECG abnormalities } \\
\text { Peak of cTnI in SAH patients was } \\
\text { lower than matched patients with } \\
\text { MI }\end{array}$ & $\begin{array}{l}\text { Very } \\
\text { low }\end{array}$ \\
\hline $\begin{array}{l}\text { Deibert et al. } \\
\text { [90] }\end{array}$ & 43 & $\mathrm{P}$ & $\mathrm{SAH}$ & Echography & $\begin{array}{l}\text { To assess the relationship between } \\
\text { LV dysfunction and markers of } \\
\text { heart injury }\end{array}$ & $\begin{array}{l}\text { RWMA associated with high cTnI } \\
\text { RWMA resolved over time in all } \\
\text { patients }\end{array}$ & Low \\
\hline $\begin{array}{l}\text { Hravnak et al. } \\
\text { [91] }\end{array}$ & 125 & $\mathrm{P}$ & SAH & Echography & $\begin{array}{l}\text { To assess the relationship between } \\
\text { LV dysfunction and markers of } \\
\text { heart injury }\end{array}$ & $\begin{array}{l}\text { High cTnI was associated with } \\
\text { RWMA and lower LVEF } \\
\text { Only } 26 \% \text { of patients returned to } \\
\text { normal cardiac function over time }\end{array}$ & Low \\
\hline $\begin{array}{l}\text { Naidech et al. } \\
\text { [29] }\end{array}$ & 253 & $\mathrm{R}$ & $\mathrm{SAH}$ & Echography & $\begin{array}{l}\text { To assess the relationship between } \\
\text { LV dysfunction and markers of } \\
\text { heart injury }\end{array}$ & $\begin{array}{l}\text { High cTnI was associated with } \\
\text { RWMA and low LVEF }\end{array}$ & $\begin{array}{l}\text { Very } \\
\text { low }\end{array}$ \\
\hline $\begin{array}{l}\text { Parekh et al. } \\
{[30]}\end{array}$ & 41 & $\mathrm{P}$ & SAH & Echography & $\begin{array}{l}\text { To assess the relationship between } \\
\text { LV dysfunction and markers of } \\
\text { heart injury }\end{array}$ & $\begin{array}{l}\text { High cTnI was associated with low } \\
\text { LVEF }\end{array}$ & Low \\
\hline $\begin{array}{l}\text { Tung et al. } \\
{[31]}\end{array}$ & 223 & $\mathrm{P}$ & $\mathrm{SAH}$ & Echography & $\begin{array}{l}\text { To assess the relationship between } \\
\text { LV dysfunction and markers of } \\
\text { heart injury }\end{array}$ & Low LVEF predicted high cTnI & Low \\
\hline $\begin{array}{l}\text { Kothavale } \\
\text { et al. [92] }\end{array}$ & 300 & $\mathrm{P}$ & SAH & Echography & $\begin{array}{l}\text { To assess the relationship between } \\
\text { LV dysfunction and markers of } \\
\text { heart injury }\end{array}$ & $\begin{array}{l}\text { RWMA in } 18 \% \text { patients } \\
\text { RWMA associated with poor } \\
\text { neurological status and high cTnI } \\
\text { levels }\end{array}$ & Low \\
\hline $\begin{array}{l}\text { Apak et al. } \\
\text { [93] }\end{array}$ & 62 & $\mathrm{P}$ & Stroke & Echography & $\begin{array}{l}\text { To assess the relationship between } \\
\text { LV dysfunction and markers of } \\
\text { heart injury }\end{array}$ & $\begin{array}{l}\text { Serum levels of cTnT were inversely } \\
\text { correlated with LVEF }\end{array}$ & Low \\
\hline $\begin{array}{l}\text { Zaroff et al. } \\
\text { [94] }\end{array}$ & 30 & $\mathrm{P}$ & SAH & Echography & $\begin{array}{l}\text { To assess the relationship between } \\
\text { RWMA and patterns of } \\
\text { coronary artery disease }\end{array}$ & $\begin{array}{l}\text { RWMA did not correlate with typical } \\
\text { patterns of coronary artery disease } \\
\text { RWMA resolved in all patients }\end{array}$ & $\begin{array}{l}\text { Very } \\
\text { low }\end{array}$ \\
\hline $\begin{array}{l}\text { Banki et al. } \\
\text { [33] }\end{array}$ & 42 & $\mathrm{P}$ & SAH & Echography & $\begin{array}{l}\text { To assess the relationship between } \\
\text { LV dysfunction of myocardial } \\
\text { perfusion and innervation }\end{array}$ & $\begin{array}{l}\text { LV systolic dysfunction was } \\
\text { associated with normal myocardial } \\
\text { perfusion and abnormal } \\
\text { sympathetic innervation }\end{array}$ & Low \\
\hline $\begin{array}{l}\text { Abdelmoneim } \\
\text { et al. [32] }\end{array}$ & 10 & $\mathrm{P}$ & SAH & RTP-CE & $\begin{array}{l}\text { To assess microvascular perfusion } \\
\text { and echographic abnormalities } \\
\text { after SAH }\end{array}$ & $\begin{array}{l}\text { RWMA was not associated with } \\
\text { altered myocardial perfusion }\end{array}$ & $\begin{array}{l}\text { Very } \\
\text { low }\end{array}$ \\
\hline $\begin{array}{l}\text { Sugimoto et al. } \\
\text { [28] }\end{array}$ & 77 & $\mathrm{R}$ & SAH & Echography & $\begin{array}{l}\text { To assess the relationship between } \\
\text { LV dysfunction and estradiol } \\
\text { (ES) or norepinephrine (NE) }\end{array}$ & $\begin{array}{l}\text { The incidence of RWMA in the high- } \\
\text { NE/low-ES group was significantly } \\
\text { higher than the low-NE/high-ES } \\
\text { group }\end{array}$ & $\begin{array}{l}\text { Very } \\
\text { low }\end{array}$ \\
\hline $\begin{array}{l}\text { Sugimoto et al. } \\
\text { [27] }\end{array}$ & 48 & $\mathrm{R}$ & SAH & Echography & $\begin{array}{l}\text { To assess the relationship between } \\
\text { LV dysfunction and } \\
\text { norepinephrine (NE) levels }\end{array}$ & $\begin{array}{l}\text { Plasma NE levels were significantly } \\
\text { higher in patients with RWMA and } \\
\text { inversely correlated with LVEF }\end{array}$ & $\begin{array}{l}\text { Very } \\
\text { low }\end{array}$ \\
\hline $\begin{array}{l}\text { Tanabe et al. } \\
\text { [22] }\end{array}$ & 103 & $\mathrm{P}$ & SAH & Echography & $\begin{array}{l}\text { To assess the relationship between } \\
\text { LV dysfunction and PE }\end{array}$ & $\begin{array}{l}\text { Higher incidence of systolic or } \\
\text { diastolic dysfunction in patients } \\
\text { with elevated cTnI }\end{array}$ & Low \\
\hline $\begin{array}{l}\text { Kopelnik et al. } \\
\text { [23] }\end{array}$ & 207 & $\mathrm{P}$ & SAH & Echography & $\begin{array}{l}\text { To assess the incidence of } \\
\text { diastolic dysfunction and its } \\
\text { relationship with PE }\end{array}$ & $\begin{array}{l}\text { Diastolic dysfunction was observed in } \\
71 \% \text { of subjects } \\
\text { Diastolic dysfunction was an } \\
\text { independent predictor of PE }\end{array}$ & Low \\
\hline
\end{tabular}




\begin{tabular}{|c|c|c|c|c|c|c|c|}
\hline Reference & $\begin{array}{l}\text { Patient } \\
\text { number }\end{array}$ & $\begin{array}{l}\text { Study } \\
\text { design }\end{array}$ & Group & $\begin{array}{l}\text { Technique } \\
\text { assessment }\end{array}$ & End-point & Findings & $\begin{array}{l}\text { Quality } \\
\text { of } \\
\text { evidence }\end{array}$ \\
\hline $\begin{array}{l}\text { Tung et al. } \\
\text { [95] }\end{array}$ & 57 & $\mathrm{R}$ & SAH & Echography & $\begin{array}{l}\text { To assess the relationship between } \\
\text { LV dysfunction and elevated } \\
\text { BNP }\end{array}$ & $\begin{array}{l}\text { High BNP in patients with systolic or } \\
\text { diastolic dysfunction }\end{array}$ & $\begin{array}{l}\text { Very } \\
\text { low }\end{array}$ \\
\hline $\begin{array}{l}\text { Meaudre et al. } \\
{[96]}\end{array}$ & 31 & $\mathrm{P}$ & SAH & Echography & $\begin{array}{l}\text { To assess the relationship between } \\
\text { LV dysfunction and elevated } \\
\text { BNP }\end{array}$ & $\begin{array}{l}\text { No correlation between diastolic } \\
\text { dysfunction and BNP }\end{array}$ & $\begin{array}{l}\text { Very } \\
\text { low }\end{array}$ \\
\hline $\begin{array}{l}\text { Naidech et al. } \\
\text { [35] }\end{array}$ & 171 & $\mathrm{P}$ & SAH & Echography & $\begin{array}{l}\text { To assess the relationship between } \\
\text { LV dysfunction and PE }\end{array}$ & $\begin{array}{l}\text { No association of LV dysfunction and } \\
\text { PE }\end{array}$ & Low \\
\hline $\begin{array}{l}\text { McLaughin } \\
\text { et al. [97] }\end{array}$ & 178 & $\mathrm{R}$ & SAH & Echography & $\begin{array}{l}\text { To assess the relationship between } \\
\text { LV systolic or diastolic } \\
\text { dysfunction and PE }\end{array}$ & $\begin{array}{l}\text { Occurrence of PE was associated with } \\
\text { both systolic or diastolic } \\
\text { dysfunction }\end{array}$ & $\begin{array}{l}\text { Very } \\
\text { low }\end{array}$ \\
\hline Sato et al. [37] & 49 & $\mathrm{P}$ & SAH & TT & $\begin{array}{l}\text { To assess variables related to the } \\
\text { development of PE }\end{array}$ & $\begin{array}{l}\text { Patients with PE had lower cardiac } \\
\text { function than others }\end{array}$ & Low \\
\hline $\begin{array}{l}\text { Junttila et al. } \\
\text { [36] }\end{array}$ & 108 & $\mathrm{P}$ & $\mathrm{ICH}$ & Echography & $\begin{array}{l}\text { To evaluate the predictive value of } \\
\text { echographic abnormalities for } \\
\text { NPE }\end{array}$ & $\begin{array}{l}\text { LVEF }<50 \% \text { and } \mathrm{E} / \mathrm{A}>2 \text { more } \\
\text { frequent in NPE patients } \\
\text { No predictive value of such } \\
\text { abnormalities for NPE }\end{array}$ & Low \\
\hline $\begin{array}{l}\text { Kuwagata } \\
\text { et al. [62] }\end{array}$ & 8 & $\mathrm{P}$ & TBI & Echography & $\begin{array}{l}\text { To assess the effects of } \mathrm{TH} \text { on } \\
\text { cardiac function }\end{array}$ & $\begin{array}{l}\text { TH did not affect stroke volume and } \\
\text { diastolic function }\end{array}$ & $\begin{array}{l}\text { Very } \\
\text { low }\end{array}$ \\
\hline \multicolumn{8}{|c|}{ Cardiac function monitoring findings and outcome } \\
\hline $\begin{array}{l}\text { Yousef et al. } \\
\text { [47] }\end{array}$ & 149 & $\mathrm{P}$ & SAH & Echography & $\begin{array}{l}\text { To evaluate which hemodynamic } \\
\text { variable was associated with } \\
\text { DCI }\end{array}$ & $\begin{array}{l}\text { No influence of LVEF or RWMA on } \\
\text { DCI }\end{array}$ & Low \\
\hline $\begin{array}{l}\text { Jyotsna et al. } \\
\text { [98] }\end{array}$ & 56 & $\mathrm{P}$ & SAH & Echography & $\begin{array}{l}\text { To evaluate the prognostic value } \\
\text { of myocardial dysfunction after } \\
\text { SAH }\end{array}$ & $\begin{array}{l}\text { LV dysfunction was associated with } \\
\text { poor outcome }\end{array}$ & Low \\
\hline $\begin{array}{l}\text { Sugimoto et al. } \\
\text { [60] }\end{array}$ & 47 & $\mathrm{P}$ & SAH & Echography & $\begin{array}{l}\text { To evaluate the prognostic value } \\
\text { of myocardial dysfunction after } \\
\text { SAH }\end{array}$ & $\begin{array}{l}\text { RWMA independent risk factor of } \\
\text { mortality }\end{array}$ & Low \\
\hline $\begin{array}{l}\text { Papanikolaou } \\
\text { et al. [99] }\end{array}$ & 37 & $\mathrm{P}$ & SAH & Echography & $\begin{array}{l}\text { To evaluate the prognostic value } \\
\text { of myocardial dysfunction after } \\
\text { SAH }\end{array}$ & $\begin{array}{l}\text { LV dysfunction associatedwith DCI } \\
\text { and poor outcome }\end{array}$ & Low \\
\hline $\begin{array}{l}\text { Temes et al. } \\
{[3]}\end{array}$ & 119 & $\mathrm{P}$ & SAH & Echography & $\begin{array}{l}\text { To assess the impact of LV } \\
\text { dysfunction on cerebral } \\
\text { infarction and neurological } \\
\text { outcome }\end{array}$ & $\begin{array}{l}\text { LV dysfunction independent predictor } \\
\text { of DCI but not of neurologic } \\
\text { outcome }\end{array}$ & Low \\
\hline $\begin{array}{l}\text { Vannemreddy } \\
\text { et al. [59] }\end{array}$ & 42 & $\mathrm{P}$ & SAH & Echography & $\begin{array}{l}\text { To evaluate the prognostic value } \\
\text { of myocardial dysfunction after } \\
\text { SAH }\end{array}$ & $\begin{array}{l}\text { RWMA was associated with poor } \\
\text { GCS on admission and increased } \\
\text { hospital stay but not with increased } \\
\text { mortality }\end{array}$ & Low \\
\hline $\begin{array}{l}\text { Urbaniak et al. } \\
\text { [63] }\end{array}$ & 266 & $\mathrm{P}$ & SAH & Echography & $\begin{array}{l}\text { To evaluate the prognostic value } \\
\text { of myocardial dysfunction after } \\
\text { SAH }\end{array}$ & $\begin{array}{l}\text { LV dysfunction not associated with } \\
\text { outcome }\end{array}$ & Low \\
\hline $\begin{array}{l}\text { Yarlagadda } \\
\text { et al. [64] }\end{array}$ & 300 & $\mathrm{P}$ & SAH & Echography & $\begin{array}{l}\text { To evaluate the prognostic value } \\
\text { of myocardial dysfunction after } \\
\text { SAH }\end{array}$ & LVEF not associated with outcome & Low \\
\hline $\begin{array}{l}\text { Front et al. } \\
{[100]}\end{array}$ & 64 & $\mathrm{R}$ & Stroke & Radionuclide & $\begin{array}{l}\text { To evaluate the prognostic value } \\
\text { of LVEF after stroke }\end{array}$ & $\begin{array}{l}\text { Non-survivors had lowe LVEF } \\
\qquad \begin{array}{l}(52 \pm 18 \%) \text { than survivors } \\
(64 \pm 10 \%)\end{array}\end{array}$ & $\begin{array}{l}\text { Very } \\
\text { low }\end{array}$ \\
\hline $\begin{array}{l}\text { Chang et al. } \\
\text { [61] }\end{array}$ & 165 & $\mathrm{P}$ & CA & Echography & $\begin{array}{l}\text { To assess the LV function and its } \\
\text { relationship with outcome }\end{array}$ & $\begin{array}{l}\text { Lower LVEF associated with previous } \\
\text { cardiac disease and epinephrine } \\
\text { doses } \\
\text { LVEF }<40 \% \text { had higher mortality } \\
\text { than normal LVEF }\end{array}$ & Low \\
\hline
\end{tabular}




\begin{tabular}{|c|c|c|c|c|c|c|c|}
\hline Reference & $\begin{array}{l}\text { Patient } \\
\text { number }\end{array}$ & $\begin{array}{l}\text { Study } \\
\text { design }\end{array}$ & Group & $\begin{array}{l}\text { Technique } \\
\text { assessment }\end{array}$ & End-point & Findings & $\begin{array}{l}\text { Quality } \\
\text { of } \\
\text { evidence }\end{array}$ \\
\hline $\begin{array}{l}\text { Khan et al. } \\
{[101]}\end{array}$ & 138 & $\mathrm{P}$ & $\mathrm{CA}$ & Echography & $\begin{array}{l}\text { To assess the LV function and its } \\
\text { relationship with outcome }\end{array}$ & $\begin{array}{l}\text { LVEF }<40 \% \text { had higher mortality } \\
\text { than normal LVEF }\end{array}$ & Low \\
\hline
\end{tabular}

$P$ prospective, $R$ retrospective, $S A H$ subarachnoid haemorrhage, $T B I$ traumatic brain injury, $T T$ transpulmonary thermodilution, $P E$ pulmonary edema, $C O$ cardiac output, $P C W A$ pulse contour wave analysis, $L V E F$ left ventricular ejection fraction, $N P E$ neurogenic pulmonary edema, $C V$ cerebral vasospasm, $C I$ cardiac index, $P E$ pulmonary edema, $I A B P$ intra-aortic balloon counterpulsation, $L V E F$ low ventricular ejection fraction, $c T n I$ troponin I, GEDVI global end-diastolic volume index, $G E F$ global ejection fraction, $D C I$ delayed cerebral infarction, $B N P$ brain natriuretic peptide, $S V$ stroke volume, $E C G$ electrocardiogram, $V A$ ventricular arrhythmias, $N P E$ neurogenic pulmonary edema, $R T P-C E$ real-time contrast echocardiography

Studies evaluating cardiac output $(\mathrm{CO})$ in acute brain injury patients

\begin{tabular}{|c|c|c|c|c|c|c|c|}
\hline Reference & $\begin{array}{l}\text { Patient } \\
\text { number }\end{array}$ & $\begin{array}{l}\text { Study } \\
\text { design }\end{array}$ & Group & $\begin{array}{l}\text { Technique } \\
\text { assessment }\end{array}$ & End-point & Findings & $\begin{array}{l}\text { Quality } \\
\text { of } \\
\text { evidence }\end{array}$ \\
\hline
\end{tabular}

Incidence of altered $\mathrm{CO}$

Mutoh et al. $46 \quad \mathrm{P}$
$[24]$

Trieb et al. $\quad 30 \quad \mathrm{P} \quad$ Stroke PAC [25]

Laurent et al. $165 \quad \mathrm{R} \quad \mathrm{CA} \quad \mathrm{PAC}$ [26]

$\begin{array}{cclcc}\begin{array}{c}\text { Rzheutskaya } \\ \text { et al. [102] }\end{array} & 13 & \text { P } & \text { TBI } & \text { TT } \\ \begin{array}{c}\text { Schulte Esch } \\ \text { et al. [40] }\end{array} & 12 & \text { P } & \text { TBI } & \text { PAC }\end{array}$
cardiac function

To assess hemodynamic alterations after TBI

assess hemodynamic alterations after TBI

To evaluate the time course of High CI on admission which diminished Low on day 5

Hgher CI in patients with poor neurological status

To evaluate $\mathrm{CO}$ after ischemic Patients with stroke had significantly higher $\mathrm{CO}$ than comparable controls

Low CI is common in the early phase Very low after $\mathrm{CA}$, which normalizes thereafter, except in those dying with cardiogenic shock and MOF

Four different hemodynamic response according to CI, SVR, SVV and response to fluid administration

Elevated CI with high PAOP and low Very low SVRI were reported injury-related cardiopulmonary complications

\begin{tabular}{|c|c|c|c|c|}
\hline $\begin{array}{l}\text { Sato et al. } \\
{[37]}\end{array}$ & 49 & $P$ & SAH & $\mathrm{TT}$ \\
\hline $\begin{array}{l}\text { Deehan et al. } \\
\text { [38] }\end{array}$ & 24 & $\mathrm{R}$ & $\mathrm{SAH}$ & PAC \\
\hline $\begin{array}{l}\text { Vespa et al. } \\
\text { [39] }\end{array}$ & 56 & $\mathrm{R}$ & SAH & PAC \\
\hline $\begin{array}{l}\text { Tamaki et al. } \\
{[103]}\end{array}$ & 15 & $P$ & TBI & PAC \\
\hline
\end{tabular}

To assess variables related to the development of PE

Patients with PE had lower CI than others

To evaluate hemodynamics in Variable hemodynamic variables patients with $\mathrm{PE}$

Increased CI and decreased PAOP in

To assess effects of dobutamine patients with $\mathrm{PE}$

To evaluate the mechanisms of Similar hemodynamics between patients Very low poor oxygenation after SAH with and without poor oxygenation

To assess hemodynamic alterations after TBI

All patients had high PAOP and PVR

Hypotensive patients had low $\mathrm{CI}$ and elevated SVRI

Normotensive patients had high SVRI

To assess hemodynamic alterations after TBI

High $\mathrm{CI}$ and MAO with reduced tissue oxygenation were found

Survivors had higher CI and tissue oxygenation than non-survivors

To evaluate the effects of $\mathrm{TH} \mathrm{TH}$ lowered heart rate, filling pressures, Low on hemodynamics $\mathrm{CO}$ and MAP without deleterious effects on $\mathrm{SvO}_{2}$

To evaluate the effects of $\mathrm{TH} \quad \mathrm{TH}$ improved hemodynamics during Low on hemodynamics during cardiogenic shock following $\mathrm{CA}$ 


\begin{tabular}{|c|c|c|c|c|c|c|c|}
\hline Reference & $\begin{array}{l}\text { Patient } \\
\text { number }\end{array}$ & $\begin{array}{l}\text { Study } \\
\text { design }\end{array}$ & Group & $\begin{array}{l}\text { Technique } \\
\text { assessment }\end{array}$ & End-point & Findings & $\begin{array}{l}\text { Quality } \\
\text { of } \\
\text { evidence }\end{array}$ \\
\hline $\begin{array}{l}\text { Sato et al. } \\
\text { [43] }\end{array}$ & 60 & $\mathrm{P}$ & $\mathrm{SAH}$ & PAC & $\begin{array}{l}\text { To evaluate the effects of TH } \\
\text { on systemic and cerebral } \\
\text { hemodynamics during } \\
\text { surgery }\end{array}$ & $\begin{array}{l}\text { TH was associated with decreased } \mathrm{CI} \text { and } \\
\text { increased arterio-jugular difference in } \\
\text { oxygen }\end{array}$ & Low \\
\hline \multicolumn{8}{|c|}{ Association between $\mathrm{CO}$ and brain perfusion, neurological complications or outcome } \\
\hline $\begin{array}{l}\text { Tone et al. } \\
\text { [48] }\end{array}$ & 42 & $\mathrm{P}$ & $\mathrm{SAH}$ & PAC & $\begin{array}{l}\text { To evaluate the correlation } \\
\text { between hemodynamic } \\
\text { variables and } \mathrm{CBF}\end{array}$ & $\mathrm{CBF}$ was correlated with $\mathrm{CI}$ & Very low \\
\hline $\begin{array}{l}\text { Hashimoto } \\
\text { et al. [105] }\end{array}$ & 20 & $\mathrm{P}$ & BS & TT & $\begin{array}{l}\text { To evaluate the correlation } \\
\text { between hemodynamic } \\
\text { variables and CBF }\end{array}$ & $\begin{array}{l}\text { CBF was not correlated with CI after } \\
\text { BAVM resection }\end{array}$ & Very low \\
\hline $\begin{array}{l}\text { Watanabe } \\
\text { et al. [34] }\end{array}$ & 34 & $\mathrm{P}$ & $\mathrm{SAH}$ & TT & $\begin{array}{l}\text { To evaluate which } \\
\text { hemodynamic variable was } \\
\text { associated with the } \\
\text { occurrence of DCI }\end{array}$ & DCI was associated with lower CI & Low \\
\hline $\begin{array}{l}\text { Mayer et al. } \\
{[45]}\end{array}$ & 72 & $\mathrm{R}$ & SAH & Echography & $\begin{array}{l}\text { To evaluate which } \\
\text { hemodynamic variable was } \\
\text { associated with the } \\
\text { occurrence of DCI }\end{array}$ & DCI was associated with lower CI & Very low \\
\hline $\begin{array}{l}\text { Yousef et al. } \\
\text { [47] }\end{array}$ & 149 & $\mathrm{P}$ & $\mathrm{SAH}$ & Echography & $\begin{array}{l}\text { To evaluate which } \\
\text { hemodynamic variable was } \\
\text { associated with the } \\
\text { occurrence of DCI }\end{array}$ & DCI was associated with lower CI & Low \\
\hline $\begin{array}{l}\text { Torgesen } \\
\text { et al. [106] }\end{array}$ & 153 & $\mathrm{R}$ & $\mathrm{CA}$ & PAC & $\begin{array}{l}\text { To evaluate the impact of } \\
\text { hemodynamic variables on } \\
\text { outcome during NT }\end{array}$ & $\begin{array}{l}\text { No association of hemodynamic } \\
\text { variables with outcome }\end{array}$ & Very low \\
\hline $\begin{array}{l}\text { Torgesen } \\
\text { et al. [107] }\end{array}$ & 134 & $\mathrm{R}$ & $\mathrm{CA}$ & PAC & $\begin{array}{l}\text { To evaluate the impact of } \\
\text { hemodynamic variables on } \\
\text { outcome during } \mathrm{TH}\end{array}$ & $\begin{array}{l}\text { Elevated CI was associated with poor } \\
\text { outcome }\end{array}$ & Very low \\
\hline $\begin{array}{l}\text { Yamada } \\
\text { et al. [108] }\end{array}$ & 34 & $\mathrm{P}$ & TBI & Dye Dilution & $\begin{array}{l}\text { To evaluate the impact of } \\
\text { hemodynamic variables on } \\
\text { outcome after severe TBI }\end{array}$ & $\begin{array}{l}\text { Low CI was associated with poor } \\
\text { outcome }\end{array}$ & Very low \\
\hline \multicolumn{8}{|c|}{ Effects of therapies modifying $\mathrm{CO}$ on neurological status } \\
\hline $\begin{array}{l}\text { Chatterjee } \\
\text { et al. [109] }\end{array}$ & 15 & $\mathrm{P}$ & BS & Echography & $\begin{array}{l}\text { To evaluate the effects of } \\
\text { mannitol on systemic } \\
\text { hemodynamics }\end{array}$ & $\begin{array}{l}\text { Mannitol increased CI during } 15 \mathrm{~min} \\
\text { after administration }\end{array}$ & Low \\
\hline $\begin{array}{l}\text { Stoll et al. } \\
{[110]}\end{array}$ & 20 & $\mathrm{P}$ & Stroke & BioImp & $\begin{array}{c}\text { To evaluate the effects of HES } \\
\text { on systemic hemodynamics }\end{array}$ & $\begin{array}{l}\text { HES administration avoided nocturnal } \\
\text { decrease in CO and MAP } \\
\text { No effects on neurological status were } \\
\text { reported }\end{array}$ & Very low \\
\hline $\begin{array}{l}\text { Finn et al. } \\
\text { [52] }\end{array}$ & 32 & $\mathrm{P}$ & $\mathrm{SAH}$ & PAC & $\begin{array}{l}\text { To evaluate the effects of } \\
\text { hemodynamic optimization } \\
\text { on neurological status }\end{array}$ & $\begin{array}{l}\text { Maintaining PAOP between } 14 \text { and } \\
16 \mathrm{mmHg} \text { reversed neurological } \\
\text { deficit; all patients had CI }>4.5 \mathrm{~L} / \\
\text { min } \mathrm{m}^{2}\end{array}$ & Very low \\
\hline $\begin{array}{l}\text { Mori et al. } \\
{[53]}\end{array}$ & 98 & $\mathrm{P}$ & SAH & PAC HHH & $\begin{array}{l}\text { To evaluate the effects of } \mathrm{HHH} \\
\text { therapy on CBF and } \\
\text { neurological status }\end{array}$ & $\begin{array}{l}\mathrm{HHH} \text { increased PAOP and CI } \\
\text { Increased MAP and CI was associated } \\
\text { with increased CBF }\end{array}$ & Low \\
\hline $\begin{array}{l}\text { Otsubo et al. } \\
{[51]}\end{array}$ & 41 & $\mathrm{P}$ & $\mathrm{SAH}$ & PAC NV-HT & $\begin{array}{l}\text { To evaluate the effects of NV- } \\
\text { HT on neurological status }\end{array}$ & $\begin{array}{l}\text { NV-HT increased also CI and improved } \\
\text { neurological status in } 71 \% \text { of } \\
\text { symptomatic vasospasm }\end{array}$ & Low \\
\hline $\begin{array}{l}\text { Muench et al. } \\
\text { [54] }\end{array}$ & 47 & $\mathrm{P}$ & SAH & $\begin{array}{l}\text { PAC HHH } \\
\quad(\mathrm{NE})\end{array}$ & $\begin{array}{l}\text { To evaluate the effects of } \\
\text { different component of } \mathrm{HHH} \\
\text { therapy on brain perfusion } \\
\text { and oxygenation }\end{array}$ & $\begin{array}{l}\text { Increased MAP but unchanged CI } \\
\text { Increase in } \mathrm{rCBF} / \mathrm{PbO}_{2} \text { only with } \mathrm{HTN}\end{array}$ & Low \\
\hline
\end{tabular}




\begin{tabular}{|c|c|c|c|c|c|c|c|}
\hline Reference & $\begin{array}{l}\text { Patient } \\
\text { number }\end{array}$ & $\begin{array}{l}\text { Study } \\
\text { design }\end{array}$ & Group & $\begin{array}{l}\text { Technique } \\
\text { assessment }\end{array}$ & End-point & Findings & $\begin{array}{l}\text { Quality } \\
\text { of } \\
\text { evidence }\end{array}$ \\
\hline $\begin{array}{l}\text { Mutoh et al. } \\
\text { [111] }\end{array}$ & 7 & $\mathrm{P}$ & SAH & TT & $\begin{array}{l}\text { To evaluate the effects of } \\
\text { hyperdynamic therapy on } \\
\text { brain oxygenation during } \\
\text { symptomatic vasospasm }\end{array}$ & $\begin{array}{l}\text { TT-guided therapy Increased } \mathrm{rSO}_{2} \\
\text { during VSP }\end{array}$ & Very low \\
\hline $\begin{array}{l}\text { Levy et al. } \\
{[55]}\end{array}$ & 23 & $\mathrm{P}$ & SAH & PAC Dobu & $\begin{array}{l}\text { To evaluate the effects of } \\
\text { dobutamine on neurological } \\
\text { status }\end{array}$ & $\begin{array}{l}\text { Increased CI improved neurological } \\
\text { status during } \mathrm{CV} \text { in } 78 \% \text { of patients } \\
\text { who failed to respond to } \mathrm{NE}\end{array}$ & Low \\
\hline $\begin{array}{l}\text { Tanabe et al. } \\
{[50]}\end{array}$ & 10 & $\mathrm{R}$ & SAH & PAC & $\begin{array}{l}\text { To evaluate the effects of IV } \\
\text { albumin on systemic } \\
\text { hemodynamics }\end{array}$ & $\begin{array}{l}\text { Increased } \mathrm{CI} \text { improved neurological } \\
\text { status during } \mathrm{CV}\end{array}$ & Very low \\
\hline $\begin{array}{l}\text { Hadeishi } \\
\text { et al. [49] }\end{array}$ & 8 & $\mathrm{R}$ & SAH & PAC Dobu & $\begin{array}{l}\text { To evaluate the effects of } \\
\text { dobutamine on neurological } \\
\text { status }\end{array}$ & $\begin{array}{l}\text { Increased CI improved neurological } \\
\text { status during CV }\end{array}$ & Very low \\
\hline $\begin{array}{l}\text { Kim et al. } \\
{[112]}\end{array}$ & 16 & $\mathrm{P}$ & SAH & $\begin{array}{l}\text { PAC Dobu/ } \\
\text { Phenyl }\end{array}$ & $\begin{array}{l}\text { To evaluate the effects of } \\
\text { dobutamine and } \\
\text { phenylephrine on } \\
\text { neurological status }\end{array}$ & $\begin{array}{l}\text { Both drugs increased } \mathrm{CBF} \text { in patients } \\
\text { with vasospasm }\end{array}$ & Very low \\
\hline $\begin{array}{l}\text { Miller et al. } \\
{[113]}\end{array}$ & 24 & $\mathrm{P}$ & SAH & $\begin{array}{l}\text { PAC } \\
\text { Phenylephr }\end{array}$ & $\begin{array}{l}\text { To evaluate the effects of } \\
\text { phenylephrine on } \\
\text { neurological status }\end{array}$ & $\begin{array}{l}\text { Increased MAP did not result in CI } \\
\text { changes- } 88 \% \text { of patients improved } \\
\text { neurological status }\end{array}$ & Low \\
\hline $\begin{array}{l}\text { Naidech } \\
\text { et al. [114] }\end{array}$ & 11 & $\mathrm{R}$ & SAH & $\begin{array}{l}\text { PACDobu/ } \\
\text { Milri }\end{array}$ & $\begin{array}{l}\text { To evaluate the effects of } \\
\text { different inotropes on } \\
\text { systemic hemodynamics }\end{array}$ & $\begin{array}{l}\text { Milrinone was more effective to increase } \\
\text { CI but was also associated with lower } \\
\text { MAP }\end{array}$ & Very low \\
\hline \multicolumn{8}{|c|}{ Impact of specific therapies dealing with optimization of $\mathrm{CO}$ on outcomes } \\
\hline $\begin{array}{l}\text { Tagami et al. } \\
\text { [65] }\end{array}$ & 1,482 & $\begin{array}{l}\mathrm{R}(\mathrm{b} / \\
\text { a) }\end{array}$ & OHCA & $\begin{array}{l}\text { TT-guided } \\
\text { therapy }\end{array}$ & $\begin{array}{l}\text { To assess the impact of TT- } \\
\text { guided therapy on outcome } \\
\text { of CA patients }\end{array}$ & Improved good neurological outcome & Low \\
\hline $\begin{array}{l}\text { Kim et al. } \\
{[67]}\end{array}$ & 453 & $\begin{array}{l}\mathrm{P}(\mathrm{b} / \\
\mathrm{a})\end{array}$ & SAH & PAC & $\begin{array}{l}\text { To evaluate the effects of } \\
\text { hemodynamic monitoring on } \\
\text { the occurrence of } \\
\text { complications }\end{array}$ & $\begin{array}{l}\text { Reduced incidence of sepsis and } \\
\text { pulmonary edema } \\
\text { Reduced mortality ( } 29 \text { vs. } 34 \% \text {, } \\
\quad p=0.04 \text { ) }\end{array}$ & Moderate \\
\hline $\begin{array}{l}\text { Mutoh et al. } \\
\text { [78] }\end{array}$ & 45 & $\mathrm{P}$ & $\mathrm{SAH}$ & TT & $\begin{array}{l}\text { To evaluate the effects of } \\
\text { hemodynamic monitoring on } \\
\text { the occurrence of } \\
\text { complications }\end{array}$ & $\begin{array}{l}\text { 4/8 DCI in patients with VSP } \\
\text { No pulmonary edema or heart failure }\end{array}$ & Low \\
\hline $\begin{array}{l}\text { Vermeij } \\
\text { et al. [115] }\end{array}$ & 348 & $\begin{array}{l}\mathrm{R}(\mathrm{b} / \\
\text { a) }\end{array}$ & SAH & $\begin{array}{l}\text { PAC (VSP) } \\
\text { HHH }\end{array}$ & $\begin{array}{l}\text { To evaluate the effects of } \\
\text { hemodynamic monitoring on } \\
\text { the occurrence of } \\
\text { complications }\end{array}$ & $\begin{array}{l}\text { Reduced mortality among patients with } \\
\text { DCI }\end{array}$ & Low \\
\hline $\begin{array}{l}\text { Medlock } \\
\text { et al. [69] }\end{array}$ & 47 & $\mathrm{P}$ & $\mathrm{SAH}$ & $\begin{array}{l}\text { PAC Proph. } \\
\text { HHH }\end{array}$ & $\begin{array}{l}\text { To evaluate the effects of } \\
\text { hemodynamic monitoring on } \\
\text { the occurrence of } \\
\text { complications }\end{array}$ & $\begin{array}{l}\text { Proph HHH did not prevent DNID } \\
26 \% \text { incidence of PE }\end{array}$ & Low \\
\hline $\begin{array}{l}\text { Rondeau } \\
\text { et al. [66] }\end{array}$ & 41 & $\mathrm{RCT}$ & $\mathrm{SAH}$ & TT & $\begin{array}{l}\text { To evaluate the effects of } \\
\text { hemodynamic monitoring on } \\
\text { the occurrence of } \\
\text { complications }\end{array}$ & $\begin{array}{l}\text { Dobu versus NE: similar VSP and DCI } \\
\text { but lower MV duration and ICU stay }\end{array}$ & Moderate \\
\hline $\begin{array}{l}\text { Mutoh et al. } \\
\text { [68] }\end{array}$ & 116 & $\mathrm{RCT}$ & SAH & $\begin{array}{l}\text { PAC (late) } \\
\text { TT }\end{array}$ & $\begin{array}{l}\text { To evaluate the effects of } \\
\text { hemodynamic monitoring on } \\
\text { the occurrence of } \\
\text { complications }\end{array}$ & $\begin{array}{l}\text { Reduced VSP, DCI, } \\
\text { VSP-related infarctions, } \\
\text { CV complications- } \\
\text { improved mRS }\end{array}$ & Moderate \\
\hline
\end{tabular}




\begin{tabular}{|c|c|c|c|c|c|c|c|}
\hline Reference & $\begin{array}{l}\text { Patient } \\
\text { number }\end{array}$ & $\begin{array}{l}\text { Study } \\
\text { design }\end{array}$ & Group & $\begin{array}{l}\text { Technique } \\
\text { assessment }\end{array}$ & End-point & Findings & $\begin{array}{l}\text { Quality } \\
\text { of } \\
\text { evidence }\end{array}$ \\
\hline $\begin{array}{l}\text { Lennihan } \\
\text { et al. [116] }\end{array}$ & 82 & RCT & SAH & $\begin{array}{l}\text { PAC HV } \\
\text { versus NV }\end{array}$ & $\begin{array}{l}\text { To evaluate the effects of } \\
\text { hemodynamic monitoring on } \\
\text { the occurrence of } \\
\text { complications }\end{array}$ & $\begin{array}{l}\text { HV did not increase } \\
\text { CBF but raised filling } \\
\text { pressures } \\
\text { No differences in } \\
\text { occurrence of VSP } \\
\text { and DCI }\end{array}$ & Moderate \\
\hline
\end{tabular}

$P$ prospective, $R$ retrospective, $S A H$ subarachnoid haemorrhage, $T B I$ traumatic brain injury, $T T$ transpulmonary thermodilution, $P E$ pulmonary edema, $C O$ cardiac output, $P C W A$ pulse contour wave analysis, $L V E F$ left ventricular ejection fraction, $N P E$ neurogenic pulmonary edema, $N R$ not reported, $C V$ cerebral vasospasm, $C I$ cardiac index, $P E$ pulmonary edema, $I A B P$ intra-aortic balloon counterpulsation, $L V E F$ low ventricular ejection fraction, $c T n I$ troponin I, GEDVI global end-diastolic volume index, $G E F$ global ejection fraction, $D C I$ delayed cerebral infarction, $B N P$ brain natriuretic peptide, $S V$ stroke volume, $E C G$ electrocardiogram, $V A$ ventricular arrhythmias

Studies evaluating preload in acute brain injury patients

\begin{tabular}{|c|c|c|c|c|c|c|c|}
\hline Reference & $\begin{array}{l}\text { Patient } \\
\text { number }\end{array}$ & $\begin{array}{l}\text { Study } \\
\text { design }\end{array}$ & Group & $\begin{array}{l}\text { Technique } \\
\text { assessment }\end{array}$ & End-point & Findings & $\begin{array}{l}\text { Quality } \\
\text { of } \\
\text { evidence }\end{array}$ \\
\hline
\end{tabular}

Role of preload monitoring to explain the mechanisms of brain injury-related cardiopulmonary complications

\begin{tabular}{|c|c|c|c|c|c|c|c|}
\hline $\begin{array}{l}\text { Deehan } \\
\text { et al. [38] }\end{array}$ & 24 & $\mathrm{R}$ & SAH & PAC & To assess effects of dobutamine & High variable PAOP in patients with $\mathrm{PE}$ & Very low \\
\hline $\begin{array}{l}\text { Watanabe } \\
\text { et al. [34] }\end{array}$ & 34 & $\mathrm{P}$ & SAH & TT & $\begin{array}{l}\text { To evaluate which hemodynamic } \\
\text { variable was associated with the } \\
\text { occurrence of PE }\end{array}$ & $\begin{array}{l}\text { PE was associated with higher GEDVI } \\
\text { DCI was associated with lower GEDVI }\end{array}$ & Very low \\
\hline $\begin{array}{l}\text { Mayer } \\
\text { et al. [45] }\end{array}$ & 72 & $\mathrm{R}$ & SAH & Echography & $\begin{array}{l}\text { To evaluate the impact of } \\
\text { hemodynamic alterations on } \\
\text { cerebral complications }\end{array}$ & $\begin{array}{l}\text { PAOP was not associated with the } \\
\text { development of DCI }\end{array}$ & Very low \\
\hline $\begin{array}{l}\text { Vespa } \\
\text { et al. [39] }\end{array}$ & 56 & $\mathrm{R}$ & SAH & PAC & $\begin{array}{l}\text { To evaluate the mechanisms of poor } \\
\text { oxygenation after SAH }\end{array}$ & $\begin{array}{l}\text { Increased ELVWI in patients with poor } \\
\text { oxygenation }\end{array}$ & Very low \\
\hline $\begin{array}{l}\text { Touho } \\
\text { et al. [44] }\end{array}$ & 25 & $\mathrm{R}$ & SAH & $\mathrm{TT}$ & $\begin{array}{l}\text { To evaluate the mechanisms of poor } \\
\text { oxygenation after SAH }\end{array}$ & $\begin{array}{l}\text { Increased intrapulmonary shunt and } \\
\text { ELWI were found in patients with } \\
\text { poor oxygenation }\end{array}$ & Very low \\
\hline $\begin{array}{l}\text { Sato et al. } \\
\text { [37] }\end{array}$ & 49 & $P$ & SAH & $\mathrm{TT}$ & $\begin{array}{l}\text { To assess variables related to the } \\
\text { development of PE }\end{array}$ & $\begin{array}{l}\text { Patients with PE had higher ELWI than } \\
\text { others }\end{array}$ & Low \\
\hline $\begin{array}{l}\text { Verein } \\
\text { et al. } \\
{[117]}\end{array}$ & 17 & $\mathrm{P}$ & Stroke & TT & $\begin{array}{l}\text { To assess the relationship between } \\
\text { ELVWI and ICP or brainstem } \\
\text { function }\end{array}$ & $\begin{array}{l}\text { ELVWI was correlated with latency of } \\
\text { auditory potentials }\end{array}$ & Very low \\
\hline \multicolumn{8}{|c|}{ Role of preload monitoring to optimize therapy } \\
\hline $\begin{array}{l}\text { Bulters } \\
\text { et al. [56] }\end{array}$ & 71 & RCT & SAH & PAC & $\begin{array}{l}\text { To assess hemodynamic changes with } \\
\text { IABP }\end{array}$ & $\begin{array}{l}\text { PAOP-guided therapy resulted in } \\
\text { increased CBF and CPP during IABP }\end{array}$ & Moderate \\
\hline $\begin{array}{l}\text { Mutoh } \\
\text { et al. } \\
{[111]}\end{array}$ & 7 & $\mathrm{P}$ & SAH & TT & $\begin{array}{l}\text { To assess the effects of hyperdynamic } \\
\text { therapy on cerebral oxygenation } \\
\text { during s-VSP }\end{array}$ & $\begin{array}{l}\text { Increased } \mathrm{CO} \text { was associated with } \\
\text { improved cerebral oxygenation }\end{array}$ & Very low \\
\hline \multicolumn{8}{|c|}{ findings and outcome } \\
\hline $\begin{array}{l}\text { Mutoh } \\
\text { et al. [78] }\end{array}$ & 45 & $\mathrm{P}$ & $\mathrm{SAH}$ & TT & $\begin{array}{l}\text { To evaluate the effects of TT-guided } \\
\text { therapy on DCI occurrence during } \\
\text { VSP }\end{array}$ & $\begin{array}{l}\text { 4/8 DCI in patients with VSP } \\
\text { No pulmonary edema or heart failure }\end{array}$ & Low \\
\hline
\end{tabular}




\begin{tabular}{|c|c|c|c|c|c|c|c|}
\hline Reference & $\begin{array}{l}\text { Patient } \\
\text { number }\end{array}$ & $\begin{array}{l}\text { Study } \\
\text { design }\end{array}$ & Group & $\begin{array}{l}\text { Technique } \\
\text { assessment }\end{array}$ & End-point & Findings & $\begin{array}{l}\text { Quality } \\
\text { of } \\
\text { evidence }\end{array}$ \\
\hline $\begin{array}{l}\text { Kim } \\
\text { et al. } \\
{[67]}\end{array}$ & 453 & $\begin{array}{l}\mathrm{P}(\mathrm{b} / \\
\mathrm{a})\end{array}$ & SAH & $\begin{array}{l}\text { PAC HHH } \\
\quad \text { versus } \\
\text { HD }\end{array}$ & $\begin{array}{l}\text { To compare the effects of two } \\
\text { therapeutic strategies on neurological } \\
\text { outcomes }\end{array}$ & $\begin{array}{l}\text { Reduced incidence of sepsis and } \\
\text { pulmonary edema } \\
\text { Reduced mortality }\end{array}$ & Moderate \\
\hline $\begin{array}{l}\text { Mutoh } \\
\text { et al. } \\
\text { [68] }\end{array}$ & 116 & $\mathrm{RCT}$ & SAH & $\begin{array}{l}\text { PAC (late) } \\
\text { TT }\end{array}$ & $\begin{array}{l}\text { To compare the effects of two } \\
\text { therapeutic strategies on neurological } \\
\text { outcomes }\end{array}$ & $\begin{array}{l}\text { Reduced VSP, DCI, VSP-related } \\
\text { infarctions, CV complications- } \\
\text { improved mRS }\end{array}$ & Moderate \\
\hline
\end{tabular}

$P$ prospective, $R$ retrospective, $S A H$ subarachnoid haemorrhage, $T T$ transpulmonary thermodilution, $P E$ pulmonary edema, $L V E F$ NPE neurogenic pulmonary edema, $N R$ not reported, $H H H$ triple-H therapy, $P A C$ pulmonary artery catheter, $H D$ hyperdynamic therapy, $C I$ cardiac index, $G E D V$ global end-diastolic volume, $E L V W I$ extravascular lung water index, $D C I$ delayed cerebral ischemia, $V S P$ vasospasm, $s$-VSP symptomatic vasospasm, $C V$ cardiovascular, $P A O P$ pulmonary artery occlusive pressure, $I A B P$ intra-aortic balloon counterpulsation

TT-guided therapy consisted in optimizing CI, GEDV, and reducing EVLWI

Studies evaluating afterload in acute brain injury patients

\begin{tabular}{|c|c|c|c|c|c|c|c|}
\hline Reference & $\begin{array}{l}\text { Patient } \\
\text { number }\end{array}$ & $\begin{array}{l}\text { Study } \\
\text { design }\end{array}$ & Group & $\begin{array}{l}\text { Technique } \\
\text { assessment }\end{array}$ & End-point & Findings & $\begin{array}{l}\text { Quality } \\
\text { of } \\
\text { evidence }\end{array}$ \\
\hline $\begin{array}{l}\text { Hadeishi } \\
\text { et al. [49] }\end{array}$ & 8 & $\mathrm{R}$ & SAH & PAC & $\begin{array}{l}\text { To assess the effects of dobutamine to treat } \\
\text { CV }\end{array}$ & Decreased SVR & Very low \\
\hline $\begin{array}{l}\text { Bulters et al. } \\
\text { [56] }\end{array}$ & 71 & RCT & SAH & PAC & $\begin{array}{l}\text { To assess hemodynamic changes with } \\
\text { IABP }\end{array}$ & Higher SVR during IABP & Moderate \\
\hline $\begin{array}{l}\text { Watanabe } \\
\text { et al. [34] }\end{array}$ & 34 & $\mathrm{P}$ & SAH & TT & $\begin{array}{l}\text { To evaluate which hemodynamic variable } \\
\text { was associated with the occurrence of } \\
\text { DCI }\end{array}$ & $\begin{array}{l}\text { DCI was associated with } \\
\text { increased SVR }\end{array}$ & Low \\
\hline $\begin{array}{l}\text { Rzheutskaya } \\
\text { et al. [102] }\end{array}$ & 13 & $\mathrm{P}$ & TBI & TT & $\begin{array}{l}\text { To evaluate hemodynamic alterations after } \\
\text { TBI }\end{array}$ & $\begin{array}{l}\text { SVRI were used to identify four } \\
\text { different patterns of } \\
\text { hemodynamic status }\end{array}$ & Very low \\
\hline $\begin{array}{l}\text { Mayer et al. } \\
\text { [45] }\end{array}$ & 72 & $\mathrm{R}$ & SAH & Echography & $\begin{array}{l}\text { To assess the impact of cardiac injury on } \\
\text { hemodynamic and cerebral } \\
\text { complications after SAH }\end{array}$ & $\begin{array}{l}\text { Higher SVRI were found in } \\
\text { patients developing s-VSP }\end{array}$ & Very low \\
\hline
\end{tabular}

$P$ prospective, $S A H$ subarachnoid haemorrhage, $T T$ transpulmonary thermodilution, $I A B P$ intra-aortic balloon counterpulsation, $D C I$ delayed cerebral infarction, $S V R$ systemic vascular resistances, $s$-VSP symptomatic vasospasm, $P A C$ pulmonary artery catheter

Studies evaluating fluid responsiveness (FR) in acute brain injury patients

\begin{tabular}{|c|c|c|c|c|c|c|c|}
\hline Reference & $\begin{array}{l}\text { Patient } \\
\text { number }\end{array}$ & $\begin{array}{l}\text { Study } \\
\text { design }\end{array}$ & Group & $\begin{array}{l}\text { Preload } \\
\text { assessment }\end{array}$ & End-point & Findings & $\begin{array}{l}\text { Quality } \\
\text { of } \\
\text { evidence }\end{array}$ \\
\hline $\begin{array}{l}\text { Berkenstadt } \\
\text { et al. [20] }\end{array}$ & 15 & $\mathrm{P}$ & BS & SVV & $\begin{array}{l}\text { To assess the accuracy of SVV to predict } \\
\text { FR }\end{array}$ & SVV was a strong predictor of FR & Low \\
\hline Li et al. [76] & 48 & $\mathrm{P}$ & BS & SVV & $\begin{array}{l}\text { To assess the accuracy of SVV when } \\
\text { compared to commonly used variables } \\
\text { to predict FR }\end{array}$ & SVV was a strong predictor of FR & Low \\
\hline $\begin{array}{l}\text { Mutoh et al. } \\
\text { [79] }\end{array}$ & 16 & $\mathrm{P}$ & SAH & SVV & $\begin{array}{l}\text { To compare SVV with GEDVI to predict } \\
\text { FR }\end{array}$ & $\begin{array}{l}\text { SVV was a better predictor than } \\
\text { GEDVI for FR }\end{array}$ & Moderate \\
\hline $\begin{array}{l}\text { Mutoh et al. } \\
\text { [68] }\end{array}$ & 116 & $\mathrm{RCT}$ & SAH & $\begin{array}{l}\text { GEDVI } \\
\text { changes }\end{array}$ & $\begin{array}{l}\text { To evaluate the changes in GEDVI versus } \\
\text { PAOP/CVP to predict FR }\end{array}$ & $\begin{array}{l}\text { Only changes in GEDVI after fluid } \\
\text { loading was associated with SV } \\
\text { changes }\end{array}$ & Moderate \\
\hline
\end{tabular}




\begin{tabular}{|c|c|c|c|c|c|c|c|}
\hline Reference & $\begin{array}{l}\text { Patient } \\
\text { number }\end{array}$ & $\begin{array}{l}\text { Study } \\
\text { design }\end{array}$ & Group & $\begin{array}{l}\text { Preload } \\
\text { assessment }\end{array}$ & End-point & Findings & $\begin{array}{l}\text { Quality } \\
\text { of } \\
\text { evidence }\end{array}$ \\
\hline $\begin{array}{l}\text { Moretti } \\
\text { et al. [77] }\end{array}$ & 29 & $\mathrm{P}$ & SAH & $\mathrm{dICV}$ & $\begin{array}{l}\text { To evaluate the changes in SVV versus } \\
\text { dICV to predict FR }\end{array}$ & $\begin{array}{l}\text { SVV and dICV were both strong } \\
\text { predictor of FR }\end{array}$ & Moderate \\
\hline $\begin{array}{l}\text { Deflandre } \\
\text { et al. [84] }\end{array}$ & 26 & $\mathrm{P}$ & BS & $\Delta \mathrm{PP}$ & $\begin{array}{l}\text { To evaluate the changes in } \triangle \mathrm{PP} \text { versus } \mathrm{DD} \\
\text { to predict FR }\end{array}$ & $\begin{array}{l}\Delta \mathrm{PP} \text { and } \mathrm{DD} \text { were both strong } \\
\text { predictor of } \mathrm{FR}\end{array}$ & Moderate \\
\hline
\end{tabular}

$P$ prospective, $R C T$ randomized clinical trial, $B S$ brain surgery, $S A H$ subarachnoid haemorrhage, $S V V$ stroke volume variation, $G E D V I$ global end-diastolic volume index, $d I C V$ distensibility of inferior vena cava, $\triangle P P$ pulse pressure variation

Studies evaluating parameters of global perfusion in acute brain injury patients

\begin{tabular}{|c|c|c|c|c|c|c|c|}
\hline Reference & $\begin{array}{l}\text { Patient } \\
\text { number }\end{array}$ & $\begin{array}{l}\text { Study } \\
\text { design }\end{array}$ & Group & $\begin{array}{l}\text { GP } \\
\text { Assessment }\end{array}$ & End-point & Findings & $\begin{array}{l}\text { Quality } \\
\text { of } \\
\text { evidence }\end{array}$ \\
\hline \multicolumn{8}{|l|}{ Venous saturation } \\
\hline $\begin{array}{l}\text { Di Filippo et al. } \\
\text { [70] }\end{array}$ & 121 & $\mathrm{P}$ & TBI & $\mathrm{ScvO}_{2}$ & $\begin{array}{l}\text { To assess the prognostic value of } \\
\mathrm{ScvO}_{2} \text { after TBI }\end{array}$ & $\begin{array}{l}\mathrm{ScvO}_{2} \text { values were lower in non- } \\
\text { survivors than in survivors } \\
(p=0.04) \text { but not } \\
\text { independently predictor of } \\
\text { mortality }\end{array}$ & Very low \\
\hline $\begin{array}{l}\text { Gaieski et al. } \\
\text { [71] }\end{array}$ & 38 & $\begin{array}{l}\mathrm{R}(\mathrm{b} / \\
\text { a) }\end{array}$ & $\mathrm{CA}$ & $\begin{array}{l}\mathrm{ScvO}_{2} \\
\quad \text { CTRL }\end{array}$ & $\begin{array}{l}\text { To assess the impact of } \mathrm{ScvO}_{2^{-}} \\
\text {guided therapy on outcome after } \\
\text { CA }\end{array}$ & $\begin{array}{l}\mathrm{ScvO}_{2} \text {-guided therapy tended to a } \\
\text { reduction in mortality }\end{array}$ & Low \\
\hline $\begin{array}{l}\text { Walters et al. } \\
\text { [72] }\end{array}$ & 55 & $\begin{array}{l}\mathrm{P}(\mathrm{b} / \\
\mathrm{a})\end{array}$ & $\mathrm{CA}$ & $\begin{array}{l}\mathrm{ScvO}_{2} \\
\quad \mathrm{CTRL}\end{array}$ & $\begin{array}{l}\text { To assess the impact of } \mathrm{ScvO}_{2^{-}} \\
\text {guided therapy on outcome after } \\
\text { CA }\end{array}$ & $\begin{array}{l}\mathrm{ScvO}_{2} \text {-guided therapy tended to an } \\
\text { improved neurological outcome }\end{array}$ & Moderate \\
\hline \multicolumn{8}{|l|}{ Lactate } \\
\hline $\begin{array}{l}\text { Donnino et al. } \\
{[75]}\end{array}$ & 79 & $\mathrm{R}$ & $\mathrm{CA}$ & Lactate & $\begin{array}{l}\text { To assess the prognostic value of } \\
\text { lactate clearance after CA }\end{array}$ & $\begin{array}{l}\text { Higher lactate clearance at 6-, } 12-\text {, } \\
\text { and } 24-\text { in survivors than non- } \\
\text { survivors }\end{array}$ & Very low \\
\hline $\begin{array}{l}\text { Karagiannis } \\
\text { et al. [118] }\end{array}$ & 28 & $\mathrm{R}$ & IHCA & Lactate & $\begin{array}{l}\text { To assess the prognostic value of } \\
\text { lactate clearance after CA }\end{array}$ & $\begin{array}{l}\text { Lactate clearance was significantly } \\
\text { lower in survivors than non- } \\
\text { survivors }\end{array}$ & Very low \\
\hline $\begin{array}{l}\text { Kliegel et al. } \\
\text { [74] }\end{array}$ & 394 & $\mathrm{R}$ & CA & Lactate & $\begin{array}{l}\text { To assess the prognostic value of } \\
\text { lactate levels and lactate } \\
\text { clearance after CA }\end{array}$ & $\begin{array}{l}\text { Lactate levels at } 48 \mathrm{~h} \text { were } \\
\text { independently associated with } \\
\text { poor neurological outcome }\end{array}$ & Very low \\
\hline $\begin{array}{l}\text { Lemiale et al. } \\
\text { [46] }\end{array}$ & 1,152 & $\mathrm{R}$ & OHCA & Lactate & $\begin{array}{l}\text { To assess the prognostic value of } \\
\text { lactate after CA }\end{array}$ & $\begin{array}{l}\text { Admission lactate was an } \\
\text { independent predictor of ICU } \\
\text { mortality }\end{array}$ & Very low \\
\hline $\begin{array}{l}\text { Starodub et al. } \\
{[73]}\end{array}$ & 199 & $\mathrm{R}$ & $\begin{array}{l}\text { OHCA } \\
\text { IHCA }\end{array}$ & Lactate & $\begin{array}{l}\text { To assess the prognostic value of } \\
\text { lactate levels and lactate } \\
\text { clearance after CA }\end{array}$ & $\begin{array}{l}\text { Initial serum lactate and lactate } \\
\text { clearance were not predictive of } \\
\text { survival }\end{array}$ & Very low \\
\hline $\begin{array}{l}\text { Cocchi et al. } \\
\text { [119] }\end{array}$ & 128 & $\mathrm{R}$ & OHCA & Lactate & $\begin{array}{l}\text { To assess the prognostic value of } \\
\text { lactate levels and vasopressors } \\
\text { after CA }\end{array}$ & $\begin{array}{l}\text { Vasopressor need and lactate } \\
\text { levels could predict mortality }\end{array}$ & Very low \\
\hline $\begin{array}{l}\text { Oddo et al. } \\
{[120]}\end{array}$ & 88 & $\mathrm{P}$ & $\mathrm{CA}$ & Lactate & $\begin{array}{l}\text { To assess the prognostic value of } \\
\text { several hospital variables after } \\
\text { CA }\end{array}$ & $\begin{array}{l}\text { Lactate on admission was an } \\
\text { independent predictor of poor } \\
\text { outcome }\end{array}$ & Low \\
\hline $\begin{array}{l}\text { Shinozaki et al. } \\
\text { [121] }\end{array}$ & 98 & $\mathrm{P}$ & OHCA & Lactate & $\begin{array}{l}\text { To assess the prognostic value of } \\
\text { lactate after CA }\end{array}$ & $\begin{array}{l}\text { Initial lactate level was } \\
\text { independently associated with } \\
\text { poor outcome } \\
\text { Level }>12 \mathrm{mmol} / \mathrm{L} \text { predicted } \\
\text { poor outcome (Sens. } 90 \% \text { and } \\
\text { Sp. } 52 \% \text { ) }\end{array}$ & Low \\
\hline
\end{tabular}




\begin{tabular}{|c|c|c|c|c|c|c|c|}
\hline Reference & $\begin{array}{l}\text { Patient } \\
\text { number }\end{array}$ & $\begin{array}{l}\text { Study } \\
\text { design }\end{array}$ & Group & $\begin{array}{l}\text { GP } \\
\text { Assessment }\end{array}$ & End-point & Findings & $\begin{array}{l}\text { Quality } \\
\text { of } \\
\text { evidence }\end{array}$ \\
\hline $\begin{array}{l}\text { Mullner et al. } \\
\text { [122] }\end{array}$ & 167 & $\mathrm{R}$ & OHCA & Lactate & $\begin{array}{l}\text { To assess the prognostic value of } \\
\text { lactate after CA }\end{array}$ & $\begin{array}{l}\text { Initial lactate values were } \\
\text { correlated with the duration of } \\
\text { arrest and associated with poor } \\
\text { outcome }\end{array}$ & Very low \\
\hline $\begin{array}{l}\text { Adrie et al. } \\
{[123]}\end{array}$ & 130 & $\mathrm{P}$ & OHCA & Lactate & $\begin{array}{l}\text { To identify clinical and laboratory } \\
\text { variables that predict outcome } \\
\text { after CA }\end{array}$ & $\begin{array}{l}\text { Lactate on admission was an } \\
\text { independent predictor of poor } \\
\text { outcome }\end{array}$ & Low \\
\hline $\begin{array}{l}\text { Zhao et al. } \\
\text { [124] }\end{array}$ & 81 & $\mathrm{P}$ & TBI & Lactate & $\begin{array}{l}\text { To assess the effect of TH on } \\
\text { lactate and glucose levels after } \\
\text { TBI }\end{array}$ & $\begin{array}{l}\text { TH reduced more rapidly lactate } \\
\text { levels than normothermia }\end{array}$ & Low \\
\hline $\begin{array}{l}\text { Yatsushige } \\
\text { et al. [125] }\end{array}$ & 12 & $\mathrm{P}$ & TBI & Lactate & $\begin{array}{l}\text { To assess predictors of poor } \\
\text { outcome after decompressive } \\
\text { craniectomy }\end{array}$ & $\begin{array}{l}\text { Lactate levels were independently } \\
\text { associated with poor outcome }\end{array}$ & Very low \\
\hline $\begin{array}{l}\text { Meierhans et al. } \\
{[126]}\end{array}$ & 20 & $\mathrm{R}$ & TBI & Lactate & $\begin{array}{l}\text { To assess the effects of arterial } \\
\text { lactate on brain metabolism }\end{array}$ & $\begin{array}{l}\text { Blood lactate }>2 \mathrm{mmol} / \mathrm{L} \\
\text { increased brain lactate and } \\
\text { decreased brain glucose }\end{array}$ & Very low \\
\hline $\begin{array}{l}\text { Cureton et al. } \\
\text { [127] }\end{array}$ & 555 & $\mathrm{R}$ & TBI & Lactate & $\begin{array}{l}\text { The impact of lactate on } \\
\text { neurological outcome }\end{array}$ & $\begin{array}{l}\text { Increased lactate was associated } \\
\text { with more severe head injury } \\
\text { Patients with lactate }>5 \mathrm{mmol} / \mathrm{L} \\
\text { had better outcome }\end{array}$ & Very low \\
\hline $\begin{array}{l}\text { Brouns et al. } \\
{[128]}\end{array}$ & 182 & $P$ & Stroke & Lactate & $\begin{array}{l}\text { The impact of lactate on } \\
\text { neurological outcome }\end{array}$ & $\begin{array}{l}\text { Blood lactate was not associated } \\
\text { with outcome }\end{array}$ & Low \\
\hline Jo et al. [129] & 292 & $\mathrm{R}$ & Stroke & Lactate & $\begin{array}{l}\text { The impact of initial lactate on } \\
\text { neurological outcome }\end{array}$ & $\begin{array}{c}\text { Initial lactate levels }>2 \mathrm{mmol} / \mathrm{L} \\
\text { associated with poor outcome }\end{array}$ & Very low \\
\hline \multicolumn{8}{|l|}{$\Delta \mathrm{CO}_{2}$} \\
\hline $\begin{array}{l}\text { Tsaousi et al. } \\
\text { [130] }\end{array}$ & 51 & $\mathrm{P}$ & BS & $\Delta \mathrm{CO}_{2}$ & $\begin{array}{l}\text { To assess the relationship between } \\
\text { CI and } \Delta \mathrm{CO}_{2}\end{array}$ & $\begin{array}{c}\text { Good correlation }\left(R^{2}=0.830\right) \\
\text { between the two variables }\end{array}$ & Very low \\
\hline
\end{tabular}

$P$ prospective, $R$ retrospective, $C A$ cardiac arrest, $O H C A$ out-of-hospital CA, $I H C A$ in-hospital $\mathrm{CA}, \mathrm{ScvO}_{2}$ central venous saturation, $\triangle \mathrm{CO} \mathrm{O}_{2}$ venoarterial $\mathrm{CO}_{2}$ difference, $B S$ brain surgery, $C I$ cardiac index, TBI traumatic brain injury, $T H$ therapeutic hypothermia, Sens. sensitivity, Spec. specificity, $C T R L$ control group

Available techniques used for hemodynamic monitoring in patients with acute brain injury and their potential advantages and disadvantages

\begin{tabular}{|c|c|c|c|c|c|c|c|}
\hline Techniques & $\begin{array}{l}\text { Cardiac } \\
\text { output }\end{array}$ & $\begin{array}{l}\mathrm{LV} \\
\text { function }\end{array}$ & Preload & $\begin{array}{l}\text { Fluid } \\
\text { responsiveness }\end{array}$ & Afterload & Advantages & Disadvantages \\
\hline PAC & + & $\begin{array}{l}-(\mathrm{LV}) \\
+(\mathrm{RV})\end{array}$ & + & - & + & $\begin{array}{l}\text { Measure of PAP, PAOP } \\
\text { Measure of } \mathrm{SvO}_{2}\end{array}$ & $\begin{array}{l}\text { Invasiveness Not beat-by- } \\
\text { beat analysis }\end{array}$ \\
\hline $\begin{array}{l}\text { Trans-pulmonary } \\
\text { Thermodilution }\end{array}$ & + & + & + & + & + & $\begin{array}{l}\text { Less invasive No need for PAC } \\
\text { positioning }\end{array}$ & $\begin{array}{l}\text { Requires a specific femoral } \\
\text { arterial catheter Not } \\
\text { beat- } \\
\text { by-beat analysis }\end{array}$ \\
\hline $\begin{array}{l}\text { External }+ \text { internal } \\
\text { calibrated } \text { PCM }^{\mathrm{a}}\end{array}$ & + & + & - & + & + & $\begin{array}{l}\text { Continuous } \mathrm{CO} \text { monitoring } \\
\text { Continuous } \mathrm{ScvO}_{2} \text { (optional) }\end{array}$ & $\begin{array}{l}\text { Recalibration every } 4-6 \mathrm{~h} \\
\text { Requires a specific } \\
\text { femoral arterial catheter }\end{array}$ \\
\hline $\begin{array}{l}\text { Internal-calibrated } \\
\mathrm{PCM}^{\mathrm{b}}\end{array}$ & + & - & - & + & + & $\begin{array}{l}\text { Continuous } \mathrm{CO} \text { monitoring } \\
\text { Continuous } \mathrm{ScvO}_{2} \text { (optional) } \\
\text { Mini-invasive }\end{array}$ & $\begin{array}{l}\text { Less accuracy for CO } \\
\text { Sensitive to SVR } \\
\text { Requires specific catheter }\end{array}$ \\
\hline Non-calibrated $\mathrm{PCM}^{\mathrm{c}}$ & + & + & - & + & + & $\begin{array}{l}\text { Continuous CO monitoring } \\
\text { No need for dedicated catheter } \\
\text { Mini-invasive }\end{array}$ & $\begin{array}{l}\text { Few data available } \\
\text { Less accuracy for CO (?) } \\
\text { Requires optimal arterial } \\
\text { pressure tracing }\end{array}$ \\
\hline
\end{tabular}




\begin{tabular}{llllllll}
\hline Techniques & $\begin{array}{l}\text { Cardiac } \\
\text { output }\end{array}$ & $\begin{array}{l}\text { LV } \\
\text { function }\end{array}$ & $\begin{array}{l}\text { Preload } \\
\text { Echocid } \\
\text { responsiveness }\end{array}$ & Afterload Advantages & Disadvantages \\
\hline Echocardiography & + & + & + & + & - & $\begin{array}{l}\text { Visualization of the heart } \\
\text { Estimate for filling pressure }\end{array}$ & $\begin{array}{l}\text { Intermittent use } \\
\text { Requires adequate training }\end{array}$
\end{tabular}

$P A C$ pulmonary artery catheter, $P C M$ pulse contour method, $\mathrm{ScvO}_{2}$ central venous oxygen saturation, $\mathrm{SvO}_{2}$ mixed venous oxygen saturation, $S V R$ systemic vascular resistances, $C O$ cardiac output, $P A P$ pulmonary artery pressure, $P A O P$ pulmonary artery occlusive pressure, $L V$ left ventricle, $R V$ right ventricle

+ possible; - not feasible

${ }^{a}$ PiCCO device (Pulsion Medical Systems, Irving, TX, USA)

b FloTrac Vigileo device (Edwards, Irvine, CA, USA)

${ }^{c}$ MostCare-PRAM device (Vygon, Padova, Italy)

Differences among different monitoring techniques for cardiac output (CO) in acute brain injury patients

\begin{tabular}{|c|c|c|c|c|c|c|}
\hline Reference & $\begin{array}{l}\text { Patient } \\
\text { number }\end{array}$ & $\begin{array}{l}\text { Study } \\
\text { design }\end{array}$ & Group & $\begin{array}{l}\text { Technique } \\
\text { assessment }\end{array}$ & Findings & $\begin{array}{l}\text { Quality of } \\
\text { evidence }\end{array}$ \\
\hline Franchi et al. [131] & 121 & $\mathrm{P}$ & TBI & PCA PCWA & $\begin{array}{l}\text { CO: correlation } 0.94 \text {; bias } 0.06 \mathrm{~L} / \mathrm{min} \text { : } \\
\text { PE } 18 \%\end{array}$ & Moderate \\
\hline Mutoh et al. [78] & 45 & $\mathrm{P}$ & SAH & PCWA TT & CI: correlation 0.77 ; bias $0.33 \mathrm{~L} / \mathrm{min} \mathrm{m}^{2}$; PE $15 \%$ & Moderate \\
\hline Mutoh et al. [68] & 116 & RCT & SAH & PAC TT & CI: correlation 0.78 ; bias $0.05 \mathrm{~L} / \mathrm{min} \mathrm{m}^{2}$; PE $14 \%$ & High \\
\hline Mutoh et al. [79] & 16 & $\mathrm{P}$ & SAH & PCWA TT & $\begin{array}{l}\text { CI: correlation } 0.82 \text {; bias was } 0.57 \mathrm{~L} / \mathrm{min} \mathrm{m}^{2} \text {; } \\
\mathrm{PE} 25 \% \text { and higher during } \mathrm{MV}\end{array}$ & Moderate \\
\hline Junttila et al. [80] & 16 & $\mathrm{P}$ & $\mathrm{BS}$ & PCWA PAC & $\begin{array}{l}\text { CO: bias } 1.7 \mathrm{~L} / \mathrm{min} \text {; PE } 45 \% \text {. } \\
\text { Larger bias during NE and NIMO therapy } \\
\text { Significant correlation SVR/bias }\end{array}$ & Moderate \\
\hline Haenggi et al. [82] & 8 & $\mathrm{P}$ & OHCA & PCWA PAC & $\begin{array}{l}\text { CO: bias } 0.23 \mathrm{~L} / \mathrm{min} \text {, PE } 34 \% \\
\text { No differences between } \mathrm{TH} \text { and } \mathrm{NT}\end{array}$ & Moderate \\
\hline Tagami et al. [83] & 88 & $\mathrm{P}$ & CA & TT & Coefficient of error $<10 \%$ ( 3 injections) & Moderate \\
\hline Mayer et al. [81] & 48 & $\mathrm{P}$ & SAH & Echography PAC & $\begin{array}{l}\mathrm{CO} \text { : correlation } 0.67 \text {; bias } 0.75 \mathrm{~L} / \mathrm{min} \text {; } \\
\text { precision } 1.34 \mathrm{~L} / \mathrm{min} \text {; echography } \\
\text { underestimated PAC-derived CO }\end{array}$ & Moderate \\
\hline
\end{tabular}

$P$ prospective, $R$ retrospective, $R C T$ randomized clinical trial, $T B I$ traumatic brain injury, $S A H$ subarachnoid hemorrhage, $O H C A$ out-of-hospital cardiac arrest, $T T$ transpulmonary thermodilution, $P C W A$ pulse contour wave analysis, $P A C$ pulmonary artery catheter, $C O$ cardiac output, $C I$ cardiac index, $P E$ percentage of error, $N E$ norepinephrine, $N I M O$ nimodipine, $S V R$ systemic vascular resistances, $T H$ therapeutic hypothermia, $N T$ normothermia

\section{Intracranial Pressure and Cerebral Perfusion Pressure: Fundamental Considerations and Rationale for Monitoring}

Indications for ICP monitoring. Are there clinical or CT findings that predict the development of intracranial hypertension and so can guide decision making about ICP monitor placement?

\begin{tabular}{|c|c|c|c|c|c|}
\hline Reference & $\begin{array}{l}\# \text { of } \\
\text { patients }\end{array}$ & Design & $\begin{array}{l}\text { Grade } \\
\text { crit. }\end{array}$ & Results & Caveats \\
\hline $\begin{array}{l}\text { Hukkelhoven } \\
\quad \text { et al. [105] }\end{array}$ & $\begin{array}{l}134 \\
\text { monitored } \\
\text { patients }\end{array}$ & $\begin{array}{l}\text { Single-centre, retrospective } \\
\text { observational analysis of } \\
\text { admission clinical predictors of } \\
\text { ICP elevation }\end{array}$ & Low & $\begin{array}{l}\text { No univariate predictors with } p<0.05 \text {. } \\
\text { Model discrimination (AUC) }=0.50 \\
(95 \% \text { CI } 0.41-0.58 \text { ) and calibration } \\
\text { (Hosmer-Lemeshow goodness of } \\
\text { fit })=0.18\end{array}$ & $\begin{array}{l}\text { No admission CT data. No control for } \\
\text { decision to monitor. Subjective } \\
\text { classification of intracranial } \\
\text { hypertension. Used only hourly ICP } \\
\text { data }\end{array}$ \\
\hline $\begin{array}{l}\text { Toutant et al. } \\
\text { [6] }\end{array}$ & 218 & $\begin{array}{l}\text { Single-centre, retrospective } \\
\text { analysis of prospective } \\
\text { observational data on correlation } \\
\text { of cisterns on admission CT and } \\
\text { ICP }\end{array}$ & Low & $\begin{array}{l}74 \% \text { of monitored patients with absent } \\
\text { cisterns had ICP }>30 \mathrm{mmHg}\end{array}$ & $\begin{array}{l}\text { Lack of rigorous definition and } \\
\text { standardization of cisternal } \\
\text { compression }\end{array}$ \\
\hline
\end{tabular}




\begin{tabular}{|c|c|c|c|c|c|}
\hline Reference & $\begin{array}{l}\text { \# of } \\
\text { patients }\end{array}$ & Design & $\begin{array}{l}\text { Grade } \\
\text { crit. }\end{array}$ & Results & Caveats \\
\hline $\begin{array}{l}\text { Mizutani } \\
\text { et al. [7] }\end{array}$ & 100 & $\begin{array}{l}\text { Single-centre, retrospective } \\
\text { analysis of correlation of } \\
\text { admission CT parameters and } \\
\text { initial ICP }\end{array}$ & Low & $\begin{array}{l}\text { Admission CT findings that contributed } \\
\text { to predicting initial degree of } \\
\text { intracranial hypertension included (in } \\
\text { order of predictive power) cisternal } \\
\text { compression, subdural size, } \\
\text { ventricular size (III and IV), } \\
\text { intracerebral haematoma size, and } \\
\text { subarachnoid haemorrhage }\end{array}$ & $\begin{array}{l}\text { ICP monitored by subarachnoid } \\
\text { catheter. No data on later } \\
\text { development of intracranial } \\
\text { hypertension }\end{array}$ \\
\hline $\begin{array}{l}\text { Eisenberg } \\
\text { et al. [8] }\end{array}$ & 753 & $\begin{array}{l}\text { Multi-centre, retrospective analysis } \\
\text { of prospective observational } \\
\text { data on prediction of abnormal } \\
\text { ICP }\end{array}$ & Mod & $\begin{array}{l}\text { For first } 72 \mathrm{~h} \text {, strongest }(p<0.001) \\
\text { independent predictors of percent of } \\
\text { monitored time that ICP }>20 \mathrm{mmHg} \\
\text { were abnormal mesencephalic } \\
\text { cisterns, midline shift, and } \\
\text { subarachnoid blood. For ICP } \\
\text { occurrences }>20 \mathrm{mmHg} \text {, the } \\
\text { strongest }(p<0.001) \text { was cisternal } \\
\text { compression, with age, midline shift, } \\
\text { and intraventricular blood reaching } \\
p<0.05\end{array}$ & Used only end-hour ICP values \\
\hline $\begin{array}{l}\text { Kishore et al. } \\
\text { [9] }\end{array}$ & $\begin{array}{l}137 \text { (47 with } \\
\text { normal } \\
\text { admission } \\
\text { CT) }\end{array}$ & $\begin{array}{l}\text { Single-centre, retrospective } \\
\text { observational analysis of } \\
\text { correlation of final Marshall CT } \\
\text { classification with ICP course }\end{array}$ & Low & $\begin{array}{l}\text { Elevated ICP was present in } \geq 55 \% \text { of } \\
\text { patients with intra- or extra-axial } \\
\text { haematomas. } 17 \% \text { of patients with } \\
\text { normal admission CT imaging had } \\
\text { ICP }>20 \mathrm{mmHg}\end{array}$ & $\begin{array}{l}\text { Used only intermittent ICP } \\
\text { measurements. Did not separate out } \\
\text { patients with persistently normal CT } \\
\text { imaging }\end{array}$ \\
\hline $\begin{array}{l}\text { Narayan } \\
\quad \text { et al., } 1982 \\
\text { [5] }\end{array}$ & 226 & $\begin{array}{l}\text { Single-centre retrospective } \\
\text { observational study of predictors } \\
\text { of intracranial hypertension }\end{array}$ & Low & $\begin{array}{l}\text { Association with intracranial } \\
\text { hypertension for abnormal admission } \\
\text { CT }=53-63 \% \text {; for normal admission } \\
\mathrm{CT}=13 \% .2+\text { of predictive } \\
\text { variables* with normal CT had } 60 \% \\
\text { incidence }(* \text { age }>40 \text { years, systolic } \\
\text { blood pressure } \leq 90 \mathrm{mmHg} \text {, or motor } \\
\text { posturing) }\end{array}$ & $\begin{array}{l}\text { No magnitude for ICP elevation. No } \\
\text { prospective verification of normal CT } \\
\text { model. Examined only admission CT } \\
\text { imaging. Used only end-hour ICP } \\
\text { values }\end{array}$ \\
\hline $\begin{array}{l}\text { Miller et al., } \\
2004[10]\end{array}$ & 82 & $\begin{array}{l}\text { Single-centre retrospective } \\
\text { observational study modeling } \\
\text { CT characteristics as predictors } \\
\text { of intracranial hypertension }\end{array}$ & Low & $\begin{array}{l}\text { Initial CT ventricle size, basilar cisterns, } \\
\text { sulcal size, transfalcine herniation, } \\
\text { and gray/white differentiation were } \\
\text { associated with, but not predictive of } \\
\text { intracranial hypertension }\end{array}$ & $\begin{array}{l}\text { Non-standardised CT variable grading } \\
\text { system. Small sample size for } \\
\text { modeling. No magnitude for ICP } \\
\text { elevation }\end{array}$ \\
\hline $\begin{array}{l}\text { Lobato et al., } \\
\qquad 1983 \text { [11] }\end{array}$ & 277 & $\begin{array}{l}\text { Single-centre, retrospective } \\
\text { observational study of outcome } \\
\text { of monitored patients }\end{array}$ & Low & $\begin{array}{l}\text { Normal CT imaging post evacuation of } \\
\text { extracerebral haematomas did not } \\
\text { have ICP problems; normal, non- } \\
\text { operative scans had } 15 \% \text { incidence of } \\
\text { intracranial hypertension, none severe } \\
\text { ( }>35 \mathrm{mmHg} \text { ). Other combinations of } \\
\text { contusions or brain swelling had much } \\
\text { higher incidences }\end{array}$ & $\begin{array}{l}\text { No multivariate statistics for ICP. } \\
\text { Examined only admission CT } \\
\text { imaging }\end{array}$ \\
\hline $\begin{array}{l}\text { Poca et al. } \\
\quad[12]\end{array}$ & 94 & $\begin{array}{l}\text { Single-centre, retrospective } \\
\text { analysis of prospective } \\
\text { observational data on correlation } \\
\text { of final Marshall CT } \\
\text { classification with ICP course }\end{array}$ & Low & $\begin{array}{l}\text { Development of intracranial } \\
\text { hypertension by final Marshall } \\
\text { Classification: DI I }=0 \% \text {; DI } \\
\text { II }=28.6 \%(10 \% \text { uncontrollable }) \\
\text { DI III }=63.2 \%(1 / 3 \text { uncontrollable }) \\
\text { DI IV }=100 \% \text { (all uncontrollable }) ; \\
\text { EML }=65.2 \%(1 / 2 \text { uncontrollable }) \\
\text { NEML }=84.6 \%(1 / 2 \text { uncontrollable })\end{array}$ & $\begin{array}{l}\text { Did not separately report admission CT } \\
\text { class as predictive of ICP course. } \\
\text { Used only intermittent ICP } \\
\text { measurements }\end{array}$ \\
\hline $\begin{array}{l}\text { Miller et al. } \\
\text { [59] }\end{array}$ & 225 & $\begin{array}{l}\text { Single-centre, retrospective } \\
\text { observational study of ICP and } \\
\text { outcome of consecutive sTBI } \\
\text { patients }\end{array}$ & Low & $\begin{array}{l}\text { Less than } 25 \% \text { incidence of persistent } \\
\text { ICP }>20 \mathrm{mmHg} \text { in patients with } \\
\text { normal admission CT imaging }\end{array}$ & $\begin{array}{l}\text { Little detail on patients with normal } \\
\text { admission CT }\end{array}$ \\
\hline
\end{tabular}




\begin{tabular}{|c|c|c|c|c|c|}
\hline Reference & $\begin{array}{l}\text { \# of } \\
\text { patients }\end{array}$ & Design & $\begin{array}{l}\text { Grade } \\
\text { crit. }\end{array}$ & Results & Caveats \\
\hline $\begin{array}{l}\text { Holliday et al. } \\
\text { [106] }\end{array}$ & 17 & $\begin{array}{l}\text { Single-centre, retrospective } \\
\text { observational study of ICP } \\
\text { course of patients with normal } \\
\text { admission CT imaging }\end{array}$ & Low & $\begin{array}{l}86 \% \text { of their patients with } \\
\text { normal admission CT and } \\
\text { ICP }>25 \mathrm{mmHg} \text { had associated } \\
\text { pulmonary complications. Patients } \\
\text { with "normal" admission } \\
\text { CT did not develop intracranial } \\
\text { hypertension }\end{array}$ & $\begin{array}{l}\text { Examined only admission CT imaging. } \\
\text { Implications of "secondary" ICP } \\
\text { elevation unclear. Normal CT could } \\
\text { include cisternal compression, slit } \\
\text { ventricles }\end{array}$ \\
\hline $\begin{array}{l}\text { Lobato et al. } \\
\qquad[107]\end{array}$ & $\begin{array}{l}46 \text { patients } \\
\text { (39 } \\
\text { monitored) }\end{array}$ & $\begin{array}{l}\text { Single-centre, retrospective } \\
\text { observational study of ICP } \\
\text { course of patients with } \\
\text { repeatedly normal CT imaging }\end{array}$ & Low & $\begin{array}{l}\text { No patient with persistently } \\
\text { normal admission CT had } \\
\text { sustained intracranial hypertension. } \\
\text { Within the first } 24 \mathrm{~h}, 10 \% \text { had } \\
\text { transient ICP elevation below } \\
25 \mathrm{mmHg}\end{array}$ & Examined only admission CT imaging. \\
\hline $\begin{array}{l}\text { O'Sullivan } \\
\text { et al. [108] }\end{array}$ & $\begin{array}{l}22 \text { patients } \\
\text { ( } 8 \text { with } \\
\text { high- } \\
\text { resolution } \\
\text { monitoring) }\end{array}$ & $\begin{array}{l}\text { Single-centre, retrospective } \\
\text { observational analysis } \\
\text { of ICP course in patients } \\
\text { without signs of ICP } \\
\text { elevation on admission } \\
\text { CT }\end{array}$ & Low & $\begin{array}{l}88 \% \text { had intracranial hypertension } \\
(\mathrm{ICP}>20 \mathrm{mmHg}), \text { severe } \\
\text { (protracted period } \geq 30 \mathrm{mmHg} \text { ) in } \\
62 \%\end{array}$ & $\begin{array}{l}\text { Primary ICP monitoring by subdural } \\
\text { systems }\end{array}$ \\
\hline Lee et al. [13] & 36 & $\begin{array}{l}\text { Single-centre, retrospective } \\
\text { observational analysis } \\
\text { of ICP course in patients } \\
\text { with CT diagnosis of } \\
\text { DAI }\end{array}$ & Low & $\begin{array}{l}28 \% \text { had no ICP }>20 \mathrm{mmHg}, \\
47 \% \text { had ICP values } 21-30 \mathrm{mmHg} \\
\text { and } 25 \% \text { had ICP } \\
\text { values }>30 \mathrm{mmHg} \text {. Only } 1 \\
\text { patient }(3 \%) \text { underwent } \\
\text { treatment }\end{array}$ & $\begin{array}{l}\text { Used only intermittent ICP } \\
\text { measurements. Incomplete } \\
\text { description of } \\
\text { management methods }\end{array}$ \\
\hline
\end{tabular}

ICP elevation and outcome

\begin{tabular}{|c|c|c|c|c|c|}
\hline Reference & \# of Patients & Design & $\begin{array}{l}\text { Grade } \\
\text { crit. }\end{array}$ & Results & Caveats \\
\hline $\begin{array}{l}\text { Treggiari, } 2007 \\
\text { [56] }\end{array}$ & $\begin{array}{l}\text { Four studies ( } 409 \text { pts) for } \\
\text { ICP values; five studies } \\
\text { ( } 677 \text { pts) for of ICP } \\
\text { patterns }\end{array}$ & $\begin{array}{l}\text { Systematic } \\
\text { review }\end{array}$ & Moderate & $\begin{array}{l}\text { OR of death: } \\
\text { ICP } 20-40=3.5[95 \% \text { CI } 1.7-7.3] \\
\text { ICP }>40=6.9[95 \% \text { CI } 3.9-12.4] \\
\text { Refractory ICP }=114.3[95 \% \text { CI } 40.5- \\
322.3]\end{array}$ & $\begin{array}{l}\text { ICP treated at } \\
\text { thresholds; } \\
\text { few studies with data } \\
\text { available for } \\
\text { quantitative } \\
\text { analysis }\end{array}$ \\
\hline
\end{tabular}

Does ICP-monitor-based management influence outcome in TBI?

\begin{tabular}{|c|c|c|c|c|c|}
\hline Reference & \# of Patients & Design & $\begin{array}{l}\text { Grade } \\
\text { crit. }\end{array}$ & Results & Caveats \\
\hline $\begin{array}{l}\text { Saul and } \\
\text { Ducker, } \\
1982 \\
{[37]}\end{array}$ & $\begin{array}{l}233 \text { (106 pre, } \\
127 \text { post) }\end{array}$ & $\begin{array}{l}\text { Single-centre, retrospective, } \\
\text { sequential case series' } \\
\text { comparing two protocols }\end{array}$ & Low & $\begin{array}{l}\text { Lower mortality (46 vs. } 28 \% \text { ) } \\
\text { associated with a stricter ICP Tx } \\
\text { protocol (with lower threshold) }\end{array}$ & $\begin{array}{l}\text { Concomitant change in ICP } \\
\text { treatment threshold; many } \\
\text { uncontrolled changes } \\
\text { associated with protocol }\end{array}$ \\
\hline $\begin{array}{l}\text { Vukic } \\
\text { et al. } \\
1999 \\
{[61]}\end{array}$ & $\begin{array}{l}28 \text { (11 pre, } 18 \\
\text { post) }\end{array}$ & $\begin{array}{l}\text { Single-centre, prospective, } \\
\text { sequential case series comparing } \\
\text { no protocol/no monitoring to } \\
\text { BTF protocol with ICP } \\
\text { monitoring }\end{array}$ & Low & $\begin{array}{l}14 \% \text { lower mortality and } 50 \% \\
\text { more favourable GOS outcome } \\
\text { in group managed via } \\
\text { monitoring/protocol }\end{array}$ & $\begin{array}{l}\text { Role of ICP monitoring in } \\
\text { protocol effects unclear. No } \\
\text { statistical analysis }\end{array}$ \\
\hline
\end{tabular}




\begin{tabular}{|c|c|c|c|c|c|}
\hline Reference & \# of Patients & Design & $\begin{array}{l}\text { Grade } \\
\text { crit. }\end{array}$ & Results & Caveats \\
\hline $\begin{array}{l}\text { Clayton } \\
\text { et al., } \\
2004 \\
{[63]}\end{array}$ & $\begin{array}{c}843 \text { (391 pre, } \\
452 \text { post) }\end{array}$ & $\begin{array}{l}\text { Single centre, retrospective, } \\
\text { sequential case series examining } \\
\text { effect of an ICP management } \\
\text { protocol }\end{array}$ & Low & $\begin{array}{l}\text { Reduction in ICU mortality } \\
\quad(19.95-13.5 \% \text {; OR } 0.47 ; 95 \% \\
\text { CI } 0.29-0.75) \text {, and hospital } \\
\text { mortality (24.55-20.8 \%; OR } \\
0.48 ; 95 \% \text { CI } 0.31-0.74)\end{array}$ & $\begin{array}{l}\text { Primary change was in CPP } \\
\text { management; role of ICP } \\
\text { monitoring unclear }\end{array}$ \\
\hline $\begin{array}{l}\text { Fakhry } \\
\text { et al. } \\
2004 \\
{[64]}\end{array}$ & $\begin{array}{l}820 \text { (219 pre- } \\
\text { protocol, } 188 \\
\text { low } \\
\text { compliance, } \\
423 \text { high } \\
\text { compliance) }\end{array}$ & $\begin{array}{l}\text { Single-centre retrospective case } \\
\text { series from prospective registry } \\
\text { of implementing BTF-based } \\
\text { management protocol }\end{array}$ & Low & $\begin{array}{l}\text { No significant change in mortality } \\
(17.8,18.6,13.7) \text {. Compliance- } \\
\text { related improvement in } \\
\text { discharge GOS } 4-5 \text { ( } 43.3,50.3 \text {, } \\
61.5 \%) \text { and appropriate } \\
\text { response on RLA ( } 43.9,44.0 \% \text {, } \\
56.6 \%) \text {. Shorter ICU and } \\
\text { hospital LOS }\end{array}$ & $\begin{array}{l}\text { No ICP data or analysis of ICP- } \\
\text { monitoring-specific effects }\end{array}$ \\
\hline $\begin{array}{l}\text { Spain } \\
\text { et al. } \\
1998 \\
{[65]}\end{array}$ & $\begin{array}{l}133 \text { (49 pre, } 84 \\
\text { post) }\end{array}$ & $\begin{array}{l}\text { Single-centre prospective case } \\
\text { series with clinical pathway } \\
\text { versus retrospective control pre- } \\
\text { pathway }\end{array}$ & Low & $\begin{array}{l}\text { Significant improvement in } \\
\text { process variables unrelated to } \\
\text { ICP monitoring; increase in } \\
\text { hospital mortality associated } \\
\text { with pathway }(12.2-21.4 \%) \\
\text { attributable to withdrawal of } \\
\text { care. No difference in functional } \\
\text { outcome }\end{array}$ & $\begin{array}{l}\text { Strong confounding by general } \\
\text { effects of clinical pathway } \\
\text { (became point of paper) }\end{array}$ \\
\hline $\begin{array}{l}\text { Arabi } \\
\text { et al. } \\
2010 \\
{[66]}\end{array}$ & $\begin{array}{l}434 \text { (74 pre, } 362 \\
\text { post) }\end{array}$ & $\begin{array}{l}\text { Single-centre retrospective case } \\
\text { series' from prospective } \\
\text { database comparing protocol to } \\
\text { pre-protocol period }\end{array}$ & Low & $\begin{array}{l}\text { Protocol use independently } \\
\text { associated with reduced hospital } \\
\text { mortality (OR } 0.45 ; 95 \% \text { CI } \\
0.24-0.86 ; p=.02) \text { and ICU } \\
\text { mortality (OR } 0.47 ; 95 \% \text { CI } \\
0.23-0.96 ; p=.04)\end{array}$ & $\begin{array}{l}\text { Small, retrospective control } \\
\text { group }\end{array}$ \\
\hline $\begin{array}{l}\text { Haddad } \\
\text { et al. } \\
2011 \\
{[67]}\end{array}$ & 477 & $\begin{array}{l}\text { Single-centre retrospective case } \\
\text { series from prospective database } \\
\text { examining role of ICP in } \\
\text { protocol-related improvements }\end{array}$ & Low & $\begin{array}{l}\text { ICP monitoring not associated } \\
\text { with significant independent } \\
\text { difference in hospital (OR } 1.71 \text {, } \\
95 \% \text { CI } 0.79-3.70, p=0.17) \\
\text { or ICU mortality OR } 1.01,95 \% \\
\text { CI } 0.41-2.45, p=0.99)\end{array}$ & $\begin{array}{l}\text { Associated decrease in ICP } \\
\text { monitoring frequency not } \\
\text { explained. No control for } \\
\text { choice to monitor }\end{array}$ \\
\hline $\begin{array}{l}\text { Bulger } \\
\text { et al. } \\
2002 \\
{[68]}\end{array}$ & 182 & $\begin{array}{l}\text { Multi-centre retrospective cohort } \\
\text { study from prospective database } \\
\text { examining outcome based on } \\
\text { "aggressiveness" of TBI care }\end{array}$ & $\begin{array}{l}\text { Low- } \\
\text { Mod }\end{array}$ & $\begin{array}{l}\text { Adjusted hazard ratio for death of } \\
0.43 \text { ( } 95 \% \text { CI } 0.27-0.66 \text { ) for } \\
\text { management at an "aggressive" } \\
\text { center compared to a } \\
\text { "nonaggressive" center. No } \\
\text { significant difference in } \\
\text { discharge functional status of } \\
\text { survivors }\end{array}$ & $\begin{array}{l}\text { General trauma database lacked } \\
\text { important demographic } \\
\text { information. ICP as marker, } \\
\text { causality not assessed }\end{array}$ \\
\hline $\begin{array}{l}\text { Cremer } \\
\text { et al. } \\
2005 \\
{[69]}\end{array}$ & 333 & $\begin{array}{l}\text { Two-centre retrospective cohort } \\
\text { study comparing a centre } \\
\text { monitoring ICP versus on not } \\
\text { monitoring ICP }\end{array}$ & $\begin{array}{l}\text { Low- } \\
\text { Mod }\end{array}$ & $\begin{array}{l}\text { No difference in hospital mortality } \\
\text { for ICP group }(33 \%) \text { versus no- } \\
\text { ICP group ( } 34 \% ; p=0.87 \text { ). No } \\
\text { difference in functional outcome } \\
\text { at } \geq 12 \text { months (OR } 0.95 ; 95 \% \\
\text { CI } 0.62-1.44 \text { ) }\end{array}$ & $\begin{array}{l}\text { No description of management } \\
\text { approaches. Only } 67 \% \\
\text { monitored at monitoring } \\
\text { centre. Excluded } \\
\text { deaths } \leq 24 \mathrm{~h}\end{array}$ \\
\hline $\begin{array}{l}\text { Lane et al. } \\
\quad 2000 \\
{[76]}\end{array}$ & 5,507 & $\begin{array}{l}\text { Multi-centre retrospective cohort } \\
\text { study from prospective database } \\
\text { examining correlation of ICP } \\
\text { monitoring and outcome }\end{array}$ & $\begin{array}{l}\text { Low- } \\
\text { Mod }\end{array}$ & $\begin{array}{l}\text { ICP monitoring independently } \\
\text { associated with improved } \\
\text { survival }(p<0.015)\end{array}$ & $\begin{array}{l}\text { General trauma database lacked } \\
\text { important demographic } \\
\text { information. No control for } \\
\text { centre differences or choice } \\
\text { to monitor }\end{array}$ \\
\hline $\begin{array}{l}\text { Shafi } \\
\text { et al. } \\
2008 \\
{[77]}\end{array}$ & 1,646 & $\begin{array}{l}\text { Multi-centre retrospective cohort } \\
\text { study from prospective database } \\
\text { examining correlation of ICP } \\
\text { monitoring and outcome }\end{array}$ & $\begin{array}{l}\text { Low- } \\
\text { Mod }\end{array}$ & $\begin{array}{l}\text { Higher adjusted hospital mortality } \\
\text { for monitored patients (OR } \\
0.55 ; 95 \% \text { CI } 0.39-0.76 \\
p<0.001)\end{array}$ & $\begin{array}{l}\text { General trauma database lacked } \\
\text { important demographic } \\
\text { information. No control for } \\
\text { centre differences or choice } \\
\text { to monitor. Excluded } \\
\text { deaths } \leq 48 \mathrm{~h}\end{array}$ \\
\hline
\end{tabular}




\begin{tabular}{|c|c|c|c|c|c|}
\hline Reference & \# of Patients & Design & $\begin{array}{l}\text { Grade } \\
\text { crit. }\end{array}$ & Results & Caveats \\
\hline $\begin{array}{l}\text { Mauritz } \\
\text { et al. } \\
2008 \\
\text { [73] }\end{array}$ & 1,856 & $\begin{array}{l}\text { Multi-centre retrospective cohort } \\
\text { study from prospective database } \\
\text { examining correlation of ICP } \\
\text { monitoring and outcome }\end{array}$ & Low & $\begin{array}{l}\text { No significant association of ICP } \\
\text { monitoring with hospital } \\
\text { outcome as a single factor nor in } \\
\text { interaction with SAPS II }\end{array}$ & $\begin{array}{l}\text { Significant, unexplained centre } \\
\text { differences in ICP monitoring } \\
\text { and outcome }\end{array}$ \\
\hline $\begin{array}{l}\text { Farahvar } \\
\text { et al. } \\
2012 \\
{[17]}\end{array}$ & 1,446 & $\begin{array}{l}\text { Multi-centre retrospective cohort } \\
\text { study from prospective database } \\
\text { examining correlation of ICP } \\
\text { monitoring and outcome }\end{array}$ & $\begin{array}{l}\text { Low- } \\
\text { Mod }\end{array}$ & $\begin{array}{l}\text { Trend toward reduced } 2 \text {-week } \\
\text { mortality for monitored patients } \\
\text { by multivariate logistic } \\
\text { regression modeling (OR } 0.64 \text {; } \\
\quad 95 \% \text { CI } 0.41-1.00 ; p=0.05 \text { ) }\end{array}$ & $\begin{array}{l}\text { No control for decision to } \\
\text { monitor or to treat } \\
\text { unmonitored patients for } \\
\text { intracranial hypertension }\end{array}$ \\
\hline $\begin{array}{l}\text { Stein } \\
\text { et al. } \\
2010 \\
{[78]}\end{array}$ & $\begin{array}{l}127 \text { studies } \\
\text { containing } \\
>125,000 \\
\text { patients }\end{array}$ & $\begin{array}{l}\text { Meta- } \\
\text { analysis of mortality data from } \\
127 \text { studies containing } \geq 90 \\
\text { patients, examining influence of } \\
\text { treatment intensity (based on } \\
\text { prevalence of ICP monitoring) } \\
\text { on } 6 \text { month mortality }\end{array}$ & $\begin{array}{l}\text { Low- } \\
\text { Mod }\end{array}$ & $\begin{array}{l}\text { "High-intensity" treatment } \\
\text { associated with a approximately } \\
12 \% \text { lower adjusted mortality } \\
\text { rate }(p<0.001) \text { and a } 6 \% \\
\text { higher pooled mean rate of } \\
\text { favorable outcomes } \\
(p<0.001)\end{array}$ & $\begin{array}{l}\text { Did not access original data. Ad } \\
\text { hoc definition of and } \\
\text { threshold for treatment } \\
\text { intensity }\end{array}$ \\
\hline $\begin{array}{l}\text { Chesnut } \\
\text { et al. } \\
2012 \\
\text { [79] }\end{array}$ & 324 & $\begin{array}{l}\text { RCT comparing BTF-based } \\
\text { protocol based on ICP } \\
\text { monitoring to protocol based on } \\
\text { imaging and clinical exam } \\
\text { without monitoring }\end{array}$ & $\begin{array}{l}\text { Mod- } \\
\text { high }\end{array}$ & $\begin{array}{l}\text { Primary outcome }=\text { no significant } \\
\text { difference in 6-month composite } \\
\text { outcome measure (OR } 1.09 ; \\
95 \% \text { CI } 0.74-1.58 ; p=0.49) \\
\text { Secondary outcome = no } \\
\text { significant difference in } 14 \text { day } \\
\text { mortality (OR } 1.36 ; 95 \% \text { CI } \\
0.87-2.11 ; p=0.18) \\
\text { cumulative 6-month mortality } \\
\text { OR } 1.10 ; 95 \% \text { CI } 0.77-1.57 ; \\
p=0.60) \text {, or 6-month GOS-E } \\
\text { (OR } 1.23 ; 95 \% \text { CI } 0.77-1.96)\end{array}$ & $\begin{array}{l}\text { Generalizability limited by } \\
\text { issues surrounding } \\
\text { prehospital care, choice of } \\
\text { primary outcome measure, } \\
\text { and management protocols }\end{array}$ \\
\hline $\begin{array}{l}\text { Smith } \\
\text { et al. } \\
1986 \\
{[80]}\end{array}$ & 77 & $\begin{array}{l}\text { Prospective randomized trial of } \\
\text { patients treated based on ICP } \\
\text { versus scheduled treatment }\end{array}$ & Low & $\begin{array}{l}\text { No significant difference in } 1 \text { year } \\
\text { GOS by univariate analysis. } \\
\text { Mean ICP } 5.5 \mathrm{mmHg} \text { higher in } \\
\text { monitor-based-treatment group }\end{array}$ & $\begin{array}{l}\text { Small sample size. Investigation } \\
\text { not designed to study ICP } \\
\text { monitor utility }\end{array}$ \\
\hline
\end{tabular}

Does successfully managing intracranial pressure improve outcome?

\begin{tabular}{|c|c|c|c|c|c|}
\hline Reference & $\begin{array}{l}\text { \# of } \\
\text { patients }\end{array}$ & Design & $\begin{array}{l}\text { Grade } \\
\text { crit. }\end{array}$ & Results & Caveats \\
\hline $\begin{array}{l}\text { Treggiari } \\
\text { et al., } \\
2007 \\
{[56]}\end{array}$ & $\begin{array}{l}677 \\
\quad \text { (five } \\
\text { studies) }\end{array}$ & $\begin{array}{l}\text { Systematic review of association of } \\
\text { ICP values and patterns with } \\
\text { outcome }\end{array}$ & Mod & $\begin{array}{l}\text { Odds of death in responders were } 2.2 \\
\text { times higher (OR 2.2; } 95 \% \text { CI } \\
1.42-3.30 \text { ) and the odds of poor } \\
\text { recovery (GOS } 2 \text { and } 3 \text { ) were four } \\
\text { times higher (OR } 4.095 \% \mathrm{CI} \\
\text { 2.27-7.04) compared to patients } \\
\text { with normal ICP courses } \\
\text { (threshold }=20 \mathrm{mmHg} \text { ) }\end{array}$ & $\begin{array}{l}\text { Did not access original data. } \\
\text { Unable to control for numerous } \\
\text { confounding variables }\end{array}$ \\
\hline $\begin{array}{l}\text { Farahvar } \\
\text { et al. } \\
2011 \\
\text { [29] }\end{array}$ & 388 & $\begin{array}{l}\text { Multi-centre retrospective cohort } \\
\text { study from prospective database } \\
\text { examining ICP response to } \\
\text { treatment and outcome }\end{array}$ & Low & $\begin{array}{l}\text { Lower risk of } 14 \text { day mortality in } \\
\text { patients responding to treatment } \\
\text { (OR } 0.46 ; 95 \% \text { CI } 0.23-0.92 ; \\
p=0.03) .20 \% \text { greater likelihood } \\
\text { of treatment response for each } 1-\mathrm{h} \\
\text { decrease in hours of } \\
\text { ICP }>25 \mathrm{mmHg} \text { in first } 24 \mathrm{~h}(\mathrm{OR} \\
0.80 ; 95 \% \text { CI } 0.71-0.90, \\
p=0.0003)\end{array}$ & $\begin{array}{l}\text { Results very sensitive to ad hoc } \\
\text { definitions of intracranial } \\
\text { hypertension and treatment } \\
\text { response }\end{array}$ \\
\hline
\end{tabular}




\begin{tabular}{|c|c|c|c|c|c|}
\hline Reference & $\begin{array}{l}\text { \# of } \\
\text { patients }\end{array}$ & Design & $\begin{array}{l}\text { Grade } \\
\text { crit. }\end{array}$ & Results & Caveats \\
\hline $\begin{array}{l}\text { Eisenberg } \\
\text { et al. } \\
1988 \\
{[82]}\end{array}$ & 73 & $\begin{array}{l}\text { Multi-centre RCT of high-dose } \\
\text { pentobarbital versus } \\
\text { conventional therapy in } \\
\text { managing refractory intracranial } \\
\text { hypertension }\end{array}$ & Mod & $\begin{array}{l}30 \text { day survival was } 92 \% \text { for patients } \\
\text { who's ICP responded to treatment } \\
\text { versus } 17 \% \text { in nonresponders. } \\
80 \% \text { of all deaths were due to } \\
\text { uncontrolled ICP }\end{array}$ & $\begin{array}{l}\text { Survival/recovery not primary } \\
\text { outcome. Underpowered }\end{array}$ \\
\hline $\begin{array}{l}\text { Shiozaki } \\
\text { et al. } \\
1993 \\
{[83]}\end{array}$ & 33 & $\begin{array}{l}\text { Single-centre RCT of hypothermia } \\
\text { versus conventional therapy in } \\
\text { managing refractory intracranial } \\
\text { hypertension }\end{array}$ & Mod & $\begin{array}{l}\text { For the } 17 \text { hypothermia patients, the } 5 \\
\text { patients with non-responsive ICP } \\
\text { died; } 6 \text {-month mortality among } \\
\text { responders was } 27 \% \text {. Among the } \\
17 \text { controls, } 3 \text { patients survived } \\
\text { (18\% mortality) }\end{array}$ & $\begin{array}{l}\text { ICP courses not described in any } \\
\text { detail. Refractory ICP not well } \\
\text { defined. Underpowered. } \\
\text { Outcome only analysed by study } \\
\text { group }\end{array}$ \\
\hline $\begin{array}{l}\text { Cooper } \\
\text { et al. } \\
2011 \\
{[84]}\end{array}$ & 155 & $\begin{array}{l}\text { Multi-centre RCT of } \\
\text { decompressive craniectomy } \\
\text { versus maximal medical } \\
\text { management of early refractory } \\
\text { intracranial hypertension }\end{array}$ & Low & $\begin{array}{l}\text { 6-month mortality was similar (19 vs. } \\
18 \% \text { ). Adjusted GOS-E scores } \\
\text { were marginally worse for the } \\
\text { craniectomy group (adjusted OR } \\
1.66 ; 95 \% \text { CI } 0.94-2.94 ; \\
p=0.08 \text { ) }\end{array}$ & $\begin{array}{l}\text { ICP response versus outcome not } \\
\text { analysed independently. No data } \\
\text { specific to non-responders }\end{array}$ \\
\hline
\end{tabular}

Is there an optimal ICP treatment threshold the maintenance of which is critical to optimize recovery?

\begin{tabular}{|c|c|c|c|c|c|}
\hline Reference & $\begin{array}{l}\text { \# of } \\
\text { patients }\end{array}$ & Design & $\begin{array}{l}\text { Grade } \\
\text { crit. }\end{array}$ & Results & Caveats \\
\hline $\begin{array}{l}\text { Miller et al., } \\
1977 \text { [58] }\end{array}$ & 160 & $\begin{array}{l}\text { Single-centre } \\
\quad \text { retrospective case series }\end{array}$ & Low & $\begin{array}{l}\text { No ICP threshold for outcome in } \\
\text { patients with mass lesion. When } \\
\text { ICP was } 0-10 \mathrm{mmHg} \text { in patients } \\
\text { without mass lesions, } 85 \% \text { made } \\
\text { a good recovery (GOS } 4-5) \text { and } \\
8 \% \text { died. When ICP was } 11- \\
20 \mathrm{mmHg} \text {, good recovery rate } \\
\text { was } 64 \text { and } 25 \% \text { died }\left(\chi^{2}=5.30 \text {; }\right. \\
p<0.02)\end{array}$ & $\begin{array}{l}\text { All patients treated for elevated ICP. } \\
\text { Minimal risk adjustment or } \\
\text { multifactorial analysis }\end{array}$ \\
\hline $\begin{array}{l}\text { Nordby and } \\
\text { Gunnerod, } \\
1985 \text { [47] }\end{array}$ & 130 & $\begin{array}{l}\text { Single-centre retrospective case } \\
\text { series }\end{array}$ & Low & $\begin{array}{l}\text { Significantly worse outcome in } \\
\text { patients whose ICP exceeded } \\
20 \mathrm{mmHg}(p<0.001) \text {. } \\
\text { ICP } \geq 40 \mathrm{mmHg} \text { had high risk of } \\
\text { progressing to brain death }\end{array}$ & $\begin{array}{l}\text { All patients treated for elevated ICP. } \\
\text { Minimal risk adjustment or } \\
\text { multifactorial analysis. Epidural } \\
\text { monitoring }\end{array}$ \\
\hline $\begin{array}{l}\text { Marshall } \\
\text { et al. } 1979 \\
\text { [72] }\end{array}$ & 100 & $\begin{array}{l}\text { Single-centre retrospective case } \\
\text { series }\end{array}$ & Low & $\begin{array}{l}\text { For patients without mass lesions } \\
\text { with ICP }<15 \mathrm{mmHg}, 77 \% \\
\text { achieved favorable outcome } \\
(\mathrm{GOS}=4-5) \text { versus those with } \\
\mathrm{ICP} \geq 15 \mathrm{mmHg} \text { for } \geq 15 \mathrm{~min}, \\
\text { wherein } 42 \% \text { achieved } \\
\text { favourable outcome }(p<0.01 \text { by } \\
\text { univariate analysis). Favorable } \\
\text { outcomes were achieved in } 43 \% \\
\text { with ICP } \geq 15 \text { for } 15 \mathrm{~min} \text { and in } \\
42 \% \text { with ICP }>40 \mathrm{mmHg} \text { for } \\
15 \text { min }\end{array}$ & $\begin{array}{l}\text { All patients treated for } \\
\text { ICP }>15 \mathrm{mmHg} \text {. Minimal risk } \\
\text { adjustment or multifactorial } \\
\text { analysis }\end{array}$ \\
\hline
\end{tabular}




\begin{tabular}{|c|c|c|c|c|c|}
\hline Reference & $\begin{array}{l}\text { \# of } \\
\text { patients }\end{array}$ & Design & $\begin{array}{l}\text { Grade } \\
\text { crit. }\end{array}$ & Results & Caveats \\
\hline $\begin{array}{l}\text { Saul and } \\
\text { Ducker, } \\
1982 \text { [37] }\end{array}$ & 233 & $\begin{array}{l}\text { Single-centre, retrospective, } \\
\text { sequential case series' } \\
\text { comparing two protocols }\end{array}$ & Low & $\begin{array}{l}\text { Mortality rate was } 46 \% \text { for those } \\
\text { treated with a } 20-25 \mathrm{mmHg} \\
\text { threshold protocol versus } 28 \% \\
\text { for those treated with a } 15 \mathrm{mmHg} \\
\text { protocol }(p<0.0005 \text { by } \\
\text { univariate analysis). For those } \\
\text { with ICP's } \geq 25 \mathrm{mmHg}, \\
\text { respective mortality was } 84 \text { versus } \\
69 \%(p<0.05) \text {. For those with } \\
\text { ICP's } \leq 25 \mathrm{mmHg} \text {, respective } \\
\text { mortalities were } 26 \% \text { and } 15 \% \\
(p<0.025)\end{array}$ & $\begin{array}{l}\text { Threshold analysis confounded by } \\
\text { concomitant general protocol } \\
\text { effects. Minimal risk adjustment } \\
\text { or multifactorial analysis }\end{array}$ \\
\hline $\begin{array}{l}\text { Marmarou } \\
\text { et al. } 2005 \\
\text { [85] }\end{array}$ & 428 & $\begin{array}{l}\text { Multi-centre retrospective } \\
\text { analysis of prospectively } \\
\text { collected database }\end{array}$ & Low & $\begin{array}{l}\text { The proportion of measurements } \\
\text { with ICP }>20 \mathrm{mmHg} \text { was the } \\
\text { most powerful predictor of } \\
6 \text { month outcome after age, } \\
\text { admission GCS motor score, and } \\
\text { abnormal admission pupils. The } \\
\text { full model correctly explained } \\
53 \% \text { of observed outcomes. ICP } \\
\text { proportion modeling power } \\
\text { peaked at } 20 \mathrm{mmHg}\end{array}$ & $\begin{array}{l}\text { Confounding by choice of threshold } \\
\text { variable responses to supra- } \\
\text { threshold values of different } \\
\text { magnitudes, the beneficial and } \\
\text { toxic effects of treatments, and the } \\
\text { interaction of ICP with other } \\
\text { variables in individual patients. } \\
\text { Their model assumes equal effect } \\
\text { of each descriptor over its entire } \\
\text { range }\end{array}$ \\
\hline $\begin{array}{l}\text { Chambers } \\
\text { et al. } 2001 \\
\text { [87] }\end{array}$ & $\begin{array}{l}207 \\
\text { adults }\end{array}$ & $\begin{array}{l}\text { Single-centre retrospective } \\
\text { observational study }\end{array}$ & Low & $\begin{array}{l}\text { ROC analysis of maximum ICP from } \\
\text { hourly averages of automated ICP } \\
\text { data found optimal prediction of } \\
6 \text { month dichotomized GOS } \\
\text { outcome to be } 35 \mathrm{mmHg}\end{array}$ & Studied only maximal ICP values \\
\hline $\begin{array}{l}\text { Ratanalert } \\
\text { et al. } 2004 \\
\text { [86] }\end{array}$ & 27 & $\begin{array}{l}\text { Prospective randomized trial of } \\
\text { protocolised treatment at two } \\
\text { different ICP thresholds ( } 20 \mathrm{vs} \text {. } \\
25 \mathrm{mmHg} \text { ) }\end{array}$ & Low & $\begin{array}{l}\text { No significant difference in 6-month } \\
\text { GOS by univariate or multivariate } \\
\text { analysis }\end{array}$ & $\begin{array}{l}\text { Very small sample size. Little detai } \\
\text { provided on study design and } \\
\text { management }\end{array}$ \\
\hline $\begin{array}{l}\text { Smith et al. } \\
1986[80]\end{array}$ & 77 & $\begin{array}{l}\text { Prospective randomized trial of } \\
\text { patients treated based on ICP } \\
\text { versus scheduled treatment }\end{array}$ & Low & $\begin{array}{l}\text { No significant difference in } 1 \text { year } \\
\text { GOS by univariate analysis. Mean } \\
\text { ICP } 5.5 \mathrm{mmHg} \text { higher in monitor- } \\
\text { based-treatment group }\end{array}$ & $\begin{array}{l}\text { Small sample size. Investigation no } \\
\text { designed to study ICP threshold }\end{array}$ \\
\hline $\begin{array}{l}\text { Resnick } \\
\quad \text { et al. } 1997 \\
\text { [88] }\end{array}$ & 37 & $\begin{array}{l}\text { Single-centre retrospective } \\
\text { observational study on patients } \\
\text { with ICP }>20 \mathrm{mmHg} \text { that } \\
\text { persisted for }>96 \mathrm{~h}\end{array}$ & Low & $\begin{array}{l}38 \% \text { reached GOS } 4-5 \\
\text { at } \geq 6 \text { months; } 43 \% \text { GOS } 1-2 . \\
\text { Patients }<30 \text { years had better } \\
\text { outcome, } 57 \% \text { reaching GOS } 4-5 \\
\text { versus } 12.5 \%(p<0.02) \text {. } \\
\text { Patients with good outcomes were } \\
\text { significantly younger } \\
(p=0.0098) \text {. The association of } \\
\text { age and GCS with outcome was } \\
\text { significant }(p<0.005)\end{array}$ & $\begin{array}{l}\text { No detail on the degree of ICP } \\
\text { resistance or magnitude of relatec } \\
\text { insults (low CPP, herniation) }\end{array}$ \\
\hline $\begin{array}{l}\text { Young et al. } \\
2003 \text { [89] }\end{array}$ & 9 & $\begin{array}{l}\text { Single-centre retrospective } \\
\text { observational study of patients } \\
\text { with ICP }>25 \text { for } \geq 2 \mathrm{~h}\end{array}$ & Low & $\begin{array}{l}\text { Mortality }=56 \% .44 \% \text { survived, } \\
\text { with GOS }=4 \text { at rehabilitation } \\
\text { discharge }\end{array}$ & $\begin{array}{l}\text { Small series. No quantification of } \\
\text { ICP or CPP insults. No } \\
\text { comparison to those who died }\end{array}$ \\
\hline $\begin{array}{l}\text { Vik et al. } \\
2008 \text { [53] }\end{array}$ & 93 & $\begin{array}{l}\text { Single-centre retrospective } \\
\text { observational trial analyzing } \\
\text { ICP as AUC }\end{array}$ & Low & $\begin{array}{l}\text { The dose of ICP was an independent } \\
\text { predictor of death }(\mathrm{OR} 1.04 ; 95 \% \\
\text { CI } 1.003-1.08 ; p=0.035) \text { and } \\
\text { poor outcome (OR } 1.05 ; 95 \% \mathrm{CI} \\
1.003-1.09 ; p=0.034) \text { at } \\
6 \text { months, by multiple regression }\end{array}$ & $\begin{array}{l}\text { No control for monitoring duration } \\
\text { or terminal events. Arbitrary } \\
\text { stratification of AUC categories }\end{array}$ \\
\hline
\end{tabular}




\begin{tabular}{|c|c|c|c|c|}
\hline Reference & $\begin{array}{l}\text { \# of } \\
\text { patients }\end{array}$ & Design & $\begin{array}{l}\text { Grade } \\
\text { crit. }\end{array}$ & Caveats \\
\hline $\begin{array}{l}\text { Kahraman } \\
\text { et al. } 2010 \\
\text { [90] }\end{array}$ & 30 & $\begin{array}{l}\text { Single-centre retrospective } \\
\text { observational trial using } \\
\text { prospective data analyzing } \\
\text { manual versus automated ICP } \\
\text { as AUC versus mean }\end{array}$ & Low & $\begin{array}{l}\text { For automated data, total ICU AUC } \\
\text { had high predictive power for } \\
\text { GOS-E } 1-4 \text { (area under the ROC } \\
\text { curve }=0.92 \pm 0.05) \text { and } \\
\text { moderate predictive power for in- } \\
\text { hospital mortality }(0.76 \pm 0.15) \text {. } \\
\text { The percentage of monitoring } \\
\text { time that ICP }>20 \mathrm{mmHg} \text { had } \\
\text { significantly lower predictive } \\
\text { power for } 3 \text { month GOS-E } \\
\text { compared with AUC using } \\
20 \text { mmHg as the cutoff } \\
(p=0.016)\end{array}$ \\
\hline
\end{tabular}

\section{Systemic and Brain Oxygenation}

Evidentiary table: $\mathrm{PbtO}_{2}$ monitoring

\begin{tabular}{|c|c|c|c|c|c|c|c|}
\hline Reference & $\begin{array}{l}\text { Patient } \\
\text { number }\end{array}$ & Study design & Patient group & $\begin{array}{l}\text { Technique } \\
\text { assessment }\end{array}$ & Endpoint & Findings & $\begin{array}{l}\text { Quality } \\
\text { of } \\
\text { evidence }\end{array}$ \\
\hline $\begin{array}{l}\text { Hoffmann, } \\
1997\end{array}$ & 32 & Retrospective & $\begin{array}{l}\text { Cerebrovascular } \\
\text { surgery }\end{array}$ & $\mathrm{PbtO}_{2}$ & $\begin{array}{l}\text { Definition of normal } \\
\mathrm{PbtO}_{2} \text { thresholds }\end{array}$ & $\begin{array}{l}\text { Normal } \mathrm{PbtO}_{2} \text { of controls: } \\
31 \pm 8 \mathrm{mmHg} \text {; normal } \\
\mathrm{PbtO}_{2} \text { of cerebrovascular } \\
\text { surgery subjects was } 70 \% \\
\text { lower }(\sim 23 \mathrm{mmHg})\end{array}$ & Low \\
\hline Dings, 1998 & 101 & Observational & TBI & $\mathrm{PbtO}_{2}$ & $\begin{array}{l}\text { Definition of normal } \\
\mathrm{PbtO}_{2} \text { thresholds }\end{array}$ & $\begin{array}{l}\text { Normal } \mathrm{PbtO}_{2} \text { values varied } \\
\text { depending on probe distance } \\
\text { below the dura: } 7-17 \mathrm{~mm}= \\
33.0 \pm 13.3 \mathrm{mmHg} ; 17- \\
22 \mathrm{~mm}= \\
25.7 \pm 8.3 \mathrm{mmHg} ; 22- \\
27 \mathrm{~mm}=23.8 \pm \\
8.1 \mathrm{mmHg}\end{array}$ & Low \\
\hline Pennings, 2008 & 25 & Observational & Brain surgery & $\mathrm{PbtO}_{2}$ & $\begin{array}{l}\text { Definition of normal } \\
\mathrm{PbtO}_{2} \text { thresholds }\end{array}$ & $\begin{array}{l}\text { Normal } \\
\mathrm{PbtO}_{2}=22.6 \pm 7.2 \mathrm{mmHg} \\
\text { in the frontal white matter. } \\
\text { In } 11 \text { patients, } \\
\text { measurements were } \\
\text { continued for } 24 \mathrm{~h}: \mathrm{PbtO}_{2} \\
\text { was } 23.1 \pm 6.6 \mathrm{mmHg}\end{array}$ & Low \\
\hline $\begin{array}{l}\text { Doppenberg, } \\
1998 \text { Acta } \\
\text { Neurochir } \\
\text { Suppl }\end{array}$ & 24 & Observational & TBI & $\mathrm{PbtO}_{2}$ and $\mathrm{PET}$ & $\begin{array}{l}\text { Definition of } \\
\text { ischemic } \mathrm{PbtO}_{2} \\
\text { thresholds }\end{array}$ & $\begin{array}{l}\text { Ischemic threshold } \\
(\mathrm{CBF}=18 \mathrm{~mL} / 100 \mathrm{~g} / \mathrm{min}) \\
\text { was } \mathrm{PbtO}_{2}=22 \mathrm{mmHg} \text {. } \\
\text { The critical value for } \mathrm{PbtO}_{2} \\
\text { was } 19-23 \mathrm{mmHg}\end{array}$ & Low \\
\hline $\begin{array}{l}\text { Sarrafzadeh, } \\
2000\end{array}$ & 35 & Retrospective & TBI & $\begin{array}{l}\mathrm{PbtO}_{2} \text { and } \\
\text { CMD }\end{array}$ & $\begin{array}{l}\text { Definition of } \\
\text { ischemic } \mathrm{PbtO}_{2} \\
\text { thresholds }\end{array}$ & $\begin{array}{l}\mathrm{PbtO}_{2}<10 \mathrm{mmHg} \text { is critical } \\
\text { to induce metabolic changes } \\
\text { seen during hypoxia/ } \\
\text { ischemia (increased cerebral } \\
\text { microdialysis glutamate and } \\
\text { lactate/pyruvate ratio) }\end{array}$ & Low \\
\hline
\end{tabular}




\begin{tabular}{|c|c|c|c|c|c|c|c|}
\hline Reference & $\begin{array}{l}\text { Patient } \\
\text { number }\end{array}$ & Study design & Patient group & $\begin{array}{l}\text { Technique } \\
\text { assessment }\end{array}$ & Endpoint & Findings & $\begin{array}{l}\text { Quality } \\
\text { of } \\
\text { evidence }\end{array}$ \\
\hline $\begin{array}{l}\text { Kett-White, } \\
\text { 2002a }\end{array}$ & 46 & Observational & $\begin{array}{c}\text { Aneurysm } \\
\text { surgery }\end{array}$ & $\mathrm{PbtO}_{2}$ & $\begin{array}{l}\text { Definition of } \\
\text { ischemic } \mathrm{PbtO}_{2} \\
\text { thresholds }\end{array}$ & $\begin{array}{l}\text { Temporary clipping caused } \\
\mathrm{PbtO}_{2} \text { decrease: in patients } \\
\text { in whom no subsequent } \\
\text { infarction developed in the } \\
\text { monitored region, } \mathrm{PbtO}_{2} \\
\text { was } \sim 11 \mathrm{mmHg} ; \\
\mathrm{PbtO}_{2}<8 \mathrm{mmHg} \text { for } \\
30 \text { min was associated with } \\
\text { infarction }\end{array}$ & Low \\
\hline $\begin{array}{l}\text { Doppenberg, } \\
1998 \text { Surg } \\
\text { Neurol }\end{array}$ & 25 & Observational & TBI & $\begin{array}{l}\mathrm{PbtO}_{2} \text { with } \\
\text { regional } \\
\text { CBF (Xenon } \\
\text { CT) }\end{array}$ & $\begin{array}{l}\text { Correlation between } \\
\mathrm{PbtO}_{2} \text { and } \mathrm{CBF}\end{array}$ & $\begin{array}{l}\mathrm{PbtO}_{2} \text { strongly correlated with } \\
\mathrm{CBF}(R=0.74 \\
p<0.001) \\
\mathrm{CBF}<18 \mathrm{~mL} / 100 \mathrm{~g} / \mathrm{min} \\
\text { was always accompanied by } \\
\mathrm{PbtO}_{2} \leq 26 \mathrm{mmHg}\end{array}$ & Low \\
\hline Valadka, 2002 & 18 & Observational & TBI & $\begin{array}{l}\mathrm{PbtO}_{2} \text { with } \\
\text { regional } \\
\text { CBF (Xenon } \\
\text { CT) }\end{array}$ & $\begin{array}{l}\text { Correlation between } \\
\mathrm{PbtO}_{2} \text { and } \mathrm{CBF}\end{array}$ & $\begin{array}{l}\mathrm{PbtO}_{2} \text { varied linearly with both } \\
\text { regional and global CBF }\end{array}$ & Low \\
\hline Jaeger, 2005b & 8 & Observational & $\begin{array}{l}\text { Mixed (TBI, } \\
\text { SAH) }\end{array}$ & $\begin{array}{l}\mathrm{PbtO}_{2} \text { with } \\
\text { regional } \\
\text { CBF (TDP) }\end{array}$ & $\begin{array}{l}\text { Correlation between } \\
\mathrm{PbtO}_{2} \text { and } \mathrm{CBF}\end{array}$ & $\begin{array}{l}\text { Significant correlation between } \\
\mathrm{PbtO}_{2} \text { and } \mathrm{CBF}(R=0.36) ; \\
\text { in } 72 \% \text { of } 400 \text { intervals of } \\
30 \text { min duration with } \mathrm{PbtO}_{2} \\
\text { changes larger than } \\
5 \text { mmHg, a strong } \\
\text { correlation between } \mathrm{PbtO}_{2} \\
\text { and CBF was found } \\
(R>0.6)\end{array}$ & Low \\
\hline Rosenthal, 2008 & 14 & Observational & TBI & $\begin{array}{l}\mathrm{PbtO}_{2} \text { with } \\
\text { regional } \\
\mathrm{CBF}(\mathrm{TDP}) \\
\text { and } \mathrm{SjvO}_{2}\end{array}$ & $\begin{array}{l}\text { Correlation between } \\
\mathrm{PbtO}_{2} \text { and } \mathrm{CBF}\end{array}$ & $\begin{array}{l}\mathrm{PbtO}_{2}=\text { product of } \mathrm{CBF} \text { and } \\
\text { cerebral arterio-venous } \mathrm{O}_{2} \\
\text { tension difference }\end{array}$ & Low \\
\hline Longhi, 2007 & 32 & $\begin{array}{l}\text { Prospective } \\
\text { observational }\end{array}$ & TBI & $\mathrm{PbtO}_{2}$ & $\begin{array}{l}\text { Probe location: } \\
\text { normal versus } \\
\text { peri-contusional }\end{array}$ & $\begin{array}{l}\mathrm{PbtO}_{2} \text { lower in peri- } \\
\text { contusional } \\
(19.7 \pm 2.1 \mathrm{mmHg}) \text { than in } \\
\text { normal-appearing tissue } \\
(25.5 \pm 1.5 \mathrm{mmHg}) \\
\text { median duration of } \\
\mathrm{PbtO}_{2}<20 \mathrm{mmHg} \text { was } \\
\text { longer in peri-contusional } \\
\text { versus normal-appearing } \\
\text { tissue }(51 \text { vs. } 34 \% \text { of } \\
\text { monitoring time })\end{array}$ & Low \\
\hline Hlatky, 2008 & 83 & Observational & TBI & $\mathrm{PbtO}_{2}$ & $\begin{array}{l}\text { Probe location: } \\
\text { normal versus } \\
\text { peri-contusional }\end{array}$ & $\begin{array}{l}\mathrm{PbtO}_{2} \text { response to hyperoxia in } \\
\text { normal }(n=20) \text {, peri- } \\
\text { contusional }(n=35) \text { and } \\
\text { abnormal }(n=28) \text { brain } \\
\text { areas: poor response to } \\
\text { hyperoxia when Licox was } \\
\text { in abnormal brain }\end{array}$ & Low \\
\hline
\end{tabular}




\begin{tabular}{|c|c|c|c|c|c|c|c|}
\hline Reference & $\begin{array}{l}\text { Patient } \\
\text { number }\end{array}$ & Study design & Patient group & $\begin{array}{l}\text { Technique } \\
\text { assessment }\end{array}$ & Endpoint & Findings & $\begin{array}{l}\text { Quality } \\
\text { of } \\
\text { evidence }\end{array}$ \\
\hline Ponce, 2012 & 405 & $\begin{array}{l}\text { Prospective } \\
\text { observational }\end{array}$ & TBI & $\mathrm{PbtO}_{2}$ & $\begin{array}{l}\text { Probe location: } \\
\text { normal versus } \\
\text { peri-contusional }\end{array}$ & $\begin{array}{l}\text { Average } \mathrm{PbtO}_{2} \text { lower in peri- } \\
\text { contusional } \\
(25.6 \pm 14.8 \mathrm{mmHg}) \text { versus } \\
\text { normal } \\
(30.8 \pm 18.2 \mathrm{mmHg}) \text { brain } \\
(p<.001) . \mathrm{PbtO}_{2} \text { was } \\
\text { significantly associated to } \\
\text { outcome in univariate } \\
\text { analyses, but independent } \\
\text { linear relationship between } \\
\text { low } \mathrm{PbtO}_{2} \text { and 6-month } \\
\text { GOS score was found only } \\
\text { when the } \mathrm{PbtO}_{2} \text { probe was } \\
\text { placed in peri-contusional } \\
\text { brain }\end{array}$ & Low \\
\hline Ulrich, 2013 & 100 & Retrospective & SAH & $\mathrm{PbtO}_{2}$ & $\begin{array}{l}\text { Likelihood of } \mathrm{PbtO}_{2} \\
\text { monitoring to be } \\
\text { placed in } \\
\text { vasospasm or } \\
\text { infarction territory }\end{array}$ & $\begin{array}{l}\text { The probability that a single } \\
\mathrm{PbtO}_{2} \text { probe was situated in } \\
\text { the territory of severe } \\
\text { vasospasm/infarction was } \\
\text { accurate for MCA/ICA } \\
\text { aneurysms }(80-90 \%) \text {, but } \\
\text { not for ACA }(50 \%) \text { or VBA } \\
\text { aneurysms }(25 \%)\end{array}$ & Low \\
\hline Johnston, 2004 & 11 & $\begin{array}{l}\text { Prospective, } \\
\text { interventional }\end{array}$ & TBI & $\mathrm{PbtO}_{2}$ and PET & $\begin{array}{l}\text { Effect of CPP } \\
\text { augmentation } \\
\quad(70 \rightarrow 90 \mathrm{mmHg}) \\
\text { on } \mathrm{PbtO}_{2}\end{array}$ & $\begin{array}{l}\text { Induced hypertension resulted } \\
\text { in a significant increase in } \\
\mathrm{PbtO}_{2}(17 \pm 8 \mathrm{vs} \text {. } \\
22 \pm 8 \mathrm{mmHg}, p<0.001) \\
\text { and } \mathrm{CBF}(27.5 \pm 5.1 \mathrm{vs} . \\
29.7 \pm 6.0 \mathrm{~mL} / 100 \mathrm{~g} / \mathrm{min}, \\
p<0.05) \text { and a significant } \\
\text { decrease in oxygen } \\
\text { extraction fraction } \\
(33.4 \pm 5.9 \mathrm{vs.} \\
30.3 \pm 4.6 \%, p<0.05)\end{array}$ & \\
\hline Jaeger, 2010 & 38 & $\begin{array}{l}\text { Prospective } \\
\text { observational }\end{array}$ & TBI & $\mathrm{PbtO}_{2}$ & $\begin{array}{l}\text { Identification of } \\
\text { "optimal" CPP }\end{array}$ & $\begin{array}{l}\text { Optimal CPP could be } \\
\text { identified in } 32 / 38 \text { patients. } \\
\text { Median optimal CPP was } \\
70-75 \mathrm{mmHg} \text { (range } 60- \\
100 \mathrm{mmHg} \text { ). Below the } \\
\text { level of optimal CPP, } \mathrm{PbtO}_{2} \\
\text { decreased in parallel to } \mathrm{CPP} \text {, } \\
\text { whereas } \mathrm{PbtO}_{2} \text { reached a } \\
\text { plateau above optimal CPP. } \\
\text { Average } \mathrm{PbtO}_{2} \text { at optimal } \\
\text { CPP was } 24.5 \pm 6.0 \mathrm{mmHg}\end{array}$ & \\
\hline Schneider, 1998 & 15 & Prospective & TBI & $\mathrm{PbtO}_{2}$ & $\begin{array}{c}\text { Effect of moderate } \\
\text { hyperventilation }\end{array}$ & $\begin{array}{l}\text { Hyperventilation }\left(\mathrm{PaCO}_{2}: 27-\right. \\
32 \mathrm{mmHg}) \text { significantly } \\
\text { reduced } \mathrm{PbtO}_{2} \text { from } \\
24.6 \pm 1.4 \text { to } \\
21.9 \pm 1.7 \mathrm{mmHg}\end{array}$ & Low \\
\hline Imberti, 2002 & 36 & Prospective & TBI & $\begin{array}{c}\mathrm{PbtO}_{2} \text { and } \\
\mathrm{SjvO}_{2}\end{array}$ & $\begin{array}{c}\text { Effect of moderate } \\
\text { hyperventilation }\end{array}$ & $\begin{array}{l}\text { 20-min periods of moderate } \\
\text { hyperventilation (27- } \\
32 \mathrm{mmHg} \text { ) in most tests } \\
(79.8 \%) \text { led to both } \mathrm{PbtO}_{2} \\
\text { and } \mathrm{SjvO}_{2} \text { decrease. }\end{array}$ & Low \\
\hline
\end{tabular}




\begin{tabular}{|c|c|c|c|c|c|c|c|}
\hline Reference & $\begin{array}{l}\text { Patient } \\
\text { number }\end{array}$ & Study design & Patient group & $\begin{array}{l}\text { Technique } \\
\text { assessment }\end{array}$ & Endpoint & Findings & $\begin{array}{l}\text { Quality } \\
\text { of } \\
\text { evidence }\end{array}$ \\
\hline Raabe, 2005 & 45 & Retrospective & SAH & $\mathrm{PbtO}_{2}$ & $\begin{array}{l}\text { Effect of induced } \\
\text { hypertension and } \\
\text { hypervolemia }\end{array}$ & $\begin{array}{l}\text { During the } 55 \text { periods of } \\
\text { moderate hypertension, an } \\
\text { increase in } \mathrm{PbtO}_{2} \text { was found } \\
\text { in } 50 \text { cases }(90 \%) \text {, with } \\
\text { complications occurring in } \\
\text { three patients ( } 8 \% \text { ); During } \\
\text { the } 25 \text { periods of } \\
\text { hypervolemia, an increase in } \\
\mathrm{PbtO}_{2} \text { was found during } \\
\text { three intervals ( } 12 \% \text { ), with } \\
\text { complications occurring in } \\
\text { nine patients }(53 \%)\end{array}$ & Low \\
\hline Muench, 2007 & 10 & Prospective & SAH & $\begin{array}{c}\mathrm{PbtO}_{2} \text { and } \\
\text { TDP }\end{array}$ & $\begin{array}{l}\text { Effect of induced } \\
\text { hypertension and } \\
\text { hypervolemia }\end{array}$ & $\begin{array}{l}\text { Induced hypertension } \\
(\mathrm{MAP} \approx 140 \mathrm{mmHg}) \\
\text { resulted in a significant } \\
(p<.05) \text { increase of } \mathrm{PbtO}_{2} \\
\text { and regional } \mathrm{CBF} . \mathrm{In} \\
\text { contrast, hypervolemia/ } \\
\text { hémodilution induced only a } \\
\text { slight increase of regional } \\
\mathrm{CBF} \text { while } \mathrm{PbtO}_{2} \text { did not } \\
\text { improve }\end{array}$ & Low \\
\hline Al-Rawi, 2010 & 44 & Prospective & SAH & $\mathrm{PbtO}_{2}$ & $\begin{array}{l}\text { Osmotherapy with } \\
\text { HTS to treat } \\
\text { ICP }>20 \mathrm{mmHg}\end{array}$ & $\begin{array}{l}(2 \mathrm{~mL} / \mathrm{kg}) \text { of } 23.5 \% \mathrm{HTS} \\
\text { resulted in a significant } \\
\text { increase in } \mathrm{PbtO}_{2} \\
(P<0.05) . \text { A sustained } \\
\text { increase in } \mathrm{PbtO}_{2} \\
(>210 \text { min) was associated } \\
\text { with favorable outcome }\end{array}$ & Low \\
\hline Francony, 2008 & 20 & RCT & $\begin{array}{l}\text { Mixed (17 TBI, } \\
3 \mathrm{SAH})\end{array}$ & $\mathrm{PbtO}_{2}$ & $\begin{array}{l}\text { Osmotherapy with } \\
\text { MAN versus } \\
\text { HTS to treat } \\
\text { ICP }>20 \mathrm{mmHg}\end{array}$ & $\begin{array}{l}\text { A single equimolar infusion } \\
\text { ( } 255 \text { mOsm dose) of } 20 \% \\
\text { MAN ( } N=10 \text { patients) or } \\
7.45 \% \text { HTS }(N=10 \\
\text { patients) equally and } \\
\text { durably reduced ICP. No } \\
\text { major changes in } \mathrm{PbtO}_{2} \\
\text { were found after each } \\
\text { treatment }\end{array}$ & High \\
\hline Smith, 2005 & 35 & Prospective & $\begin{array}{l}\text { Mixed (TBI, } \\
\text { SAH) }\end{array}$ & $\mathrm{PbtO}_{2}$ & Effect of RBCT & $\begin{array}{l}\text { RBCT was associated with an } \\
\text { increase in } \mathrm{PbtO}_{2} \text { in most } \\
(74 \%) \text { patients }\end{array}$ & Low \\
\hline $\begin{array}{l}\text { Leal-Noval, } \\
2006\end{array}$ & 60 & Prospective & TBI & $\mathrm{PbtO}_{2}$ & Effect of RBCT & $\begin{array}{l}\text { RBCT was associated with an } \\
\text { increase in } \mathrm{PbtO}_{2} \text { during a 6- } \\
\text { h period in } 78.3 \% \text { of the } \\
\text { patients. All patients with } \\
\text { basal } \mathrm{PbtO}_{2}<15 \mathrm{mmHg} \\
\text { showed an increment in } \\
\mathrm{PbtO}_{2} \text { versus } 74.5 \% \text { of } \\
\text { patients with basal } \\
\mathrm{PbtO}_{2} \geq 15 \mathrm{mmHg}\end{array}$ & Low \\
\hline Zygun, 2009 & 30 & Prospective & TBI & $\mathrm{PbtO}_{2}$ & $\begin{array}{c}\text { Effect of RBC } \\
\text { transfusion }\end{array}$ & $\begin{array}{l}\text { RBCT was associated with an } \\
\text { increase in } \mathrm{PbtO}_{2} \text { in } 57 \% \text { of } \\
\text { patients }\end{array}$ & Low \\
\hline
\end{tabular}




\begin{tabular}{lllllll}
\hline Reference & $\begin{array}{l}\text { Patient } \\
\text { number }\end{array}$ & Study design & Patient group & $\begin{array}{l}\text { Technique } \\
\text { assessment }\end{array}$ & Endpoint & Findings \\
\hline
\end{tabular}

Menzel, 1999b $24 \quad$ Retrospective TBI $\quad \mathrm{PbtO}_{2}$ and
CMD

Nortje, $2008 \quad 11 \quad$ Prospective $\quad$ TBI

Meixensberger, $91 \quad$ Retrospective
$2003 \mathrm{~b}$

Stiefel, $2005 \quad 53 \quad$ Retrospective

TBI

Martini, $2009 \quad 629 \quad$ Retrospective

TBI

Adamides, $200930 \quad$ Prospective

TBI

McCarthy, $2009111 \quad$ Prospective $\quad$ TBI

TBI

$\mathrm{PbtO}$

therapy

versus

standard

$\mathrm{PbtO}_{2}$

therapy

versus

standard

versus versus
$\mathrm{ICP} / \mathrm{CPP}$

management

$\mathrm{ICP} / \mathrm{CPP}$

management

$\mathrm{PbtO}_{2}$ therapy Effect on outcome

standard

$\mathrm{ICP} / \mathrm{CPP}$

management

Effect on outcome

Effect of normobaric hyperoxia

hyperoxia

Effect on outcome

$$
N=
$$

$\mathrm{PbtO}_{2}$ therapy Effect on outcome standard $\mathrm{ICP} / \mathrm{CPP}$ management

$\mathrm{PbtO}_{2}$ therapy Effect on outcome versus standard $\mathrm{ICP} / \mathrm{CPP}$ management$$
\mathrm{PbtO}_{2} \text { threshold }
$$$$
\text { reduced }
$$$$
\text { mortality at discharge ( } 25
$$$$
\text { vs. } 44 \%, p<0.05 \text { ) }
$$

$N=123$ versus $N=506$ pts; Low $\mathrm{PbtO}_{2}$ threshold

$20 \mathrm{mmHg} \rightarrow$ lower functional independence score (FIM) at discharge (7.6 vs. $8.6, p<0.01$ )

was increased to period of $6 \mathrm{~h}$ by raising the $\mathrm{FiO}_{2}$ from 35 to $100 \%$ ho received (mean $\mathrm{PaO}_{2} 136 \mathrm{mmHg}$ ): the mean $\mathrm{PbtO}_{2}$ increased in of the baseline level enhancement period, whereas the mean CMD lactate levels decreased by $40 \%(p<0.05)$ $0.35-0.50)$ increased mean $57 \pm 47 \mathrm{mmHg}$ associated with a slight but statistically significant

$\mathrm{PbtO}_{2}$ threshold

$\mathrm{mmHg} \rightarrow$ no difference in 6-month-GOS (65 vs. $54 \%, p<0.01)$

$$
\text { (7.6 vs. 8.6, } p<0.01 \text { ) }
$$

$N=20$ versus $N=10$ pts; $\quad$ Low $\mathrm{PbtO}_{2}$ threshold

$15 \mathrm{mmHg} \rightarrow$ no difference in 6-month GOS
$N=63$ versus $N=48$ pts; $\quad$ Low $\mathrm{PbtO}_{2}$ threshold $20 \mathrm{mmHg} \rightarrow$ trend towards better 3-month GOS (79 vs. $61 \%, p=0.09$ )




\begin{tabular}{|c|c|c|c|c|c|c|c|}
\hline Reference & $\begin{array}{l}\text { Patient } \\
\text { number }\end{array}$ & Study design & Patient group & $\begin{array}{l}\text { Technique } \\
\text { assessment }\end{array}$ & Endpoint & Findings & $\begin{array}{l}\text { Quality } \\
\text { of } \\
\text { evidence }\end{array}$ \\
\hline Narotam, 2009 & 168 & Retrospective & TBI & $\begin{array}{l}\mathrm{PbtO}_{2} \text { therapy } \\
\text { versus } \\
\text { standard } \\
\text { ICP/CPP } \\
\text { management }\end{array}$ & Effect on outcome & $\begin{array}{l}N=127 \text { versus } N=41 \text { pts; } \\
\mathrm{PbtO}_{2} \text { threshold } \\
20 \mathrm{mmHg} \rightarrow \text { better } 6- \\
\text { month GOS ( } 3.5 \text { vs. } 2.7 \\
p=0.01 \text { ) }\end{array}$ & Low \\
\hline Spiotta, 2010 & 123 & Retrospective & TBI & $\begin{array}{l}\mathrm{PbtO}_{2} \text { therapy } \\
\text { versus } \\
\text { standard } \\
\mathrm{ICP} / \mathrm{CPP} \\
\text { management }\end{array}$ & Effect on outcome & $\begin{array}{l}N=70 \text { versus } N=53 \text { pts; } \\
\mathrm{PbtO}_{2} \text { threshold } \\
20 \mathrm{mmHg} \rightarrow \text { better } 3- \\
\text { month GOS }(64 \text { vs. } 40 \% \\
p=0.01)\end{array}$ & Low \\
\hline Green, 2013 & 74 & Retrospective & TBI & $\begin{array}{l}\mathrm{PbtO}_{2} \text { therapy } \\
\text { versus } \\
\text { standard } \\
\mathrm{ICP} / \mathrm{CPP} \\
\text { management }\end{array}$ & Effect on outcome & $\begin{array}{l}N=37 \text { versus } N=37 \text { pts; } \\
\mathrm{PbtO}_{2} \text { threshold } \\
20 \mathrm{mmHg} \rightarrow \text { no difference } \\
\text { in mortality ( } 65 \text { vs. } 54 \%, \\
p=0.34 \text { ) }\end{array}$ & Low \\
\hline Fletcher, 2010 & 41 & Retrospective & TBI & $\begin{array}{l}\mathrm{PbtO}_{2} \text { therapy } \\
\text { versus } \\
\text { standard } \\
\mathrm{ICP} / \mathrm{CPP} \\
\text { management }\end{array}$ & Effect on outcome & $\begin{array}{l}N=21 \text { versus } N=20 \mathrm{pts} ; \\
\mathrm{PbtO}_{2} \text { threshold } \\
20 \mathrm{mmHg} \rightarrow \text { higher } \\
\text { cumulative fluid balance, } \\
\text { higher rate of vasopressor } \\
\text { use and pulmonary edema }\end{array}$ & Low \\
\hline
\end{tabular}

Evidentiary table: $\mathrm{SjvO}_{2}$ monitoring

\begin{tabular}{|c|c|c|c|c|c|c|c|}
\hline Reference & $\begin{array}{l}\text { Patient } \\
\text { number }\end{array}$ & Study design & Patient group & $\begin{array}{l}\text { Technique } \\
\text { assessment }\end{array}$ & Endpoint & Findings & $\begin{array}{l}\text { Quality } \\
\text { of } \\
\text { evidence }\end{array}$ \\
\hline Kiening, 1996 & 15 & Prospective & TBI & $\begin{array}{l}\mathrm{SjvO}_{2} \text { and } \\
\mathrm{PbtO}_{2}\end{array}$ & $\begin{array}{l}\text { Quality of data: } \mathrm{SjvO}_{2} \\
\text { versus } \mathrm{PbtO}_{2}\end{array}$ & $\begin{array}{l}\text { The "time of good data } \\
\text { quality" was } 95 \% \text { for } \mathrm{PbtO}_{2} \\
\text { versus } 43 \% \text { for } \mathrm{SjvO}_{2} ; \\
\mathrm{PbtO}_{2} \text { monitoring could be } \\
\text { performed twice as long as } \\
\mathrm{SjvO}_{2} \text { monitoring }\end{array}$ & Low \\
\hline $\begin{array}{l}\text { Meixensberger, } \\
1998\end{array}$ & 55 & Prospective & TBI & $\begin{array}{l}\mathrm{SjvO}_{2} \text { and } \\
\mathrm{PbtO}_{2}\end{array}$ & $\begin{array}{l}\text { Quality of data: } \mathrm{SjvO}_{2} \\
\text { versus } \mathrm{PbtO}_{2}\end{array}$ & $\begin{array}{l}\text { Analyzing reliability and good } \\
\text { data quality, } \mathrm{PbtO}_{2}(\sim 95 \%) \\
\text { was superior to } \mathrm{SjvO}_{2} \\
(\sim 50 \%)\end{array}$ & Low \\
\hline $\begin{array}{l}\text { Robertson, } \\
1989\end{array}$ & 51 & Observational & $\begin{array}{l}\text { Mixed (TBI, } \\
\text { SAH, } \\
\text { stroke) }\end{array}$ & $\begin{array}{l}\mathrm{SjvO}_{2} \text { and } \\
\text { PET- } \\
\text { scan }\end{array}$ & $\begin{array}{l}\text { Correlation between } \mathrm{SjvO}_{2} \\
\text { and } \mathrm{CBF}\end{array}$ & $\begin{array}{l}\mathrm{AVDO}_{2} \text { had only a modest } \\
\text { correlation with CBF } \\
(R=-0.24) \text {. When patients } \\
\text { with ischemia, indicated by } \\
\text { an increased CMRLactate, } \\
\text { were excluded from the } \\
\text { analysis, CBF and AVDO } \\
\text { had a much improved } \\
\text { correlation ( } R=-0.74) \text {. } \\
\text { Most patients with a very } \\
\text { low CBF would have been } \\
\text { misclassified as having a } \\
\text { normal/increased CBF based } \\
\text { on } \mathrm{AVDO}_{2}\end{array}$ & Low \\
\hline
\end{tabular}




\begin{tabular}{|c|c|c|c|c|c|c|c|}
\hline Reference & $\begin{array}{l}\text { Patient } \\
\text { number }\end{array}$ & Study design & Patient group & $\begin{array}{l}\text { Technique } \\
\text { assessment }\end{array}$ & Endpoint & Findings & $\begin{array}{l}\text { Quality } \\
\text { of } \\
\text { evidence }\end{array}$ \\
\hline $\begin{array}{l}\text { Gopinath, } 1999 \\
\text { Neurosurgery }\end{array}$ & 35 & Observational & TBI & $\begin{array}{l}\mathrm{SjvO}_{2} \text { and } \\
\mathrm{TDP}\end{array}$ & $\begin{array}{l}\text { Correlation between } \mathrm{SjvO}_{2} \\
\text { and } \mathrm{CBF}\end{array}$ & $\begin{array}{l}\text { When the change in regional } \\
\mathrm{CBF} \text { was at least } 10 \mathrm{~mL} / \\
100 \mathrm{~g} / \mathrm{min} \text { during } \mathrm{ICP} \\
\text { elevation, the change of } \\
\text { regional } \mathrm{CBF} \text { reflected the } \\
\text { change in } \mathrm{SjvO}_{2} \text { on } 85 \% \text { of } \\
\text { the occasions }\end{array}$ & Low \\
\hline Coles, 2004 & 15 & Prospective & TBI & $\begin{array}{l}\mathrm{SjvO}_{2} \\
\text { and } \\
\text { PET- } \\
\text { scan }\end{array}$ & $\begin{array}{l}\text { Correlation between } \\
\mathrm{SjvO}_{2} \text { and } \mathrm{CBF}\end{array}$ & $\begin{array}{l}\mathrm{SjvO}_{2} \text { correlated well with the } \\
\text { amount of ischemic blood } \\
\text { volume (IBV) measured by } \\
\text { PET scan }(R=0.8, \\
p<0.01) \text {, however, } \\
\text { ischemic } \mathrm{SjvO}_{2} \\
\text { values }<50 \% \text { were only } \\
\text { achieved at an IBV of } \\
170 \pm 63 \mathrm{~mL}, \text { which } \\
\text { corresponded to an average } \\
\text { of } 13 \% \text { of the brain. } \\
\text { Therefore, the sensitivity of } \\
\mathrm{SjvO}_{2} \text { monitoring in } \\
\text { detecting ischemia was low }\end{array}$ & Low \\
\hline Keller, 2002 & 10 & Prospective & $\begin{array}{l}\text { Large } \\
\text { hemispheric } \\
\text { stroke }\end{array}$ & $\begin{array}{l}\mathrm{SjvO}_{2} \text { and } \\
\text { PET- } \\
\text { scan }\end{array}$ & $\begin{array}{l}\text { Correlation between } \mathrm{SjvO}_{2} \\
\text { and } \mathrm{CBF}\end{array}$ & $\begin{array}{l}\text { Out of } 101 \mathrm{ICP} / \mathrm{SjvO}_{2} \text {, and } 92 \\
\mathrm{CBF} \\
\text { measurements, only two } \\
\mathrm{SjvO}_{2} \text { values were below the } \\
\text { ischemic thresholds } \\
\left(\mathrm{SjvO}_{2}<50 \%\right) . \mathrm{SjvO}_{2} \text { did } \\
\text { not reflect changes in } \mathrm{CBF}\end{array}$ & Low \\
\hline Fandino, 1999 & 9 & Prospective & TBI & $\begin{array}{l}\mathrm{SjvO}_{2} \text { and } \\
\mathrm{PbtO}_{2}\end{array}$ & $\begin{array}{l}\text { Value of } \mathrm{SjvO}_{2} \text { versus } \\
\mathrm{PbtO}_{2} \text { to predict ischemia }\end{array}$ & $\begin{array}{l}\text { Low correlation between } \mathrm{SjvO}_{2} \\
\text { and } \mathrm{PbtO}_{2} \text { during } \mathrm{CO}_{2^{-}} \\
\text {reactivity test: in comparison } \\
\text { to } \mathrm{SjvO}_{2}, \mathrm{PbtO}_{2} \text { is more } \\
\text { accurate to detect focal } \\
\text { ischemic events }\end{array}$ & Low \\
\hline $\begin{array}{l}\text { Gopinath, } 1999 \\
\text { Crit Care Med }\end{array}$ & 58 & Prospective & TBI & $\begin{array}{l}\mathrm{SjvO}_{2} \text { and } \\
\mathrm{PbtO}_{2}\end{array}$ & $\begin{array}{l}\text { Value of } \mathrm{SjvO}_{2} \text { versus } \\
\mathrm{PbtO}_{2} \text { to predict ischemia }\end{array}$ & $\begin{array}{l}\text { Sensitivities of the two } \\
\text { monitors for detecting } \\
\text { ischemia were similar }\end{array}$ & Low \\
\hline Gupta, 1999 & 13 & Prospective & TBI & $\begin{array}{l}\mathrm{SjvO}_{2} \text { and } \\
\mathrm{PbtO}_{2}\end{array}$ & $\begin{array}{l}\text { Value of } \mathrm{SjvO}_{2} \text { versus } \\
\mathrm{PbtO}_{2} \text { to predict ischemia }\end{array}$ & $\begin{array}{l}\text { In areas without focal } \\
\text { pathology, good correlation } \\
\text { between changes in } \mathrm{SjvO}_{2} \\
\text { and } \mathrm{PbtO}_{2}\left(R^{2}=0.69,\right. \\
p<0.0001) . \mathrm{In} \text { areas with } \\
\text { focal pathology, no } \\
\text { correlation between } \mathrm{SjvO}_{2} \\
\text { and } \mathrm{PbtO}_{2}\left(R^{2}=0.07,\right. \\
p=0.23) . \mathrm{PbtO}_{2} \text { reflects } \\
\text { regional brain oxygenation } \\
\text { better than } \mathrm{SjvO}_{2}\end{array}$ & Low \\
\hline $\begin{array}{l}\text { Robertson, } \\
1998\end{array}$ & 44 & Prospective & TBI & $\begin{array}{l}\mathrm{SjvO}_{2} \text { and } \\
\mathrm{PbtO}_{2}\end{array}$ & $\begin{array}{l}\text { Value of } \mathrm{SjvO}_{2} \text { versus } \\
\mathrm{PbtO}_{2} \text { to predict ischemia }\end{array}$ & $\begin{array}{l}\text { Good correlation in global } \\
\text { ischemic episodes; during } \\
\text { regional ischemic episodes, } \\
\text { only } \mathrm{PbtO}_{2} \text { decreased, while } \\
\mathrm{SjvO}_{2} \text { did not change }\end{array}$ & Low \\
\hline De Deyne, 1996 & 150 & Retrospective & TBI & $\mathrm{SjvO}_{2}$ & $\begin{array}{l}\text { Detection of ischemia in the } \\
\text { early phase }(<12 \mathrm{~h})\end{array}$ & $\begin{array}{l}\text { Initial } \mathrm{SjvO}_{2}<50 \% \text { in } 57 \\
\text { patients }(38 \%) \text {. jugular bulb } \\
\text { desaturation was related to } \\
\mathrm{CPP}<60 \mathrm{mmHg} \text { and } \\
\mathrm{PaCO}_{2}<30 \mathrm{mmHg}\end{array}$ & Low \\
\hline
\end{tabular}




\begin{tabular}{|c|c|c|c|c|c|c|c|}
\hline Reference & $\begin{array}{l}\text { Patient } \\
\text { number }\end{array}$ & Study design & Patient group & $\begin{array}{l}\text { Technique } \\
\text { assessment }\end{array}$ & Endpoint & Findings & $\begin{array}{l}\text { Quality } \\
\text { of } \\
\text { evidence }\end{array}$ \\
\hline Vigue, 1999 & 27 & Prospective & TBI & $\mathrm{SjvO}_{2}$ & $\begin{array}{l}\text { CPP augmentation with } \\
\text { vasopressors and volume } \\
\text { resuscitation in the early } \\
\text { phase of TBI }\end{array}$ & $\begin{array}{l}\text { Before treatment, } 37 \% \text { of } \\
\text { patients had an } \\
\mathrm{SjvO}_{2}<55 \% \text {, and } \mathrm{SjvO}_{2} \\
\text { was significantly correlated } \\
\text { with CPP }(R=0.73, \\
p<0.0001) . \text { After } \\
\text { treatment, we observed a } \\
\text { significant increase in CPP } \\
\text { (from } 53 \pm 15 \text { to } \\
78 \pm 10 \mathrm{mmHg}), \mathrm{MAP} \\
(79 \pm 9 \mathrm{vs.} \\
103 \pm 10 \mathrm{mmHg}) \text { and } \\
\mathrm{SvjO}_{2}(56 \pm 12 \text { vs. } \\
72 \pm 7 \%), \text { without a } \\
\text { significant change in ICP }\end{array}$ & Low \\
\hline Fortune, 1995 & 22 & Observational & TBI & $\mathrm{SjvO}_{2}$ & ICP therapy & $\begin{array}{l}\text { Effective ICP therapy was } \\
\text { associated with an } \\
\text { improvement in } \mathrm{SjvO}_{2} \\
(+2.5 \pm 0.7 \%)\end{array}$ & Low \\
\hline $\begin{array}{c}\text { Robertson, } \\
1999\end{array}$ & 189 & $\mathrm{RCT}$ & TBI & $\mathrm{SjvO}_{2}$ & $\begin{array}{l}\text { Therapy targeted to } \mathrm{CBF} / \\
\mathrm{CPP}(\mathrm{CPP}>70 \mathrm{mmHg} \text {, } \\
\left.\mathrm{PaCO}_{2} 35 \mathrm{mmHg}\right) \text { versus } \\
\text { to } \mathrm{ICP} \\
(\mathrm{CPP}>50 \mathrm{mmHg} \text {, } \\
\left.\mathrm{PaCO}_{2} 25-30 \mathrm{mmHg}\right)\end{array}$ & $\begin{array}{l}\text { CBF-targeted protocol reduced } \\
\text { the frequency of jugular } \\
\text { desaturation from } 50.6 \text { to } \\
30 \% \text { ( } p=0.006 \text { ); adjusted } \\
\text { risk of jugula desaturation } \\
\text { 2.4-fold greater with the } \\
\text { ICP-targeted protocol. No } \\
\text { difference in GOSE score at } \\
6 \text { months. The beneficial } \\
\text { effects of the CBF-targeted } \\
\text { protocol may have been } \\
\text { offset by a fivefold increase } \\
\text { in the frequency of adult } \\
\text { respiratory distress } \\
\text { syndrome }\end{array}$ & High \\
\hline
\end{tabular}

Evidentiary table (selected key studies only): non-invasive cerebral oxygenation monitoring (NIRS)

\begin{tabular}{|c|c|c|c|c|c|c|c|}
\hline Reference & $\begin{array}{l}\text { Patient } \\
\text { number }\end{array}$ & $\begin{array}{l}\text { Study } \\
\text { design }\end{array}$ & Patient group & $\begin{array}{l}\text { Technique } \\
\text { assessment }\end{array}$ & Endpoint & Findings & $\begin{array}{l}\text { Quality } \\
\text { of } \\
\text { evidence }\end{array}$ \\
\hline $\begin{array}{l}\text { Buchner, } \\
2000\end{array}$ & 31 & Prosp Obs & SAH, TBI & $\begin{array}{l}\text { NIRS With } \\
\mathrm{PbtO}_{2}\end{array}$ & $\begin{array}{l}\text { Data quality, } \\
\text { factors } \\
\text { influencing } \\
\text { signal, } \\
\text { parameter } \\
\text { correlation }\end{array}$ & $\begin{array}{l}50-80 \% \text { good quality data, signal } \\
\text { influenced by optode wetting, galea } \\
\text { hematoma, subdural air; partial } \\
\text { correlation of NIRS with } \mathrm{PbtO}_{2}\end{array}$ & Low \\
\hline $\begin{array}{l}\text { Kirkpatrick, } \\
1998\end{array}$ & 130 & Prosp Obs & $\begin{array}{l}\text { Carotid } \\
\text { endarterectomy }\end{array}$ & $\begin{array}{l}\text { NIRS with } \\
\text { EEG, } \\
\text { TCD } \\
\text { CBFV }\end{array}$ & $\begin{array}{l}\text { Ischemia } \\
\text { thresholds }\end{array}$ & $80 \%$ good quality data & Low \\
\hline Davie, 2012 & 12 & Prosp Obs & $\begin{array}{l}\text { Healthy } \\
\text { volunteers }\end{array}$ & NIRS & $\begin{array}{l}\text { Extracerebral } \\
\text { signal influence }\end{array}$ & $\begin{array}{l}\text { Head cuff inflation reveals } 7-17 \% \\
\text { extracranial signal contribution in } \\
\text { three commercial NIRS monitors }\end{array}$ & Low \\
\hline $\begin{array}{l}\text { Yoshitani, } \\
2007\end{array}$ & 103 & Prosp Obs & $\begin{array}{l}\text { Cardiac/Neuro- } \\
\text { ICU }\end{array}$ & NIRS & $\begin{array}{l}\text { Factors } \\
\text { influencing the } \\
\text { signal }\end{array}$ & $\begin{array}{l}\text { NIRS signal }\left(\mathrm{rSO}_{2}\right) \text { influenced by skull } \\
\text { thickness, CSF layer, hemoglobin }\end{array}$ & Moderate \\
\hline
\end{tabular}




\begin{tabular}{|c|c|c|c|c|c|c|c|}
\hline Reference & $\begin{array}{l}\text { Patient } \\
\text { number }\end{array}$ & $\begin{array}{l}\text { Study } \\
\text { design }\end{array}$ & Patient group & $\begin{array}{l}\text { Technique } \\
\text { assessment }\end{array}$ & Endpoint & Findings & $\begin{array}{l}\text { Quality } \\
\text { of } \\
\text { evidence }\end{array}$ \\
\hline $\begin{array}{l}\text { Brawanski, } \\
2002\end{array}$ & 12 & Prosp Obs & TBI, SAH & $\begin{array}{l}\text { NIRS with } \\
\mathrm{PbtO}_{2}\end{array}$ & $\begin{array}{l}\text { Inter-monitoring } \\
\text { correlation }\end{array}$ & Good correlation & Low \\
\hline $\begin{array}{l}\text { Rothoerl, } \\
2002\end{array}$ & 13 & Prosp Obs & TBI, SAH & $\begin{array}{l}\text { NIRS with } \\
\mathrm{PbtO}_{2}\end{array}$ & $\begin{array}{l}\text { Inter-monitoring } \\
\text { correlation }\end{array}$ & Good correlation & Low \\
\hline $\begin{array}{l}\text { McLeod, } \\
2003\end{array}$ & 8 & Prosp Obs & TBI & $\begin{array}{l}\text { NIRS with } \\
\mathrm{PbtO}_{2} \\
\mathrm{SjvO}_{2}\end{array}$ & $\begin{array}{l}\text { Inter-monitoring } \\
\text { correlation }\end{array}$ & Good correlation & Low \\
\hline $\begin{array}{l}\text { Ter } \\
\text { Minassian, } \\
1999\end{array}$ & 9 & Prosp Obs & TBI & $\begin{array}{l}\text { NIRS with } \\
\mathrm{SjvO}_{2}\end{array}$ & $\begin{array}{l}\text { Inter-monitoring } \\
\text { correlation }\end{array}$ & Poor correlation & Low \\
\hline Buunk, 1998 & 10 & Prosp CS & Cardiac arrest & $\begin{array}{l}\text { NIRS with } \\
\mathrm{SjvO}_{2}\end{array}$ & $\begin{array}{l}\text { Inter-monitoring } \\
\text { correlation }\end{array}$ & Poor correlation & Low \\
\hline $\begin{array}{l}\text { Weerakkody, } \\
2012\end{array}$ & 40 & Prosp Obs & TBI & $\begin{array}{l}\text { NIRS with } \\
\text { ICP/CPP }\end{array}$ & $\begin{array}{l}\text { Inter-monitoring } \\
\text { correlation }\end{array}$ & Good correlation & Low \\
\hline $\begin{array}{r}\text { Zweifel, } \\
2010 \mathrm{a}\end{array}$ & 40 & Prosp Obs & TBI & $\begin{array}{l}\text { NIRS with } \\
\text { ICP/CPP } \\
\text { PRx }\end{array}$ & $\begin{array}{l}\text { Inter-monitoring } \\
\text { correlation }\end{array}$ & Good correlation & Moderate \\
\hline $\begin{array}{l}\text { Zweifel, } \\
\text { 2010b }\end{array}$ & 27 & Prosp Obs & $\mathrm{SAH}$ & $\begin{array}{l}\text { NIRS with } \\
\text { TCD } \\
\text { CBFV/ } \\
\text { MAP Mx }\end{array}$ & $\begin{array}{l}\text { Inter-monitoring } \\
\text { correlation }\end{array}$ & Good correlation & Moderate \\
\hline $\begin{array}{l}\text { Rothoerl, } \\
2003\end{array}$ & 9 & Prosp Obs & TBI & $\begin{array}{l}\text { NIRS with } \\
\text { Xe133 } \\
\text { perfusion }\end{array}$ & $\begin{array}{l}\text { Inter-monitoring } \\
\text { correlation }\end{array}$ & Poor correlation & Low \\
\hline $\begin{array}{l}\text { Terborg, } \\
2004\end{array}$ & 25 & $\begin{array}{l}\text { Prosp } \\
\quad \text { CaseCont }\end{array}$ & Hem AIS & $\begin{array}{l}\text { NIRS with } \\
\text { MRI } \\
\text { perfusion }\end{array}$ & $\begin{array}{l}\text { Inter-monitoring } \\
\text { correlation }\end{array}$ & Good correlation & Moderate \\
\hline Frisch, 2012 & 5 & Case series & Card arrest & $\begin{array}{l}\text { NIRS with } \\
\text { PetCO }_{2}\end{array}$ & $\begin{array}{l}\text { Inter-monitoring } \\
\text { correlation }\end{array}$ & Poor correlation & Very low \\
\hline Bhatia, 2007 & 32 & Prosp Obs & SAH & $\begin{array}{l}\text { NIRS with } \\
\text { DSA }\end{array}$ & $\begin{array}{l}\text { Inter-monitoring } \\
\text { correlation }\end{array}$ & Good correlation & Low \\
\hline $\begin{array}{l}\text { Taussky, } \\
2012\end{array}$ & 6 & Retrosp CS & SAH, AIS, ICH & $\begin{array}{l}\text { NIRS with } \\
\text { CT } \\
\text { perfusion }\end{array}$ & $\begin{array}{l}\text { Inter-monitoring } \\
\text { correlation }\end{array}$ & Good correlation & Very low \\
\hline Aries, 2012 & 9 & Prosp Obs & AIS & $\begin{array}{l}\text { NIRS with } \\
\mathrm{SaO}_{2} \text { and } \\
\text { blood } \\
\text { pressure }\end{array}$ & $\begin{array}{l}\text { Signal response to } \\
\text { drops in } \mathrm{SaO}_{2} \\
\text { and } \mathrm{BP}\end{array}$ & $\begin{array}{l}\text { Good detection of desaturations } \\
\text { less good detection of hypotension }\end{array}$ & Very low \\
\hline $\begin{array}{l}\text { Hargroves, } \\
2008\end{array}$ & 7 & Prosp Obs & AIS & NIRS & $\begin{array}{l}\text { Signal response to } \\
\text { position of } \\
\text { head of bed }\end{array}$ & $\begin{array}{l}\text { Good reflection of position-related } \\
\text { oxygenation changes }\end{array}$ & Very low \\
\hline Damian, 2007 & 24 & Retro Obs & AIS & NIRS & $\begin{array}{l}\text { Outcome, clinical } \\
\text { course, } \\
\text { imaging }\end{array}$ & $\begin{array}{l}\text { Bilateral NIRS with interhemispheric } \\
\text { difference reflecting clinical course, } \\
\text { outcome and effect of decompressive } \\
\text { surgery }\end{array}$ & Low \\
\hline $\begin{array}{l}\text { Bonoczk, } \\
2002\end{array}$ & 43 & RCT interv. & AIS & $\begin{array}{l}\text { NIRS with } \\
\text { TCD }\end{array}$ & $\begin{array}{l}\text { Response of } \mathrm{rSO}_{2} \\
\text { and } \mathrm{CBFV} \text { to } \\
\text { vinpocetine }\end{array}$ & $\begin{array}{l}\text { Increase of } \mathrm{rSO}_{2} \text { in response to } \\
\text { vinpocetine }\end{array}$ & Moderate \\
\hline $\begin{array}{l}\text { Naidech, } \\
\quad 2008\end{array}$ & 6 & Prosp CS & SAH & $\begin{array}{l}\text { NIRS with } \\
\text { TCD } \\
\text { DSA }\end{array}$ & $\begin{array}{l}\text { Change of NIRS } \\
\text { signal in } \\
\text { vasospasm }\end{array}$ & $\begin{array}{l}\text { No reliable detection of vasospasm by } \\
\text { NIRS }\end{array}$ & Very low \\
\hline Yokose, 2010 & 11 & Prosp CS & SAH & $\begin{array}{l}\text { NIRS With } \\
\text { TCD, } \\
\text { DSA }\end{array}$ & $\begin{array}{l}\text { Change of NIRS } \\
\text { signal in } \\
\text { vasospasm }\end{array}$ & Good detection of vasospasm & Very low \\
\hline
\end{tabular}




\begin{tabular}{|c|c|c|c|c|c|c|c|}
\hline Reference & $\begin{array}{l}\text { Patient } \\
\text { number }\end{array}$ & $\begin{array}{l}\text { Study } \\
\text { design }\end{array}$ & Patient group & $\begin{array}{l}\text { Technique } \\
\text { assessment }\end{array}$ & Endpoint & Findings & $\begin{array}{l}\text { Quality } \\
\text { of } \\
\text { evidence }\end{array}$ \\
\hline Mutoh, 2010 & 7 & Prosp CS & SAH & NIRS & $\begin{array}{l}\text { Response of } \\
\text { NIRS signal to } \\
\text { dobutamine }\end{array}$ & $\begin{array}{l}\text { Detection of vasospasm by NIRS, NIRS } \\
\text { signal increasing with incremental } \\
\text { dobutamine }\end{array}$ & Low \\
\hline $\begin{array}{l}\text { Gopinath, } \\
1993\end{array}$ & 40 & Prosp Obs & TBI & $\begin{array}{l}\text { NIRS with } \\
\text { CT }\end{array}$ & $\begin{array}{r}\text { Detection of } \\
\text { secondary } \\
\text { hematoma }\end{array}$ & $\begin{array}{l}\text { Detection secondary hematoma by } \\
\text { NIRS }\end{array}$ & Low \\
\hline $\begin{array}{l}\text { Gopinath, } \\
1995\end{array}$ & 167 & Prosp Obs & TBI & $\begin{array}{l}\text { NIRS with } \\
\text { CT, ICP, } \\
\text { clinical }\end{array}$ & $\begin{array}{l}\text { Time to detection } \\
\text { of secondary } \\
\text { hematomy }\end{array}$ & $\begin{array}{l}\text { Earlier detection of secondary } \\
\text { hematoma than by ICP, clinical signs } \\
\text { or CT }\end{array}$ & Moderate \\
\hline $\begin{array}{l}\text { Budohoski, } \\
2012\end{array}$ & 121 & Prosp Obs & TBI & $\begin{array}{l}\text { NIRS with } \\
\text { TCD } \\
\text { CBFV, } \\
\mathrm{PbtO}_{2}, \\
\text { MAP, } \\
\text { ICP }\end{array}$ & $\begin{array}{l}\text { Time to cerebral } \\
\text { parameter } \\
\text { changes MAP } \\
\text { and ICP } \\
\text { increases }\end{array}$ & $\begin{array}{l}\text { Earlier reflection of MAP and ICP } \\
\text { changes by NIRS than by TCD and } \\
\mathrm{PbtO}_{2}\end{array}$ & Moderate \\
\hline
\end{tabular}

Evidentiary table (selected key studies only): systemic monitoring of oxygen

\begin{tabular}{|c|c|c|c|c|c|c|c|}
\hline Reference & $\begin{array}{l}\text { Patient } \\
\text { number }\end{array}$ & $\begin{array}{l}\text { Study } \\
\text { design }\end{array}$ & $\begin{array}{l}\text { Patient } \\
\text { group }\end{array}$ & $\begin{array}{l}\text { Technique } \\
\text { assessment }\end{array}$ & Endpoint & Findings & $\begin{array}{l}\text { Quality } \\
\text { of } \\
\text { evidence }\end{array}$ \\
\hline Sulter, 2000 & 49 & $\begin{array}{l}\text { Prosp } \\
\text { Obs }\end{array}$ & AIS & $\begin{array}{l}\text { Pulse oximetry } \\
\mathrm{SpO}_{2}, \mathrm{ABG} \\
\mathrm{SatO}_{2}\end{array}$ & Detection $\mathrm{SatO}_{2}<96 \%$ & Pulse oximetry appears useful to titrate $\mathrm{O}_{2}$ therapy & Low \\
\hline $\begin{array}{l}\text { Tisdall, } \\
\text { 2008a }\end{array}$ & 8 & $\begin{array}{l}\text { Prosp } \\
\text { Obs }\end{array}$ & TBI & $\begin{array}{l}\text { ABG } \mathrm{PaO}_{2} \text { and } \\
\mathrm{SatO}_{2} \text {, with } \\
\mathrm{PbtO}_{2}, \text { NIRS, } \\
\text { MD }\end{array}$ & $\begin{array}{l}\text { Parameter response to raising } \\
\mathrm{FiO}_{2}\end{array}$ & 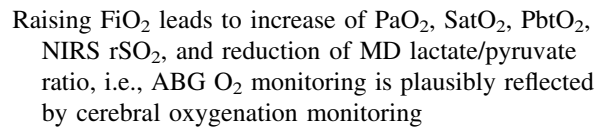 & Low \\
\hline $\begin{array}{l}\text { Diringer, } \\
2007\end{array}$ & 5 & $\begin{array}{l}\text { Prosp } \\
\text { Obs }\end{array}$ & TBI & $\begin{array}{l}\mathrm{ABG} \mathrm{PaO}_{2} \text { with } \\
\mathrm{PbtO}_{2}, \mathrm{PET} \\
\mathrm{CBF} \text { and } \\
\mathrm{CMRO}_{2}\end{array}$ & $\begin{array}{l}\text { Parameter response to raising } \\
\mathrm{FiO}_{2}\end{array}$ & 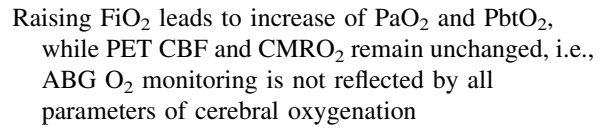 & Low \\
\hline Zhang, 2011 & 9 & $\begin{array}{l}\text { Prosp } \\
\text { Obs }\end{array}$ & $\begin{array}{l}\text { ICH, } \\
\text { TBI, } \\
\text { SAH }\end{array}$ & $\begin{array}{l}\mathrm{ABG} \mathrm{PaO}_{2} / \mathrm{FiO}_{2} \\
\text { with ICP, } \\
\text { CPP }\end{array}$ & $\begin{array}{l}\text { Parameter response to raising } \\
\text { PEEP }\end{array}$ & $\begin{array}{l}\text { Raising PEEP leads to improvement of pulmonary } \\
\text { oxygenation, to increase of ICP, and decrease of } \\
\text { CPP }\end{array}$ & Low \\
\hline $\begin{array}{l}\text { Koutsoukou, } \\
2006\end{array}$ & 21 & $\mathrm{RCT}$ & $\begin{array}{l}\text { ICH, } \\
\text { TBI }\end{array}$ & $\begin{array}{l}\mathrm{ABG} \mathrm{PaO}_{2} / \mathrm{FiO}_{2} \\
\text { with lung } \\
\text { mechanics } \\
\text { parameters }\end{array}$ & $\begin{array}{l}\text { Lung mechanics in PEEP } \\
\text { versus NoPEEP }\end{array}$ & $\begin{array}{l}\text { Improvement of pulmonary oxygenation (assessable by } \\
\text { ABG } \mathrm{O}_{2} \text { monitoring) and lung mechanics in PEEP } \\
\text { compared to No PEEP group }\end{array}$ & Moderate \\
\hline $\begin{array}{l}\text { Muench, } \\
2005\end{array}$ & 10 & $\begin{array}{l}\text { Prosp } \\
\text { Obs }\end{array}$ & SAH & $\begin{array}{l}\mathrm{ABG} \mathrm{PaO}_{2} / \mathrm{FiO}_{2} \\
\text { with CPP } \\
\mathrm{PbtO}_{2}\end{array}$ & $\begin{array}{l}\text { Parameter response to raising } \\
\text { PEEP }\end{array}$ & $\begin{array}{l}\text { Raising PEEP leaves pulmonary oxygenation } \\
\text { unchanged and leads to decrease in } \mathrm{CPP} \text { and } \mathrm{PbtO}_{2} \text {, } \\
\text { i.e., no strong correlation between systemic and } \\
\text { cerebral } \mathrm{O}_{2} \text { monitoring }\end{array}$ & Low \\
\hline Wolf, 2005 & 13 & $\begin{array}{l}\text { Prosp } \\
\text { Obs }\end{array}$ & $\begin{array}{l}\text { SAH, } \\
\text { TBI }\end{array}$ & $\begin{array}{l}\text { ABG SatO } \mathrm{S}_{2} \text { and } \\
\mathrm{PaO}_{2} \text {, with } \\
\mathrm{FiO}_{2}, \mathrm{PbtO}_{2}\end{array}$ & $\begin{array}{l}\text { Long-term response of } \\
\text { systemic and cerebral } \\
\text { oxygenation to raising } \\
\text { PEEP }\end{array}$ & $\begin{array}{l}\text { Raising PEEP allows reduction of } \mathrm{FiO}_{2} \text { after } 24 \mathrm{~h} \text { and } \\
\text { is associated with increased } \mathrm{PbtO}_{2} \text {, i.e., } \mathrm{ABG} \mathrm{O} \mathrm{O}_{2} \\
\text { monitoring reflects improved long-term cerebral } \\
\text { oxygenation }\end{array}$ & Low \\
\hline Bein, 2002 & 11 & $\begin{array}{l}\text { Prosp } \\
\text { Obs }\end{array}$ & $\begin{array}{l}\text { TBI, } \\
\text { ICH, } \\
\text { SAH }\end{array}$ & $\begin{array}{l}\mathrm{ABG} \mathrm{PaO}_{2} \text { and } \\
\mathrm{SatO}_{2} \text { with } \\
\mathrm{CPP}, \mathrm{SjvO}_{2}\end{array}$ & $\begin{array}{l}\text { Response of systemic and } \\
\text { cerebral oxygenation/ } \\
\text { perfusion to raising } \\
\text { ventilator pressure }\end{array}$ & $\begin{array}{l}\text { Raising peak pressure leads to increased } \mathrm{PaO}_{2} \text { and } \\
\mathrm{SaOO}_{2} \text {, while CPP and } \mathrm{SjvO}_{2} \text { are decreased, i.e., } \\
\mathrm{ABG} \mathrm{O}_{2} \text { monitoring might not reflect net cerebral } \\
\text { oxygenation }\end{array}$ & Low \\
\hline Nemer, 2011 & 16 & $\mathrm{RCT}$ & SAH & $\begin{array}{l}\mathrm{ABG} \mathrm{PaO}_{2} / \mathrm{FiO}_{2} \\
\text { with ICP, } \\
\text { CPP }\end{array}$ & $\begin{array}{l}\text { Oxygenation and cerebral } \\
\text { pressure response to two } \\
\text { different recruitment } \\
\text { maneuvers }\end{array}$ & $\begin{array}{l}\text { PV recruitment leads to improved pulmonary } \\
\text { oxygenation (reflected by } \mathrm{ABG} \mathrm{O}_{2} \text { monitoring) and } \\
\text { leaves ICP and CPP unaffected as compared to } \\
\text { CPAP recruitment }\end{array}$ & Moderate \\
\hline $\begin{array}{l}\text { Nekludov, } \\
2006\end{array}$ & 8 & $\begin{array}{l}\text { Prosp } \\
\text { Obs }\end{array}$ & $\begin{array}{l}\text { TBI, } \\
\text { SAH, } \\
\text { ICH }\end{array}$ & $\begin{array}{l}\mathrm{ABG} \mathrm{PaO} \text { with } \\
\text { MAP, ICP } \\
\text { CPP }\end{array}$ & $\begin{array}{l}\text { Systemic oxygenation and } \\
\text { cerebral pressures response } \\
\text { to proning }\end{array}$ & $\begin{array}{l}\text { Prone positioning leads to improved pulmonary } \\
\text { oxygenation (as reflected by } \mathrm{ABG}_{2} \text { monitoring), to } \\
\text { a slight increase in ICP, a stronger increase in MAP } \\
\text { and hence a net increase in CPP }\end{array}$ & Low \\
\hline
\end{tabular}




\begin{tabular}{|c|c|c|c|c|c|c|c|}
\hline Reference & $\begin{array}{l}\text { Patient } \\
\text { number }\end{array}$ & $\begin{array}{l}\text { Study } \\
\text { design }\end{array}$ & $\begin{array}{l}\text { Patient } \\
\text { group }\end{array}$ & $\begin{array}{l}\text { Technique } \\
\text { assessment }\end{array}$ & Endpoint & Findings & $\begin{array}{l}\text { Quality } \\
\text { of } \\
\text { evidence }\end{array}$ \\
\hline Davis, 2009 & 3,420 & Retrosp & TBI & AGB $\mathrm{PaO}_{2}$ & Mortality & $\begin{array}{l}\text { Higher mortality both in hypoxemia and extreme } \\
\text { hyperoxemia, as reflected by } \mathrm{AGB} \mathrm{PaO}_{2} \text { on } \\
\text { admission }\end{array}$ & Low \\
\hline Davis, 2004a & 59 & $\begin{array}{l}\text { Prosp } \\
\text { Obs }\end{array}$ & TBI & $\begin{array}{l}\text { Pulse oximetry } \\
\qquad \mathrm{SpO}_{2}\end{array}$ & Mortality, "good outcome" & $\begin{array}{l}\text { Pulse oximetry useful to detect outcome-relevant } \\
\text { desaturation }\end{array}$ & Low \\
\hline $\begin{array}{l}\text { Pfenninger, } \\
1991\end{array}$ & 47 & $\begin{array}{l}\text { Prosp } \\
\text { Obs }\end{array}$ & TBI & ABG $\mathrm{PaO}_{2}$ & $\begin{array}{l}\text { Correlation of pre-hospital } \\
\mathrm{PaO}_{2} \text { with level of } \\
\text { consciousness }\end{array}$ & $\mathrm{PaO}_{2}$ only weakly correlated with GCS $(r=0.54)$ & Low \\
\hline
\end{tabular}

Evidentiary table (selected key studies only): systemic monitoring of carbon dioxide

\begin{tabular}{|c|c|c|c|c|c|c|c|}
\hline Reference & $\begin{array}{l}\text { Patient } \\
\text { number }\end{array}$ & Study design & Patient group & $\begin{array}{l}\text { Technique } \\
\text { assessment }\end{array}$ & Endpoint & Findings & $\begin{array}{l}\text { Quality of } \\
\text { evidence }\end{array}$ \\
\hline Davis, 2004b & 426 & Prosp Reg & TBI & $\mathrm{PetCO}_{2}$ & $\begin{array}{l}\text { Occurence of } \\
\text { inadvertent } \mathrm{HV}\end{array}$ & $\begin{array}{l}\text { Pre-hospital monitoring by portable } \\
\text { PetCO }_{2} \text { helps to avoid HV }\end{array}$ & Low \\
\hline Dyer, 2013 & 56 & Prosp Obs & TBI & $\begin{array}{l}\text { ABG } \mathrm{PaCO}_{2} \text { with } \\
\text { PetCO }_{2}\end{array}$ & $\begin{array}{l}\text { Factors influencing } \\
\text { the } \mathrm{PaCO}_{2} / \\
\mathrm{PetCO}_{2} \text { gap }\end{array}$ & $\begin{array}{l}\text { Difference between } \mathrm{PaCO}_{2} \text { and } \\
\text { PetCO }_{2} \text { influenced by injury } \\
\text { severity, rib fractures, high BMI }\end{array}$ & Low \\
\hline $\begin{array}{l}\text { Carmona Suazo, } \\
2000\end{array}$ & 90 & Prosp Obs & TBI & $\begin{array}{l}\text { AGB } \mathrm{PaCO}_{2} \text { with } \\
\mathrm{PbtO}_{2}\end{array}$ & $\begin{array}{l}\mathrm{PbtoO}_{2} / \mathrm{PaCO}_{2} \\
\quad \text { reactivity to } \mathrm{HV}\end{array}$ & $\begin{array}{l}\mathrm{HV} \text { leads to decrease in } \mathrm{PbtO}_{2} \\
\text { and } \mathrm{PbtO}_{2} / \mathrm{PaCO}_{2} \text { reactivity }\end{array}$ & Low \\
\hline Coles, 2007 & $10+30$ & $\begin{array}{l}\text { Prosp } \\
\quad \text { CaseContr }\end{array}$ & $\begin{array}{l}\text { Volunteers, } \\
\text { TBI }\end{array}$ & $\begin{array}{l}\mathrm{ABG} \mathrm{PaCO}_{2} \text { with } \\
\mathrm{PET} \mathrm{CBF} \text { and } \\
\mathrm{CMRO}_{2} \text { and } \\
\mathrm{OEF}, \mathrm{SSEP} \\
\mathrm{SjvO}_{2}\end{array}$ & & $\begin{array}{l}\text { Low } \mathrm{PaCO}_{2} \text { is associated with } \\
\text { decreased PET CBF, increased } \\
\text { PET } \mathrm{CMRO}_{2} \text { and PET OEF, SSEP, } \\
\text { while } \mathrm{SjvO}_{2} \text { remains unchanged } \\
\text { when compared to high } \mathrm{PaCO}_{2} \text {, } \\
\text { i.e., ABG } \mathrm{PaCO}_{2} \text { monitoring of } \\
\mathrm{HV} \text { reflects cerebral oxygenation } \\
\text { compromise not detected by } \mathrm{SjvO}_{2}\end{array}$ & Moderate \\
\hline Carrera, 2010 & 21 & Prosp Obs & $\begin{array}{l}\text { SAH, TBI, } \\
\text { ICH }\end{array}$ & $\mathrm{PetCO}_{2}$ with $\mathrm{PbtO}_{2}$ & $\begin{array}{l}\text { Cerebral ischemia } \\
\text { in } \mathrm{HV}\end{array}$ & $\begin{array}{l}\text { Low } \mathrm{PetCO}_{2} \text { in spontaneous } \mathrm{HV} \\
\text { associated with decreased } \mathrm{PbtO}_{2} \\
\text { (to "ischemic" values) }\end{array}$ & Low \\
\hline Pfenninger, 1991 & 47 & Prosp Obs & TBI & AGB $\mathrm{PaCO}_{2}$ & $\begin{array}{l}\text { Level of } \\
\text { consciousness }\end{array}$ & $\begin{array}{l}\text { Strong correlation of high } \mathrm{PaCO}_{2} \\
\quad \text { (=hypoventilation) with low GCS } \\
\quad(r=0.9)\end{array}$ & Low \\
\hline Davis, 2004 & $59+177 c$ & $\begin{array}{l}\text { Prosp } \\
\text { CaseContr }\end{array}$ & TBI & $\mathrm{PetCO}_{2}$ & Mortality & $\begin{array}{l}\mathrm{HV} \text { leads to low } \mathrm{PetCO}_{2} \text { which is } \\
\text { associated with mortality in "dose- } \\
\text { dependent "fashion; i.e., end-tidal } \\
\mathrm{CO}_{2} \text { monitoring reflecting } \\
\text { mortality }\end{array}$ & Moderate \\
\hline Dumont, 2010 & 65 & Retrosp & TBI & $\mathrm{ABG} \mathrm{PaCO}_{2}$ & Mortality & $\begin{array}{l}\text { Hypocarbic versus normocarbic } \\
\text { versus hypocarbic associated } \\
\text { with mortality as } 77,15,61 \%\end{array}$ & Low \\
\hline Muizelaar, 1991 & 113 & RCT & TBI & ABG $\mathrm{PaCO}_{2}$ & $\begin{array}{l}\text { Functional outcome } \\
\text { after } 3 \text { and } \\
6 \text { months }\end{array}$ & $\begin{array}{l}\text { HV leads to worse outcome compared } \\
\text { to } \mathrm{NV} \text { versus } \mathrm{HV}+\text { THAM; i.e., } \\
\text { systemic } \mathrm{CO}_{2} \text { monitoring } \\
\text { reflecting outcome }\end{array}$ & Moderate \\
\hline Solaiman, 2013 & 102 & Retrosp & SAH & AGB $\mathrm{PaCO}_{2}$ & $\begin{array}{l}\text { Functional Outcome } \\
\text { (GOS) at } \\
3 \text { months }\end{array}$ & $\begin{array}{l}\text { Duration of hypocapnia associated } \\
\text { with worse outcome }\end{array}$ & Low \\
\hline
\end{tabular}

Prosp Obs prospective observational study, Retrosp retrospective study, CS case series, RCT randomized controlled trial, Reg registry, Syst Rev systematic review 


\section{Electrophysiology}

Studies evaluating EEG to detect NCSz after acute brain injury

\begin{tabular}{|c|c|c|c|c|}
\hline Authors & Design & Population & $N$ & Findings \\
\hline \multicolumn{5}{|l|}{ TBI $0-33 \% \mathrm{NCSz}$} \\
\hline Steudel et al. [218] & $\mathrm{R} \mathrm{CS}$ & & 50 & $8 \%$ on routineEEGs \\
\hline Vespa et al. [107] & P CS & & 94 & $22 \% \mathrm{NCSz}$ \\
\hline Ronne-Engstrom et al. [111] & R CS & & 70 & $33 \% \mathrm{NCSz}$ \\
\hline Olivecrona et al. [112] & P CS & & 47 & $\begin{array}{l}0 \% \mathrm{NCSz}, 8.5 \% \\
\text { clinical seizures pre EEG }\end{array}$ \\
\hline \multicolumn{5}{|l|}{ SAH 3-31 \% NCsz } \\
\hline Dennis et al. [240] & $\mathrm{R} \mathrm{CS}$ & & 233 & $3 \%(31 \%$ or 8 of 26 with EEG) \\
\hline Claassen et al. [214] & R CS & & 116 & $15 \% \mathrm{NCSz}, 11 \% \mathrm{NCSE}$ \\
\hline Little et al. [241] & $\mathrm{R} \mathrm{CS}$ & & 389 & $\begin{array}{l}3 \% \text { (but only very } \\
\text { small number got EEG) }\end{array}$ \\
\hline \multicolumn{5}{|l|}{ ICH $18-28 \%$} \\
\hline Vespa et al. [88] & $\operatorname{Pr} \mathrm{CS}$ & & 109 & $28 \%$ NCSz (only one convulsive) \\
\hline Claassen et al. [87] & R CS & & 102 & $\begin{array}{l}18 \% \text { NCSz (only one convulsive), } \\
7 \% \text { NCSE }\end{array}$ \\
\hline \multicolumn{5}{|l|}{ PRES } \\
\hline Kozak et al. [119] & R CS & & 10 & $\begin{array}{l}\text { PRES presented in all } \\
\text { cases with SE }\end{array}$ \\
\hline \multicolumn{5}{|l|}{ CNS infection $33 \% \mathrm{NCsz}$} \\
\hline Carrera et al. [116] & R CS & $64 \%$ viral & 42 & $33 \% \mathrm{NCSz}$ \\
\hline \multicolumn{5}{|l|}{ AIS $2 \% \mathrm{NCSz}$} \\
\hline Carrera et al. [124] & P CS & AIS stroke unit & 100 & $2 \% \mathrm{NCSz}$ \\
\hline \multicolumn{5}{|l|}{ Mixed neuro ICU populations } \\
\hline Jordan et al. [242] & R CS & Mixed NICU & & NCSz $34 \%$ \\
\hline Claassen et al. [4] & R CS & ICU/ward & 570 & $11 \%$ NCSz, $20 \%$ NCSE \\
\hline Pandian et al. [3] & R CS & Mixed NICU & 105 & No denominator \\
\hline Amantini et al. [113] & P CS & TBI, ICH, SAH & 68 & $3 \% \mathrm{NCSz}$ \\
\hline Drislane et al. [243] & R CS & All NCSE & 91 & No denominator \\
\hline Mecarelli et al. [115] & P CS & ICH/SAH/AIS & 232 & $\begin{array}{r}6 \% \mathrm{NCSz}, 4 \% \mathrm{NCSE} \\
(\text { spot EEG }<24 \mathrm{~h})\end{array}$ \\
\hline
\end{tabular}

$R$ retrospective, $P$ prospective, $C S$ case series, $N C S z$ nonconvulsive seizures, $N C S E$ nonconvulsive status epilepticus, $I C H$ intracerebral hemorrhage, $S A H$ subarachnoid hemorrhage, AIS acute ischemic stroke, TBI traumatic brain injury, CNS central nervous system 
EEG findings after cardiac arrest in patients undergoing therapeutic hypothermia

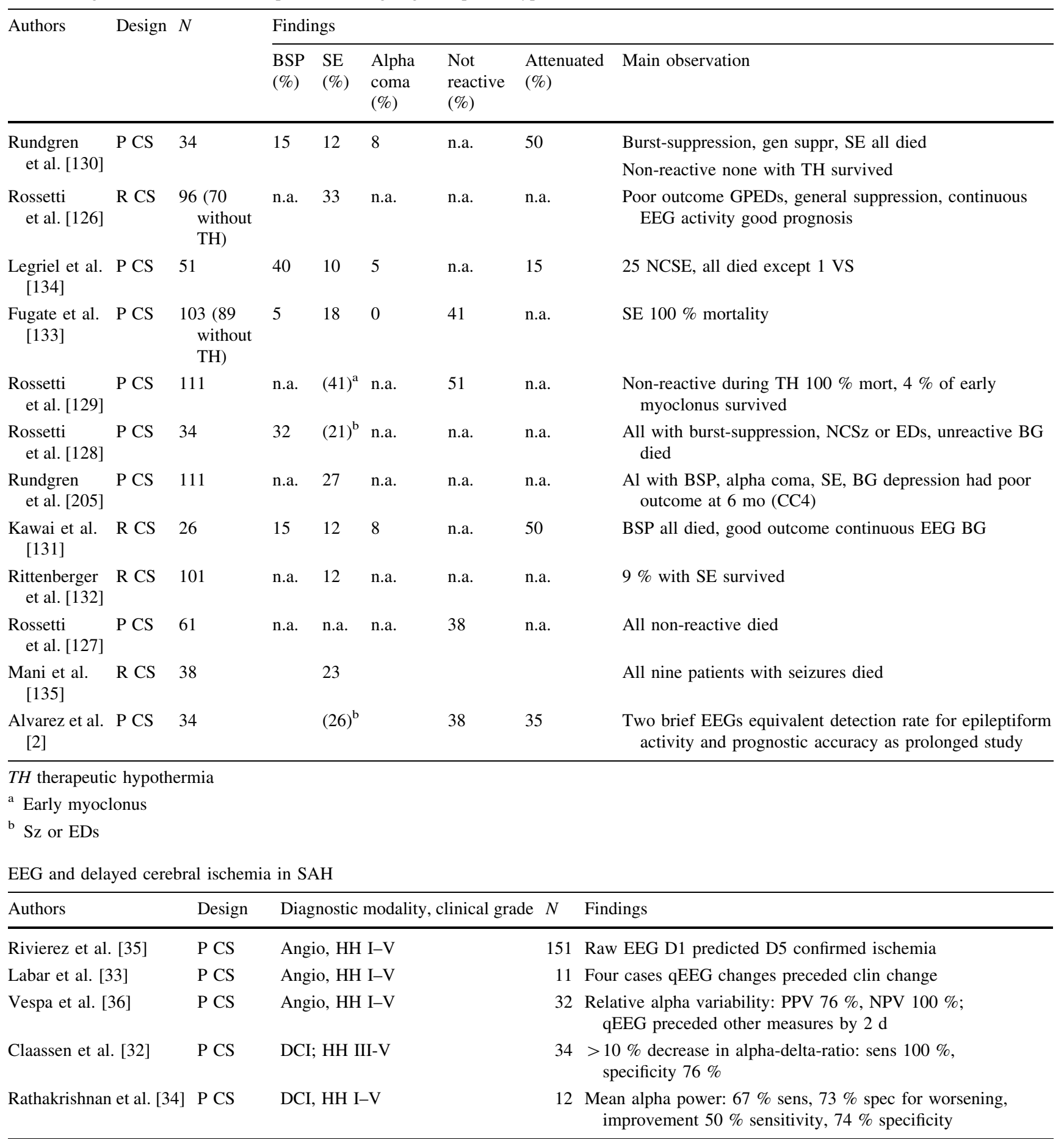

$P P V$ positive predictive value, $N P V$ negative predictive value 


\section{Cerebral Metabolism}

Evidence supporting the use of microdialysis data to determine clinical outcome

\begin{tabular}{|c|c|c|c|c|}
\hline Study & Population & $N$ & Methods & Findings \\
\hline $\begin{array}{l}\text { Timofeev } \\
\text { et al., } \\
2011\end{array}$ & TBI & 223 & $\begin{array}{l}\text { Analyte values averaged for each patient on each post } \\
\text { injury day. Outcome with } 6 \text { month GOS, GOS } 1,2-3 \text {, } \\
4-5 \text {, univariate, non parametric analysis and } \\
\text { multivariate logistic regression }\end{array}$ & $\begin{array}{l}\text { Glutamate and L/P ratio higher in patients who died or } \\
\text { had an unfavorable outcome compared to those with } \\
\text { good outcome. Glucose, pyruvate, and L/P ratio were } \\
\text { significant predictors of mortality }\end{array}$ \\
\hline $\begin{array}{l}\text { Chamoun } \\
\text { et al., } \\
2010\end{array}$ & TBI & 165 & $\begin{array}{l}\text { Microdialysis probe placed in tissue near } \mathrm{PO}_{2} \text { probe, } \\
\text { hourly dialysate samples collected. Multivariate } \\
\text { analysis with logistic regression to identify factors } \\
\text { associated with Outcome ( } 6 \text { month GOS) }\end{array}$ & $\begin{array}{l}\text { Two patterns of glutamate levels were identified. } \\
\text { (1) Levels that decreased over time } \\
\text { (2) Glutamate increased or remained abnormally } \\
\text { elevated over time } \\
\text { Mortality was associated with pattern } 2\end{array}$ \\
\hline $\begin{array}{l}\text { Stein } \\
\text { et al., } \\
2012\end{array}$ & TBI & 89 & $\begin{array}{l}\text { Multivariate model to identify factors associated with } \\
\text { GOSe at } 6 \text { months. Metabolic crisis defined as } \\
\text { Glu }<0.8 \mathrm{mmol} / \mathrm{L} \text { and LPR }>25\end{array}$ & $\begin{array}{l}\text { The length of time in metabolic crisis was significantly } \\
\text { associated with outcome. The OR for poor outcome } \\
\text { for } 12 \mathrm{~h} \text { of metabolic crisis was } 2.16 \text { (CI } 1.05-4.45 \\
p=0.036 \text { ) }\end{array}$ \\
\hline $\begin{array}{l}\text { Nagel } \\
\text { et al., } \\
2009\end{array}$ & SAH & 192 & $\begin{array}{l}\text { Multivariate analysis to identify factors associated with } \\
12 \text { month GOS in patients with low ICP after SAH } \\
\text { versus high ICP }\end{array}$ & $\begin{array}{l}\text { Elevated Glutamate and L/P ratio were associated with } \\
\text { worse } 12 \text { month GOS and were more common in the } \\
\text { high ICP group. The majority of patients with } \\
\text { elevated ICP displayed abnormal microdialysis } \\
\text { pattern before the rise in ICP }\end{array}$ \\
\hline $\begin{array}{l}\text { Oddo } \\
\text { et al., } \\
2012\end{array}$ & SAH & 31 & $\begin{array}{l}\text { Episodes of elevated brain lactate were divided into two } \\
\text { groups. Those with a low brain tissue oxygen } \\
\text { (hypoxic) and normal tissue oxygen } \\
\text { (hyperglycolytic). Outcome using dichotomized mRS }\end{array}$ & $\begin{array}{l}\text { Episodes of hypoxic elevations in brain lactate were } \\
\text { associated with mortality while episodes of } \\
\text { hyperglycolytic lactate were strong predictors of good } \\
\text { outcome }\end{array}$ \\
\hline $\begin{array}{l}\text { Nikaina } \\
\text { et al., } \\
2012\end{array}$ & $\mathrm{ICH}$ & 27 & $\begin{array}{l}\text { Linear regression model to evaluate the relationship } \\
\text { between } \mathrm{CPP}+\mathrm{L} / \mathrm{P} \text { ratio and } 6 \text { month outcome } \\
\text { measured by GOS }\end{array}$ & $\begin{array}{l}\text { The combination of CPP }>75 \text { and } \mathrm{L} / \mathrm{P}<36 \text { was } \\
\text { associated with a favorable } 6 \text { month GOS } p=.054\end{array}$ \\
\hline
\end{tabular}

Can clinical therapy change brain metabolism?

\begin{tabular}{|c|c|c|c|c|}
\hline & Population & $N$ & Methods & Findings \\
\hline $\begin{array}{l}\text { Vespa et al., } \\
2006\end{array}$ & TBI & 47 & $\begin{array}{l}\text { Nonrandomized consecutive design comparing brain } \\
\text { chemistry in patients managed with "loose" versus } \\
\text { "intensive" insulin therapy }\end{array}$ & $\begin{array}{l}\text { Patients in the intensive therapy group had lower } \\
\text { brain glucose concentrations associated with an } \\
\text { increase in glutamate and L/P ratio }\end{array}$ \\
\hline $\begin{array}{l}\text { Oddo et al., } \\
2008\end{array}$ & $\begin{array}{l}\text { SAH, TBI, } \\
\text { ICH, } \\
\text { Ischemic } \\
\text { stroke }\end{array}$ & 20 & $\begin{array}{l}\text { Multivariate logistic regression used to examine } \\
\text { relationship between multiple physiologic and } \\
\text { microdialysis variables and in-hospital mortality }\end{array}$ & $\begin{array}{l}\text { Systemic glucose concentration and insulin dose were } \\
\text { independent predictors of metabolic crisis and } \\
\text { mortality }\end{array}$ \\
\hline $\begin{array}{l}\text { Helbok } \\
\text { et al., } \\
2010\end{array}$ & SAH & 28 & $\begin{array}{l}\text { Multivariate logistic regression to examine } \\
\text { relationship between serum glucose and } \\
\text { microdialysis patterns }\end{array}$ & $\begin{array}{l}\text { Reductions in serum glucose by } 25 \% \text { were associated } \\
\text { with episodes of elevated L/P ratio and decreased } \\
\text { glucose }\end{array}$ \\
\hline $\begin{array}{l}\text { Vespa et al., } \\
2012\end{array}$ & TBI & 13 & $\begin{array}{l}\text { Prospective within subject crossover trial of "tight" } \\
\text { versus "loose" glycemic control and measured } \\
\text { glucose metabolism using FDG PET }\end{array}$ & $\begin{array}{l}\text { "Tight" glycemic control was associated with } \\
\text { elevated L/P ratio and decreased brain glucose as } \\
\text { well as an increase in brain global glucose uptake }\end{array}$ \\
\hline $\begin{array}{l}\text { Tolias et al., } \\
2004\end{array}$ & TBI & 52 & $\begin{array}{l}\text { Prospective study of } 24 \mathrm{~h} \text { of normobaric hyperoxia. } \\
\text { Microdialysis compared with baseline and also with } \\
\text { age, GCS, and ICP matched controls }\end{array}$ & $\begin{array}{l}\text { Normobaric hyperoxia treatment was associated with } \\
\text { an increase in brain glucose and a decrease in } \mathrm{L} / \mathrm{P} \\
\text { ratio as well as a reduction in ICP }\end{array}$ \\
\hline $\begin{array}{l}\text { Nortje } \\
\text { et al., } \\
2008\end{array}$ & TBI & 11 & $\begin{array}{l}\text { Brain tissue oxygen, cerebral microdialysis, and 15O- } \\
\text { PET scans were performed at normoxia and } \\
\text { hyperoxia }\end{array}$ & $\begin{array}{l}\text { Normobaric oxygen was associated with an increase } \\
\text { in brain tissue oxygen; however, the association } \\
\text { with microdialysis changes and oxygen metabolism } \\
\text { on PET was variable }\end{array}$ \\
\hline
\end{tabular}




\begin{tabular}{|c|c|c|c|c|}
\hline & Population & $N$ & Methods & Findings \\
\hline $\begin{array}{l}\text { Rockswold } \\
\text { et al., } \\
2010\end{array}$ & TBI & 69 & $\begin{array}{l}\text { Patients randomized to normobaric } \mathrm{O}_{2} \text { treatment, } \\
\text { hyperbaric } \mathrm{O}_{2} \text { treatment or control. Brain oxygen, } \\
\text { microdialysis and ICP were monitored }\end{array}$ & $\begin{array}{l}\text { Both normobaric and hyperbaric hyperoxia improved } \\
\text { microdialysis parameters. Hyperbaric } \mathrm{O}_{2} \text { had a } \\
\text { more robust and long lasting effect }\end{array}$ \\
\hline $\begin{array}{l}\text { Marion } \\
\text { et al., } \\
2002\end{array}$ & TBI & 20 & $\begin{array}{l}30 \text { min of hyperventilation performed at two time } \\
\text { points ( } 24 \mathrm{~h} \text { and } 3 \text { days) after injury, microdialysis } \\
\text { and local cerebral blood flow in vulnerable tissue } \\
\text { was studied }\end{array}$ & $\begin{array}{l}\text { Brief hyperventilation was associated with increased } \\
\text { glutamate and elevated lactate and L/P ratio. This } \\
\text { relationship was more marked at the early time } \\
\text { point }\end{array}$ \\
\hline $\begin{array}{l}\text { Hutchinson } \\
\text { et al., } \\
2002\end{array}$ & TBI & 13 & $\begin{array}{l}\text { Hyperventilation with simultaneous PET scan to } \\
\text { measure oxygen extraction fraction (OEF) }\end{array}$ & $\begin{array}{l}\text { Hyperventilation was associated with a reduction in } \\
\text { microdialysis glucose and an elevated OEF }\end{array}$ \\
\hline $\begin{array}{l}\text { Sakowitz } \\
\text { et al., } \\
2007\end{array}$ & TBI & 6 & $\begin{array}{l}\text { ICP, brain oxygen, and microdialysis parameters were } \\
\text { recorded before and after therapeutic doses of } \\
\text { mannitol }\end{array}$ & $\begin{array}{l}\text { Microdialysis concentrations rose up to } 40 \% \text { over the } \\
\text { first hour after mannitol in a nonspecific pattern }\end{array}$ \\
\hline $\begin{array}{l}\text { Helbok } \\
\text { et al., } \\
2011\end{array}$ & $\mathrm{SAH}$ ICH & 12 & $\begin{array}{l}\text { ICP, brain oxygen and microdialysis parameters were } \\
\text { measured before and after therapeutic mannitol } \\
\text { doses }\end{array}$ & $\begin{array}{l}\text { Mannitol therapy was associated with a decrease in } \\
\text { ICP as well as an } 18 \% \text { decrease in L/P ratio } \\
\text { without a change in brain glucose }\end{array}$ \\
\hline $\begin{array}{l}\text { Ho et al., } \\
2008\end{array}$ & TBI & 16 & $\begin{array}{l}\text { ICP, brain oxygen, autoregulation, and microdialysis } \\
\text { parameters were measured before and after } \\
\text { decompressive craniectomy for refractory } \\
\text { intracranial hypertension. Outcome was measured } \\
\text { with } 6 \text { month GOS }\end{array}$ & $\begin{array}{l}\text { There was a decrease in microdialysis lactate, } \mathrm{L} / \mathrm{P} \\
\text { ratio and glycerol in patient treated with } \\
\text { decompressive craniectomy in those who had a } \\
\text { favorable outcome }\end{array}$ \\
\hline $\begin{array}{l}\text { Nagel et al., } \\
2009\end{array}$ & SAH & 7 & $\begin{array}{l}\text { Data from a database was retrospectively studied to } \\
\text { determine the effect of decompressive craniectomy } \\
\text { on cerebral metabolism. } 12 \text { month GOS assessed } \\
\text { for outcome }\end{array}$ & $\begin{array}{l}\text { In patients treated with decompressive craniectomy } \\
\text { glucose and glycerol were lower after the } \\
\text { procedure. However, L/P ratio and glutamate did } \\
\text { not change }\end{array}$ \\
\hline $\begin{array}{l}\text { Soukup } \\
\text { et al., } \\
2002\end{array}$ & TBI & 58 & $\begin{array}{l}\text { ICP, brain oxygen, and microdialysis parameters were } \\
\text { measured before and after mild therapeutic } \\
\text { hypothermia was used to treat refractory ICP }\end{array}$ & $\begin{array}{l}\text { Therapeutic hypothermia was associated with lower } \\
\text { microdialysis glucose and lactate consistent with } \\
\text { decreased metabolic demand }\end{array}$ \\
\hline $\begin{array}{l}\text { Berger } \\
\text { et al., } \\
2002\end{array}$ & CVA & 12 & $\begin{array}{l}\text { ICP and microdialysis parameters measured before } \\
\text { and during therapeutic hypothermia used as rescue } \\
\text { therapy for large MCA infarcts }\end{array}$ & $\begin{array}{l}\text { Glutamate, lactate and pyruvate were all affected by } \\
\text { therapeutic hypothermia. However, the degree of } \\
\text { change varied depending on the probe position }\end{array}$ \\
\hline
\end{tabular}

\section{Cellular Damage and Degeneration}

Biomarkers for outcome following cardiac arrest without therapeutic hypothermia treatment

\begin{tabular}{|c|c|c|c|c|c|}
\hline Authors/year & Population & $N$ & $\begin{array}{l}\text { Bio- } \\
\text { marker }\end{array}$ & $\begin{array}{l}\text { Sample } \\
\text { source }\end{array}$ & Findings \\
\hline \multicolumn{6}{|c|}{ Molecules of CNS Origin } \\
\hline \multirow[t]{3}{*}{$\begin{array}{l}\text { Zandbergen, } \\
2006\end{array}$} & \multirow[t]{3}{*}{$\begin{array}{l}\text { Post cardiac arrest, unconscious }>24 \mathrm{~h} \\
\text { after CPR }\end{array}$} & \multirow[t]{3}{*}{407} & \multirow[t]{3}{*}{$\begin{array}{l}\text { NSE, } \\
\quad \text { s100 } \beta\end{array}$} & \multirow[t]{3}{*}{ Serum } & $\begin{array}{c}100 \% \text { of patients with NSE }>33 \mu \mathrm{g} / \mathrm{L} \text { at any time } \\
\text { had a poor outcome }(40 \% \mathrm{PPV} ; 0 \% \mathrm{FPR})\end{array}$ \\
\hline & & & & & $\begin{array}{c}\mathrm{s} 100 \beta>0.7 \mu \mathrm{g} / \mathrm{L} \text { at } 24-72 \mathrm{~h} \text { post cardiac arrest } \\
\text { predicts poor outcome }(47 \% \mathrm{PPV} ; 2 \% \mathrm{FPR})\end{array}$ \\
\hline & & & & & $\begin{array}{l}\text { Performance of clinical tests was inferior to SSEP } \\
\text { and NSE in predicting outcome }\end{array}$ \\
\hline \multirow[t]{2}{*}{ Meynaar, 2003} & \multirow[t]{2}{*}{ Post cardiac arrest, comatose post CPR } & \multirow[t]{2}{*}{110} & \multirow[t]{2}{*}{ NSE } & \multirow[t]{2}{*}{ Serum } & $\begin{array}{l}\text { NSE at } 24 \text { and } 48 \mathrm{~h} \text { after CPR was significantly } \\
\text { higher in patients who did not regain } \\
\text { consciousness versus those who did }\end{array}$ \\
\hline & & & & & $\begin{array}{l}\text { No one with NSE }>25 \mu \mathrm{g} / \mathrm{L} \text { at any time regained } \\
\text { consciousness (100\% specificity) }\end{array}$ \\
\hline
\end{tabular}




\begin{tabular}{|c|c|c|c|c|c|}
\hline Authors/year & Population & $N$ & $\begin{array}{l}\text { Bio- } \\
\text { marker }\end{array}$ & $\begin{array}{l}\text { Sample } \\
\text { source }\end{array}$ & Findings \\
\hline Pfeifer, 2005 & $\begin{array}{l}\text { Post cardiac arrest within } 12 \mathrm{~h} \text { of ROSC, } \\
\text { survived }>48 \mathrm{~h}\end{array}$ & 97 & $\begin{array}{l}\text { NSE, } \\
\quad \text { s100 } \beta\end{array}$ & Serum & $\begin{array}{l}\mathrm{NSE}>65 \mu \mathrm{g} / \mathrm{L} \text { predicted increased risk of death } \\
\text { and persistent vegetative state at } 28 \text { days post } \\
\text { CPR }(97 \% \mathrm{PPV}) \\
\text { s100 } \beta>1.5 \mu \mathrm{g} / \mathrm{L} \text { predicts poor outcome }(96 \% \\
\mathrm{PPV})\end{array}$ \\
\hline Rosen, 2001 & Out of hospital cardiac arrest & 66 & $\begin{array}{l}\text { s100 } \beta \\
\text { NSE }\end{array}$ & Serum & $\begin{array}{l}\mathrm{s} 100 \beta>0.217 \mu \mathrm{g} / \mathrm{L} \text { and } \mathrm{NSE}>23.2 \mu \mathrm{g} / \mathrm{L} \text { at } \\
2 \text { days post cardiac arrest predicted poor } 1 \text {-year } \\
\text { outcome }(100 \% \mathrm{PPV})\end{array}$ \\
\hline Bottiger, 2001 & $\begin{array}{l}\text { Non-traumatic out of hospital cardiac } \\
\text { arrest }\end{array}$ & 66 & $\mathrm{~s} 100 \beta$ & Serum & $\begin{array}{l}\text { Significant differences in } \mathrm{s} 100 \beta \text { level between } \\
\text { survivors and non-survivors after cardiac arrest } \\
\text { were observed from } 30 \text { min to } 7 \text { days post cardiac } \\
\text { arrest } \\
\mathrm{s} 100 \beta>1.10 \mu \mathrm{g} / \mathrm{L} \text { at } 48 \mathrm{~h} \text { post cardiac arrest } \\
\text { predicted brain damage ( } 100 \% \text { specificity) }\end{array}$ \\
\hline Martens, 1998 & $\begin{array}{l}\text { Post cardiac arrest, unconscious and } \\
\text { ventilated for }>24 \mathrm{~h}\end{array}$ & 64 & $\begin{array}{l}\text { NSE, } \\
\quad \text { s100 } \beta\end{array}$ & Serum & $\begin{array}{l}\text { s100 } \beta \text { and NSE were significantly higher in patients } \\
\text { who did not regain consciousness compared of } \\
\text { those who did } \\
\text { s100 } \beta>0.7 \mu \mathrm{g} / \mathrm{L} \text { is a predictor of not regaining } \\
\text { consciousness after cardiac arrest ( } 95 \% \mathrm{PPV} ; \\
96 \% \text { specificity) } \\
\text { NSE }>20 \mu \mathrm{g} / \mathrm{L} \text { predicted poor outcome ( } 51 \% \\
\text { sensitivity; } 89 \% \text { specificity) }\end{array}$ \\
\hline $\begin{array}{l}\text { Hachimi- } \\
\text { Idrissi, } 2002\end{array}$ & Post cardiac arrest & 58 & $\mathrm{~s} 100 \beta$ & Serum & $\begin{array}{l}\text { s100 } \beta>0.7 \mu \mathrm{g} / \mathrm{L} \text { at admission predicted not } \\
\text { regaining consciousness ( } 85 \% \text { specificity; } \\
66.6 \% \text { sensitivity; } 84 \% \mathrm{PPV} ; 78 \% \mathrm{NPV} \\
77.6 \% \text { accuracy) }\end{array}$ \\
\hline $\begin{array}{l}\text { Schoerkhuber, } \\
1999\end{array}$ & $\begin{array}{l}\text { Non-traumatic out of hospital cardiac } \\
\text { arrest }\end{array}$ & 56 & NSE & Serum & $\begin{array}{l}\text { NSE was significantly higher in patients who had } \\
\text { poor } 6 \text { month outcome at } 12,24,48 \text {, and } 72 \mathrm{~h} \\
\text { after ROSC } \\
\text { NSE cutoffs for poor outcome were: } \\
\mathrm{NSE}>38.5 \mu \mathrm{g} / \mathrm{L} \text { at } 12 \mathrm{~h}, \mathrm{NSE}>40 \mu \mathrm{g} / \mathrm{L} \text { at } \\
24 \mathrm{~h}, \mathrm{NSE}>25.1 \mu \mathrm{g} / \mathrm{L} \text { at } 48 \mathrm{~h} \text {, and } \\
\mathrm{NSE}>16.4 \mu \mathrm{g} / \mathrm{L} \text { at } 72 \mathrm{~h}(100 \% \text { specificity }) \\
\mathrm{NSE}>27.3 \mu \mathrm{g} / \mathrm{L} \text { at any time predicted poor } \\
\text { outcome }(100 \% \text { specificity) }\end{array}$ \\
\hline Molecules of nor & -CNS origin & & & & \\
\hline Nagao, 2004 & $\begin{array}{l}\text { Age }>17 \text { years, out of hospital cardiac } \\
\text { arrest of presumed cardiac origin }\end{array}$ & 401 & BNP & Blood & $\begin{array}{l}\text { Rate of survival to hospital discharge decreased in } \\
\text { dose-dependent fashion with increasing quartiles } \\
\text { of BNP on admission } \\
\text { BNP }>100 \mathrm{pg} / \mathrm{mL} \text { predicted lack of survival until } \\
\text { hospital discharge ( } 83 \% \text { sensitivity; } 96 \% \mathrm{NPV} \text { ) }\end{array}$ \\
\hline Kasai, 2011 & Post cardiac arrest & 357 & Ammonia & Blood & $\begin{array}{l}\text { Elevated ammonia on ER arrival is associated with } \\
\text { decreased odds for good outcome at hospital } \\
\text { discharge (OR } 0.98[0.96-0.99]) \\
\text { Ammonia }>192.5 \mu \mathrm{g} / \mathrm{dL} \text { had } 100 \% \mathrm{NPV} \text { for good } \\
\text { outcome at discharge } \\
61 \text { patients were treated with } \mathrm{TH}\end{array}$ \\
\hline
\end{tabular}




\begin{tabular}{ll}
\hline Authors/year & Population \\
\hline Sodeck, 2007 & Post cardiac arrest, comatose \\
Shinozaki, 2011 & $\begin{array}{r}\text { Non-traumatic out of hospital } \\
\text { cardiac arrest with ROSC }\end{array}$
\end{tabular}

CSF biomarkers

Roine, 1989 Out of hospital VF arrest who survived $>24 \mathrm{~h}$
98 Ammonia, Blood lactate
155 BNP
67 NSE, $\mathrm{CSF}$

52 CKBB CSF

34 NSE, $\mathrm{s} 100 \beta$

CSF
Sample Findings

source

Blood

Highest quartile BNP on admission is associated with poor outcome as compared to lowest quartile

BNP $>230 \mathrm{pg} / \mathrm{mL}$ predicts unfavorable neurological outcome (OR 2.25 [1.05-4.81]) and death at 6 months (OR 4.7 [1.27-17.35])

Elevated ammonia and lactate on admission were associated with poor outcome

Ammonia $>170 \mu \mathrm{g} / \mathrm{dL}$ predicted poor outcome (90\% sensitivity; $58 \%$ specificity)

Lactate $>12 \mathrm{mmol} / \mathrm{L}$ predicted poor outcome (90\% sensitivity; $52 \%$ specificity)

NSE and CKBB at 20-26 h post CPR were elevated in patients who did not regain consciousness compared with those who did

All patients with NSE $>24 \mu \mathrm{g} / \mathrm{L}$ remained unconscious or died at 3 months (74\% sensitivity; $100 \%$ specificity)

CKBB $>17 \mu \mathrm{g} / \mathrm{L}$ predicted poor outcome $(52 \%$ sensitivity; $98 \%$ specificity)

Sherman, 2000 Comatose cardiac arrest patients with SSEP studies

CSF

CKBB > 205U/L predicted non-awakening (49\% sensitivity; $100 \%$ specificity)

CSF sampling time not standardized

Martens, 1998 Post cardiac arrest, unconscious, and ventilated for $>48 \mathrm{~h}$

s100 $\beta$ and NSE were both significantly higher in patients who did not regain consciousness compared of those who did

NSE $>50 \mu \mathrm{g} / \mathrm{L}$ (89\% sensitivity; $83 \%$ specificity) and $\mathrm{s} 100 \beta>6 \mu \mathrm{g} / \mathrm{L}(93 \%$ sensitivity; $60 \%$ specificity) predicted death or vegetative state

CSF sampling time is not standardized

Rosen, 2004 Post cardiac arrest, survive $>12$ days post ROSC

22 NFL CSF

CSF sampled at 12-30 days after cardiac arrest

$\mathrm{NFL}>18,668 \mu \mathrm{g} / \mathrm{L}$ predicted dependency in ADL at 1 year (100\% specificity; $46 \%$ sensitivity)
Karkela, 1993 VF or asystolic arrest

20 CKBB, CSF NSE

14 HMGB1, CSF s100ß presumed cardiac

$351 \mathrm{CKBB}$

CSF

Case controlledCSF collected at 4, 28, and $76 \mathrm{~h}$ after resuscitation

Elevated CKBB at 4 and $28 \mathrm{~h}$, and elevated NSE at 28 and $76 \mathrm{~h}$ after cardiac arrest were associated with not regaining consciousness

CSF sampled at $48 \mathrm{~h}$ after ROSC

HMGB1 and $\mathrm{s} 100 \beta$ were significantly higher in poor outcome group compared to good outcome group and to normal controls

Tirschwell, Post cardiac arrest with CSF $1997 \quad$ CKBB measured
Retrospective study

CSF sampling time not standardized

CKBB > 205U/L predicted non-awakening at hospital discharge (100\% specificity; $48 \%$ sensitivity)

Only nine patients with CKBB > 50U/L awakened and none regained independent ADLs

All studies are prospective observational unless otherwise noted

$N P V$ negative predictive value, $P P V$ positive predictive value, $F P R$ false positive rate, $O R$ odds ratio, $R O S C$ return of spontaneous circulation, SSEP somatosensory evoked potential, $T H$ therapeutic hypothermia, $V F$ ventricular fibrillation 
Biomarkers for outcome following cardiac arrest with therapeutic hypothermia treatment

\begin{tabular}{|c|c|c|c|c|c|c|}
\hline $\begin{array}{l}\text { Authors/ } \\
\text { year }\end{array}$ & $\begin{array}{l}\text { Study } \\
\text { design }\end{array}$ & Population & $N$ & Bio-marker & $\begin{array}{l}\text { Sample } \\
\text { source }\end{array}$ & Findings \\
\hline $\begin{array}{l}\text { Tiainen, } \\
2003\end{array}$ & $\mathrm{RCT}$ & $\begin{array}{l}\text { Witnessed VF or VT } \\
\text { arrest, } \leq 60 \text { min between } \\
\text { collapse to ROSC }\end{array}$ & 70 & NSE, s100 $\beta$ & Serum & $\begin{array}{l}\text { NSE levels were lower in TH compared to } \\
\text { normothermia } \\
\text { NSE did not reach } 100 \% \text { specificity in } \mathrm{TH} \text {, whereas } \\
\text { it does in normothermia } \\
\mathrm{TH} \text { : NSE }>31.2 \mu \mathrm{g} / \mathrm{L} \text { at } 24 \mathrm{~h},>26 \mu \mathrm{g} / \mathrm{L} \text { at } 36 \mathrm{~h} \text {, } \\
\text { and }>25 \mu \mathrm{g} / \mathrm{L} \text { at } 48 \mathrm{~h} \text { predicted poor outcome } \\
\text { ( } 96 \% \text { specificity) } \\
\text { Normothermia: NSE }>13.3 \mu \mathrm{g} / \mathrm{L} \text { at } \\
24 \mathrm{~h},>12.6 \mu \mathrm{g} / \mathrm{L} \text { at } 36 \mathrm{~h} \text {, and }>8.8 \mu \mathrm{g} / \mathrm{L} \text { at } \\
48 \mathrm{~h} \mathrm{had} 100 \% \text { specificity for poor outcome } \\
\mathrm{TH}: \mathrm{s} 100 \beta>0.21 \mu \mathrm{g} / \mathrm{L} \text { at } 24 \mathrm{~h}(100 \% \text { specificity), } \\
\text { s100 }>0.21 \mu \mathrm{g} / \mathrm{L} \text { at } 36 \mathrm{~h} \text { and } \\
\text { s100 }>0.23 \mu \mathrm{g} / \mathrm{L} \text { at } 48 \mathrm{~h}(96 \% \\
\text { specificity) predicted poor outcome }\end{array}$ \\
\hline $\begin{array}{l}\text { Cronberg, } \\
2011\end{array}$ & Pro & $\begin{array}{l}\text { Post cardiac arrest with } \\
\text { GCS }<8 \text { after ROSC }\end{array}$ & 111 & NSE & Serum & $\begin{array}{l}\text { Elevated NSE was associated with worse outcome, } \\
\text { DWI changes on MRI, and worse neuropathology } \\
\text { All patients with NSE }>33 \mu \mathrm{g} / \mathrm{L} \text { at } 48 \mathrm{~h} \text { died } \\
\text { without regaining consciousness } \\
\text { NSE }>27 \mu \mathrm{g} / \mathrm{L} \text { predicted poor outcome at } \\
6 \text { months ( } 100 \% \text { specificity) }\end{array}$ \\
\hline $\begin{array}{l}\text { Rundgren, } \\
2009\end{array}$ & Pro & $\begin{array}{l}\text { In or out-of-hospital cardiac } \\
\text { arrest, GCS } \leq 7\end{array}$ & 107 & NSE, $s 100 \beta$ & Serum & $\begin{array}{l}\text { NSE }>28 \mu \mathrm{g} / \mathrm{L} \text { at } 48 \mathrm{~h} \text { predicted poor } 6 \text {-month } \\
\text { outcome }(100 \% \text { specificity; } 67 \% \text { sensitivity }) \\
\text { s100 }>0.51 \mu \mathrm{g} / \mathrm{L} \text { at } 24 \mathrm{~h} \text { predicted poor } 6 \text {-month } \\
\text { outcome }(96 \% \text { specificity; } 62 \% \text { sensitivity) }\end{array}$ \\
\hline $\begin{array}{c}\text { Daubin, } \\
2011\end{array}$ & Pro & $\begin{array}{l}\text { In or out-of-hospital cardiac } \\
\text { arrest, comatose }>48 \mathrm{~h}\end{array}$ & 97 & NSE & Serum & $\begin{array}{l}\text { Elevated NSE correlated with worse outcome at } \\
3 \text { months } \\
\text { NSE }>47 \mu \mathrm{g} / \mathrm{L} \text { predicted poor } 3 \text {-month outcome } \\
(84 \% \text { specificity; } 72 \% \text { sensitivity) } \\
\text { NSE }>97 \mu \mathrm{g} / \mathrm{L} \text { predicted poor outcome (100\% } \\
\text { PPV) }\end{array}$ \\
\hline $\begin{array}{l}\text { Shinozaki, } \\
2009\end{array}$ & Pro & $\begin{array}{l}\text { In- or out-of-hospital non- } \\
\text { traumatic cardiac arrest with } \\
\text { ROSC }>20 \text { min, with } \\
\text { GCS } \leq 8\end{array}$ & 80 & NSE, $s 100 \beta$ & Serum & $\begin{array}{l}\text { s100 } \beta \text { and NSE are both elevated in poor outcome } \\
\text { group. s100 } \beta \text { had better predictive performance } \\
\text { than NSE } \\
\text { s100 } \beta \text { cutoff for poor outcome are: } \\
\text { s100 } \beta>1.41 \mu \mathrm{g} / \mathrm{L} \text { at admission, } \\
\mathrm{s} 100 \beta>0.21 \mu \mathrm{g} / \mathrm{L} \text { at } 6 \mathrm{~h} \text {, and } \\
\mathrm{s} 100 \beta>0.05 \mu \mathrm{g} / \mathrm{L} \text { at } 24 \mathrm{~h} \text { post cardiac arrest } \\
(100 \% \text { specificity) }\end{array}$ \\
\hline $\begin{array}{l}\text { Stammet, } \\
2013\end{array}$ & Pro & Post cardiac arrest & 75 & NSE, $s 100 \beta$ & Serum & $\begin{array}{l}\text { Elevated s100 } \beta \text { and NSE levels are associated with } \\
\text { poor outcome at } 6 \text { months } \\
\text { Adding s } 100 \beta \text { to Bispectral index improved } \\
\text { predictive value for poor outcome }\end{array}$ \\
\hline $\begin{array}{r}\text { Rosetti, } \\
2012\end{array}$ & Pro & Post cardiac arrest, comatose & 61 & NSE & Serum & $\begin{array}{l}\text { Five cardiac arrest survivors, including three with } \\
\text { good outcome, had NSE }>33 \mu \mathrm{g} / \mathrm{L}\end{array}$ \\
\hline $\begin{array}{l}\text { Mortberg, } \\
2011\end{array}$ & Pro & $\begin{array}{l}\text { Post cardiac arrest, } \\
\text { SBP }>80 \mathrm{mmHg} \\
x>5 \mathrm{~min}, \\
\text { GCS } \leq 7,<6 \mathrm{~h} \\
\text { following ROSC }\end{array}$ & 31 & $\begin{array}{l}\text { NSE, s100 } \beta \text {, } \\
\text { BDNF, GFAP }\end{array}$ & Serum & $\begin{array}{l}\text { No association between BDNF and GFAP levels and } \\
\text { outcome } \\
\mathrm{NSE}>4.97 \mu \mathrm{g} / \mathrm{L} \text { at } 48 \mathrm{~h} \text { and NSE }>3.22 \mu \mathrm{g} / \mathrm{L} \text { at } \\
96 \mathrm{~h} \text { post cardiac arrest predicted poor outcome at } \\
6 \text { months }(93 \% \text { specificity) } \\
\mathrm{s} 100 \beta>1.0 \mu \mathrm{g} / \mathrm{L} \text { at } 2 \mathrm{~h}(93 \% \text { specificity), and } \\
\mathrm{s} 100 \beta>0.18 \mu \mathrm{g} / \mathrm{L} \text { at } 24 \mathrm{~h}(100 \% \text { specificity) } \\
\text { post cardiac arrest predicted poor outcome }\end{array}$ \\
\hline
\end{tabular}

$P P V$ positive predictive value, Pro prospective observational, $R C T$ randomized controlled trial, $R O S C$ return of spontaneous circulation, $T H$ therapeutic hypothermia, $V F$ ventricular fibrillation, $V T$ ventricular tachycardia 
Biomarkers for subarachnoid hemorrhage

\begin{tabular}{|c|c|c|c|c|c|c|}
\hline Author/year & $\begin{array}{l}\text { Study } \\
\text { design }\end{array}$ & Population & $N$ & Bio-marker & $\begin{array}{l}\text { Sample } \\
\text { source }\end{array}$ & Findings \\
\hline \multicolumn{7}{|c|}{ Markers of CNS origin } \\
\hline $\begin{array}{l}\text { Weisman, } \\
1997\end{array}$ & Pro & $\begin{array}{l}\text { Aneurysmal SAH within } \\
3 \text { days of ictus }\end{array}$ & 70 & $s 100 \beta$ & Serum & $\begin{array}{l}\text { s100 } \beta \text { is higher at } 24 \mathrm{~h}, 3 \text { and } 7 \text { days post SAH } \\
\text { compared to controls } \\
\text { Higher s } 100 \beta \text { levels correlate with worse HH } \\
\text { grade } \\
\text { Higher s100 } \beta \text { in the first week after SAH } \\
\text { correlate with worse } 6 \text { month outcome }\end{array}$ \\
\hline $\begin{array}{l}\text { Stranjalis, } \\
2007\end{array}$ & Pro & $\begin{array}{l}\text { Spontaneous SAH within } \\
48 \mathrm{~h} \text { of ictus }\end{array}$ & 52 & $\mathrm{~s} 100 \beta$ & Serum & $\begin{array}{l}\text { Admission } \mathrm{s} 100 \beta>0.3 \mu \mathrm{g} / \mathrm{L} \text { predicted } \\
\text { unfavorable outcome and is independent } \\
\text { predictor of short-term survival (HR } 2.2) \\
(77.8 \% \text { sensitivity; } 76 \% \text { specificity) } \\
\text { s100 } \beta \text { correlates positively with } \mathrm{HH} \text { and Fisher } \\
\text { scores } \\
\text { s100 } \beta \text { decreased after EVD insertion }\end{array}$ \\
\hline Oertel, 2006 & Pro & Aneurysmal SAH & 51 & $\begin{array}{l}\text { s100ß, } \\
\text { NSE }\end{array}$ & Serum & $\begin{array}{l}\text { s100 } \beta \text { during first } 3 \text { days of SAH is higher in } \\
\text { those who died compared to survivors } \\
\text { All patients with } \mathrm{s} 100 \beta>1.0 \mu \mathrm{g} / \mathrm{L} \text { had } \\
\text { unfavorable outcome } \\
\text { NSE had no association with outcome } \\
\text { s100 } \beta \text { is lower in patients with vasospasm (by } \\
\text { transcranial doppler) }\end{array}$ \\
\hline Coplin, 1999 & Pro & Aneurysmal SAH & 27 & CKBB & CSF & $\begin{array}{l}\mathrm{CKBB}>40 \mu / \mathrm{L} \text { is associated with poor } \\
\text { outcome at hospital discharge (100\% } \\
\text { specificity) }\end{array}$ \\
\hline \multicolumn{7}{|c|}{ Inflammatory markers } \\
\hline Pan, 2013 & Pro & Aneurysmal SAH & $\begin{array}{l}262 \\
\text { SAH, } \\
150 \\
\text { CTRL }\end{array}$ & pGSN & Blood & $\begin{array}{l}\text { pGSN were lower in SAH compared with } \\
\text { controls } \\
\text { pGSN was an independent predictor of poor } \\
\text { functional outcome (OR 0.957) and death (OR } \\
0.953 \text { ) at } 6 \text { months } \\
\text { Adding pGSN improved predictive performance } \\
\text { of WFNS and Fisher scores for functional } \\
\text { outcome but not for mortality }\end{array}$ \\
\hline Frijins, 2006 & Pro & $\begin{array}{l}\text { SAH within } 72 \mathrm{~h} \text { of } \\
\text { ictus, exclude } \\
\text { perimesencephalic } \\
\text { SAH }\end{array}$ & 106 & vWF & Serum & $\begin{array}{l}\text { vWf }>94.5 \mathrm{nmol} / \mathrm{L} \text { was independently } \\
\text { associated with increased odds for poor } \\
\text { outcome at } 3 \text { months }(\text { OR } 1.1-9.8) \\
\text { sICAM-1, sP-selectin, sE-selectin, vWf } \\
\text { propeptide, and ED 1-fibronectin were not } \\
\text { independently associated with outcome }\end{array}$ \\
\hline Mack, 2002 & Pro & $\begin{array}{l}\text { SAH, excluding those } \\
\text { with pro-inflammatory } \\
\text { disease process }\end{array}$ & 80 & sICAM-1 & Serum & $\begin{array}{l}\text { sICAM-1 was elevated in SAH }(293.3 \pm 15 \mu \mathrm{g} / \\
\text { L) compared with controlssICAM-1 on post- } \\
\text { SAH days } 810 \text {, and } 12 \text { were significantly } \\
\text { elevated in those with unfavorable mRS at } \\
\text { discharge }\end{array}$ \\
\hline $\begin{array}{l}\text { Beeftink, } \\
2011\end{array}$ & Pro & Aneurysmal SAH & 67 & $\begin{array}{l}\text { TNF } \alpha \text {, } \\
\text { Leukocytes, } \\
\text { CRP }\end{array}$ & Serum & $\begin{array}{l}\text { Neither TNF } \alpha \text { nor TNF } \alpha \text { genotype were } \\
\text { associated with DCI or with SAH outcome at } \\
3 \text { months } \\
\text { High leukocyte count and high CRP are not } \\
\text { associated with DCI or SAH outcome }\end{array}$ \\
\hline Chou, 2011 & Pro & $\begin{array}{l}\text { Spontaneous SAH, } \\
\text { within } 96 \mathrm{~h} \text { of ictus }\end{array}$ & 55 & MMP9 & CSF & $\begin{array}{l}\text { Elevation of MMP9 on post SAH day } 2-3 \text { is } \\
\text { associated with poor outcome (mRS } 3-6 \text { ) at } \\
3 \text { months }\end{array}$ \\
\hline
\end{tabular}




\begin{tabular}{|c|c|c|c|c|c|c|}
\hline Author/year & $\begin{array}{l}\text { Study } \\
\text { design }\end{array}$ & Population & $N$ & Bio-marker & $\begin{array}{l}\text { Sample } \\
\text { source }\end{array}$ & Findings \\
\hline Chou, 2011 & Pro & $\begin{array}{l}\text { Spontaneous SAH, within } \\
96 \mathrm{~h} \text { of ictus }\end{array}$ & 55 & $\begin{array}{l}\text { Neutrophil, } \\
\text { WBC }\end{array}$ & Blood & $\begin{array}{l}\text { Elevated neutrophil count on post SAH day } 3 \text { is } \\
\text { associated with poor } 3 \text {-month outcome } \\
\text { Elevated WBC count throughout post SAH days } \\
0-14 \text { is associated with angiographic } \\
\text { vasospasm }\end{array}$ \\
\hline Chou, 2012 & Pro & $\begin{array}{l}\text { Spontaneous SAH, } \\
\text { within } 96 \mathrm{~h} \text { of ictus }\end{array}$ & 52 & TNF $\alpha$, IL-6 & Serum & $\begin{array}{l}\text { Elevated TNF } \alpha \text { over post-SAH days } 0-14 \text { is } \\
\text { independently associated with poor long term } \\
\text { outcome } \\
\text { IL- } 6 \text { is not associated with SAH outcome } \\
\text { Neither TNF } \alpha \text { nor IL- } 6 \text { was associated with } \\
\text { angiographic vasospasm }\end{array}$ \\
\hline Chou, 2011 & Pro & $\begin{array}{l}\text { Spontaneous SAH, } \\
\text { within } 96 \mathrm{~h} \text { of ictus }\end{array}$ & 42 & pGSN & $\begin{array}{l}\text { CSF, } \\
\text { Serum }\end{array}$ & $\begin{array}{l}\text { Serum pGSN is decreased in SAH compared to } \\
\text { controls, and decreases over time in SAH } \\
\text { CSF pGSN is decreased in SAH compared to } \\
\text { controls } \\
\text { Novel pGSN fragments found in SAH CSF but } \\
\text { not in controls }\end{array}$ \\
\hline $\begin{array}{l}\text { Fassbender, } \\
2001\end{array}$ & Pro & $\begin{array}{l}\text { Aneurysmal SAH } \\
\text { within } 48 \mathrm{~h} \text { of ictus }\end{array}$ & 35 & $\begin{array}{l}\text { IL-1 } \beta, \text { IL-6, } \\
\text { TNF } \alpha\end{array}$ & $\begin{array}{l}\text { CSF, } \\
\text { Serum }\end{array}$ & $\begin{array}{l}\text { IL- } 1 \beta \text { and IL- } 6 \text { are significantly higher in CSF } \\
\text { than in serum in SAH } \\
\text { CSF IL- } 6 \text { on post-SAH day } 5 \text { is significantly } \\
\text { elevated in poor outcome group } \\
\text { CSF TNF } \alpha \text { did not show significant association } \\
\text { with outcome }\end{array}$ \\
\hline $\begin{array}{l}\text { Mathiesen, } \\
1997\end{array}$ & Pro & SAH patients with EVD & 22 & $\begin{array}{l}\text { IL-1R } \alpha \\
\text { TNF } \alpha\end{array}$ & CSF & $\begin{array}{l}\text { IL-1R } \alpha \text { were higher in poor grade SAH } \\
\quad(\mathrm{HH} 3-4 ; 318 \text { vs. } 82 \mathrm{pg} / \mathrm{mL}) \\
\text { Elevated IL-1Ra and TNF } \alpha \text { on post SAH days } 4- \\
10 \text { were associated with poor outcome }\end{array}$ \\
\hline Weir, 1989 & Retro & $\begin{array}{l}\text { Aneurysmal SAH with } \\
\text { vital signs and CBC } \\
\text { data }(76 \% \text { missing } \\
\text { data) }\end{array}$ & 173 & WBC & Blood & $\begin{array}{l}\text { Admission } \mathrm{WBC}>15 \times 10^{9} / \mathrm{L} \text { shows } 55 \% \\
\text { mortality versus } 25 \% \text { mortality in the lower } \\
\text { WBC group }\end{array}$ \\
\hline $\begin{array}{l}\text { Kiikawa, } \\
1997\end{array}$ & Retro & $\begin{array}{l}\text { Fisher grade } 3 \mathrm{SAH} \\
\text { treated with } \\
\text { aneurysm } \\
\text { clipping within } \\
24 \mathrm{~h} \text { of ictus }\end{array}$ & 103 & WBC & Blood & $\begin{array}{l}\text { WBC counts during days } 3-5,6-8,9-11 \text {, } \\
\text { and } 12-14 \text { after onset of SAH were } \\
\text { significantly higher in patients with than in } \\
\text { patients without symptomatic vasospasm }\end{array}$ \\
\hline \multicolumn{7}{|l|}{ Other biomarkers } \\
\hline $\begin{array}{l}\text { Niskakangas, } \\
2001\end{array}$ & $\begin{array}{l}\text { Case } \\
\quad \text { control }\end{array}$ & Aneurysmal SAH & 108 & ApoE4 & Blood & $\begin{array}{l}\text { Presence of ApoE4 was associated with } \\
\text { unfavorable outcome (OR } 2.8[1.18-6.77])\end{array}$ \\
\hline Juvela, 2009 & $\begin{array}{l}\text { Case } \\
\quad \text { control }\end{array}$ & SAH within $48 \mathrm{~h}$ of ictus & 105 & $\begin{array}{l}\varepsilon 2, \varepsilon 4- \\
\text { containing } \\
\text { genotypes }\end{array}$ & Blood & $\begin{array}{l}\text { Apolipoprotein E } \varepsilon 2 \text { or } \varepsilon 4 \text {-containing genotypes } \\
\text { were not associated with outcome or } \\
\text { occurrence of cerebral infarction }\end{array}$ \\
\hline Laterna, 2005 & $\begin{array}{l}\text { Case } \\
\quad \text { control }\end{array}$ & SAH HH grade $1-3$ & 101 & $\begin{array}{l}\text { ApoE4 } \\
\text { genotype }\end{array}$ & Blood & $\begin{array}{l}\text { Presence of Apo E4 genotype is associated with } \\
\text { negative overall outcome } \\
\text { Apo E4 genotype is associated with development } \\
\text { of DIND }\end{array}$ \\
\hline Leung, 2002 & $\begin{array}{l}\text { Case } \\
\quad \text { control }\end{array}$ & Spontaneous SAH & 72 & $\begin{array}{l}\text { ApoE4 } \\
\text { genotype }\end{array}$ & Blood & $\begin{array}{l}\text { ApoE4 genotype is associated with poor } 6 \text { month } \\
\text { outcome (OR } 11.3[2.2-57.0])\end{array}$ \\
\hline Kay, 2003 & $\begin{array}{l}\text { Case } \\
\quad \text { Control }\end{array}$ & $\begin{array}{l}\text { Spontaneous } \\
\text { SAH } \\
\text { requiring EVD }\end{array}$ & 19 & s100 $\beta$, ApoE & CSF & $\begin{array}{l}\text { s100ß is significantly higher in SAH compared to } \\
\text { controls } \\
\text { ApoE is significantly lower in SAH compared to } \\
\text { controls } \\
\text { Lower ApoE was associated with better clinical } \\
\text { outcome }\end{array}$ \\
\hline
\end{tabular}




\begin{tabular}{|c|c|c|c|c|c|c|}
\hline Author/year & $\begin{array}{l}\text { Study } \\
\text { design }\end{array}$ & Population & $N$ & Bio-marker & $\begin{array}{l}\text { Sample } \\
\text { source }\end{array}$ & Findings \\
\hline Laterna, 2007 & $\begin{array}{l}\text { Meta- } \\
\text { analysis }\end{array}$ & $\begin{array}{l}\text { Consecutive } \\
\text { SAH, with } 3 \text { month } \\
\text { follow up data }\end{array}$ & 696 & $\begin{array}{l}\text { ApoE4 } \\
\text { genotype }\end{array}$ & Blood & $\begin{array}{l}\text { Apo E4 genotype is associated with negative } \\
\text { outcome (OR 2.558 [1.610-4.065]) and } \\
\text { delayed ischemia (OR 2.044 [1.269-3.291]) }\end{array}$ \\
\hline $\begin{array}{l}\text { Moussoutas, } \\
2012\end{array}$ & Pro & $\begin{array}{l}\text { SAH with EVD, HH } \\
\text { grade } 3-5, \\
\text { endovascular aneurysm } \\
\text { treatment }\end{array}$ & 102 & Epinephrine & CSF & $\begin{array}{l}\text { Elevated CSF epinephrine within } 48 \mathrm{~h} \text { of } \\
\text { admission is independently associated with } \\
\text { mortality at } 15 \text { days (OR } 1.06[1.01-1.10]) \\
\text { and with death and disability at } 30 \text { days (OR } \\
1.05[1.02-1.09])\end{array}$ \\
\hline $\begin{array}{l}\text { Yarlagadda, } \\
2006\end{array}$ & Pro & $\begin{array}{l}\text { Spontaneous } \\
\text { SAH, }>21 \text { years }\end{array}$ & 300 & BNP, cTI & Serum & $\begin{array}{l}\text { Initial BNP }>600 \mathrm{pg} / \mathrm{mL} \text { is associated with } \\
\text { death }(\mathrm{OR} 37.7[5.0-286.2]) \\
\text { cTI }>0.3 \mathrm{mg} / \mathrm{L} \text { (on post-SAH day } 9 \pm 4) \text { is } \\
\text { associated with death (OR } 4.9[2.1-26.8]) \\
\text { No standardized time of biosample collection }\end{array}$ \\
\hline $\begin{array}{l}\text { Naidech, } \\
2005\end{array}$ & Pro & $\begin{array}{l}\text { Spontaneous non- } \\
\text { traumatic SAH }\end{array}$ & 253 & cTI & Serum & $\begin{array}{l}\text { Peak cTI was independently predictive of death } \\
\text { or severe disability at hospital discharge (OR } \\
1.4[1.1-1.9]) \\
\text { cTI not independently predictive of } 3 \text { month } \\
\text { outcome by mRS }\end{array}$ \\
\hline $\begin{array}{l}\text { Ramappa, } \\
2008\end{array}$ & Retro & $\begin{array}{l}\text { SAH diagnosed by CT } \\
\text { scan or CSF, SAH } \\
\text { ICD-9 code, with cTI } \\
\text { measured }\end{array}$ & 83 & cTI & Blood & $\begin{array}{l}\text { Peak cTI and GCS on presentation independently } \\
\text { predicted in-hospital mortality }\end{array}$ \\
\hline
\end{tabular}

Pro prospective observational, Retro retrospective, CTRL control subjects, $C B C$ complete blood count, $H H$ grade Hunt and Hess grade, WFNS World Federation of Neurosurgeons classification, DIND delayed ischemic neurological deficit, $D C I$ delayed cerebral ischemia, $m R S$ modified Rankins score, $O R$ odds ratio

Biomarkers for acute ischemic stroke

\begin{tabular}{|c|c|c|c|c|c|c|}
\hline Authors/year & $\begin{array}{l}\text { Study } \\
\text { design }\end{array}$ & Population & $N$ & $\begin{array}{l}\text { Bio- } \\
\text { marker }\end{array}$ & $\begin{array}{l}\text { Sample } \\
\text { source }\end{array}$ & Findings \\
\hline \multicolumn{7}{|c|}{ Markers of CNS origin } \\
\hline $\begin{array}{l}\text { Kazmierski, } \\
2012\end{array}$ & Pro & AIS & 458 & $\begin{array}{l}\text { s100 } \beta \\
\text { OCLN, } \\
\text { CLDN5, } \\
\text { ZO1 }\end{array}$ & Serum & $\begin{array}{l}\text { Patients with clinical deterioration due to } \\
\text { hemorrhagic transformation had higher } \\
\text { s100 } \beta \text {, OCLN, and CLDN/ZO1 ratio }\end{array}$ \\
\hline Foerch, 2004 & Pro & $\begin{array}{l}\text { AIS within } 6 \mathrm{~h} \text { of onset with } \\
\text { proximal MCA occlusion }\end{array}$ & 51 & $\mathrm{~s} 100 \beta$ & Serum & $\begin{array}{l}\text { Mean } \mathrm{s} 100 \beta \text { were higher in patients with } \\
\text { malignant cerebral edema defined } \\
\mathrm{s} 100 \beta>1.03 \mu \mathrm{g} / \mathrm{L} \text { at } 24 \mathrm{~h} \text { post AIS predicted } \\
\text { malignant infarction ( } 94 \% \text { sensitivity; } 83 \% \\
\text { specificity) }\end{array}$ \\
\hline Missler, 1997 & Pro & AIS diagnosed by CT & 44 & $\begin{array}{l}\text { s100 } \beta \\
\text { NSE }\end{array}$ & Serum & $\begin{array}{l}\text { s100 } \beta \text { correlated with infarct volume and with } \\
6 \text { month outcome } \\
\text { NSE correlated with infarct volume but not } \\
\text { with clinical outcome } \\
\text { Did not adjust for stroke subtype or tPA } \\
\text { treatment }\end{array}$ \\
\hline
\end{tabular}




\begin{tabular}{|c|c|c|c|c|c|c|}
\hline Authors/year & $\begin{array}{l}\text { Study } \\
\text { design }\end{array}$ & Population & $N$ & $\begin{array}{l}\text { Bio- } \\
\text { marker }\end{array}$ & $\begin{array}{l}\text { Sample } \\
\text { source }\end{array}$ & Findings \\
\hline Foerch, 2005 & Pro & AIS within $6 \mathrm{~h}$ of onset & 39 & s100ß & Serum & $\begin{array}{l}\text { s100 } \beta \text { at } 48-72 \mathrm{~h} \text { post AIS correlated with } \\
6 \text { month outcome and with infarct volume } \\
\text { s100 } \leq \leq 0.37 \mu \mathrm{g} / \mathrm{L} \text { at } 48 \mathrm{~h} \text { post stroke } \\
\text { predicted functional independence at } \\
6 \text { months ( } 87 \% \text { sensitivity; } 78 \% \\
\text { specificity) }\end{array}$ \\
\hline $\begin{array}{l}\text { Hermann, } \\
2000\end{array}$ & Pro & Anterior circulation AIS & 32 & $\begin{array}{l}\text { s100ß, } \\
\text { GFAP }\end{array}$ & Serum & $\begin{array}{l}\text { s100 } \beta \text { and GFAP correlated with total infarct } \\
\text { volume and neurologic status at hospital } \\
\text { discharge } \\
\text { Did not adjust for stroke subtype or tPA } \\
\text { treatment }\end{array}$ \\
\hline Foerch, 2003 & Pro & $\begin{array}{l}\text { AIS } \leq 5 \mathrm{~h} \text { of onset with M1 } \\
\text { occlusion }\end{array}$ & 23 & s100 $\beta$ & Serum & $\begin{array}{l}\mathrm{s} 100 \beta<0.4 \mu \mathrm{g} / \mathrm{L} \text { at } 48-96 \mathrm{~h} \text { post-AIS } \\
\text { predicted MCA recanalization within } 6 \mathrm{~h} \\
(86 \% \text { sensitivity } ; 100 \% \text { specificity })\end{array}$ \\
\hline \multicolumn{7}{|c|}{ Biomarkers of inflammation and blood brain barrier } \\
\hline $\begin{array}{l}\text { Den Hergot, } \\
2009\end{array}$ & $\mathrm{RCT}$ & $\begin{array}{c}\text { AIS } \leq 12 \text { h onset, no liver } \\
\text { disease, prior } \mathrm{mRS}<2\end{array}$ & 561 & CRP & Serum & $\begin{array}{l}\text { From RCT for paracetamol for ischemic stroke } \\
\text { CRP measured within } 12 \mathrm{~h} \text { of stroke onset } \\
\text { CRP }>7 \mathrm{mg} / \mathrm{L} \text { is associated with poor } \\
\text { outcome }(\mathrm{OR} 1.6[1.1-2.4]) \text { and death (OR } \\
\quad 1.7[1.0-2.9])\end{array}$ \\
\hline Idicula, 2009 & $\begin{array}{c}\text { Nested } \\
\text { Pro }\end{array}$ & AIS $\leq 24$ h onset & 498 & CRP & Serum & $\begin{array}{l}\mathrm{CRP}>10 \mathrm{mg} / \mathrm{L} \text { is independently associated } \\
\text { with high NIHSS and high long term } \\
\text { mortality at } 2.5 \text { years }\end{array}$ \\
\hline $\begin{array}{l}\text { Montaner, } \\
2006\end{array}$ & Pro & $\begin{array}{l}\text { AIS in MCA territory treated } \\
\text { with IV tPA within } 3 \mathrm{~h} \text {; } \\
\text { exclude inflammatory disease } \\
\text { or infection }\end{array}$ & 143 & CRP & Serum & $\begin{array}{l}\text { CRP measured before tPA administration } \\
\text { CRP was higher in those who died after } \\
\text { thrombolysis compared with survivors }(0.85 \\
\text { vs. } 0.53 \mathrm{mg} / \mathrm{dL}) \\
\text { CRP is independently associated with mortality } \\
\text { at } 3 \text { months (OR } 8.51[2.16-33.5])\end{array}$ \\
\hline $\begin{array}{l}\text { Winbeck, } \\
2002\end{array}$ & Pro & $\begin{array}{l}\text { AIS } \leq 12 \mathrm{~h} \text { onset, NOT treated } \\
\text { with IV tPA }\end{array}$ & 127 & CRP & Serum & $\begin{array}{l}\mathrm{CRP}>0.86 \mathrm{mg} / \mathrm{dL} 24 \mathrm{~h} \text { and at } 48 \mathrm{~h} \text { post- } \\
\text { stroke are associated with death and lower } \\
\text { likelihood of event-free survival at } 1 \text { year }\end{array}$ \\
\hline $\begin{array}{l}\text { Topakian, } \\
2008\end{array}$ & Pro & $\begin{array}{l}\text { AIS in MCA territory treated } \\
\text { with } \mathrm{IV} \mathrm{tPA} \leq 6 \mathrm{~h} \text { of onset, } \\
\text { exclude } \mathrm{CRP}>6 \mathrm{mg} / \mathrm{dL}\end{array}$ & 111 & CRP & Serum & $\begin{array}{l}\text { CRP measured before tPA administration } \\
\text { CRP level was not associated with NIHSS } \\
\text { within } 24 \mathrm{~h} \text { or outcome at } 3 \text { months }\end{array}$ \\
\hline $\begin{array}{l}\text { Shantikumar, } \\
2009\end{array}$ & Pro & AIS surviving $>30$ days & 394 & CRP & Serum & $\begin{array}{l}\text { CRP higher in subject who died compared to } \\
\text { survivors } \\
\text { CRP is independently predictive of mortality } \\
\text { after adjusting for conventional risk factors }\end{array}$ \\
\hline Elkind, 2006 & Retro & $\begin{array}{l}\text { Age }>40, \text { reside in northern } \\
\text { Manhattan }>3 \text { months }\end{array}$ & 467 & hs-CRP & Serum & $\begin{array}{l}\text { Highest quartile of hs-CRP is associated with } \\
\text { increased risk of stroke recurrence } \\
(\mathrm{HR}=2.08[1.04-4.18]) \text { and with combined } \\
\text { outcome of stroke, MI, or vascular death } \\
(\mathrm{HR}=1.86[1.01-3.42])\end{array}$ \\
\hline Huang, 2012 & Retro & $\begin{array}{l}\text { Age }>40, \text { reside in northern } \\
\text { Manhattan }>3 \text { months }\end{array}$ & 741 & hs-CRP & Serum & $\begin{array}{l}\text { hs-CRP }>3 \mathrm{mg} / \mathrm{L} \text { was associated with higher } \\
\text { mortality at } 3 \text { months and all-cause } \\
\text { mortality }(\mathrm{HR}=6.48[1.41-29.8])\end{array}$ \\
\hline $\begin{array}{l}\text { Castellanos, } \\
2003\end{array}$ & Pro & $\begin{array}{l}\text { Hemispheric AIS within } \\
7.8 \pm 4.5 \mathrm{~h} \text { of onset }\end{array}$ & 250 & MMP9 & Plasma & $\begin{array}{c}\text { MMP } 9 \geq 140 \mu \mathrm{g} / \mathrm{L} \text { predicted hemorrhagic } \\
\text { transformation }(61 \% \mathrm{PPV} ; 97 \% \mathrm{NPV})\end{array}$ \\
\hline
\end{tabular}




\begin{tabular}{|c|c|c|c|c|c|c|}
\hline Authors/year & $\begin{array}{l}\text { Study } \\
\text { design }\end{array}$ & Population & $N$ & $\begin{array}{l}\text { Bio- } \\
\text { marker }\end{array}$ & $\begin{array}{l}\text { Sample } \\
\text { source }\end{array}$ & Findings \\
\hline $\begin{array}{l}\text { Castellanos, } \\
2007\end{array}$ & Pro & AIS $\leq 3 \mathrm{~h}$ treated with IV tPA & 134 & $\begin{array}{l}\text { c-Fn, } \\
\text { MMP9 }\end{array}$ & Serum & $\begin{array}{l}\text { MMP9 } \geq 140 \mu \mathrm{g} / \mathrm{L} \text { predicted hemorrhagic } \\
\text { transformation (92\% sensitivity; } 74 \% \\
\text { specificity; } 26 \% \mathrm{PPV} ; 99 \% \mathrm{NPV}) \\
\text { c-Fn } \geq 3.6 \mu \mathrm{g} / \mathrm{mL} \text { predicted hemorrhagic } \\
\text { transformation (100\% sensitivity; } 60 \% \\
\text { specificity; } 20 \% \mathrm{PPV} ; 100 \% \mathrm{NPV})\end{array}$ \\
\hline Moldes, 2008 & Pro & AIS treated with IV tPA & 134 & $\begin{array}{l}\text { ET-1, } \\
\text { MMP9, } \\
\text { c-Fn }\end{array}$ & Serum & $\begin{array}{l}\text { ET-1, MMP9, and c-Fn measured upon } \\
\text { admission before tPA bolus. } \\
\text { ET-1 and c-Fn significantly higher in those } \\
\text { with severe cerebral edema } \\
\text { ET-1 > } 5.5 \mathrm{fmol} / \mathrm{mL} \text { before tPA was } \\
\text { independently associated with severe brain } \\
\text { edema in multivariate analysis }\end{array}$ \\
\hline Serena, 2005 & $\begin{array}{l}\text { Case } \\
\quad \text { control }\end{array}$ & $\begin{array}{l}\text { Malignant } \\
\text { MCA } \\
\text { infarction, } \\
<70 \text { years }\end{array}$ & $\begin{array}{l}40 \text { AIS, } \\
35 \\
\text { CTRL }\end{array}$ & $\begin{array}{l}\text { c-Fn, } \\
\text { MMP9 }\end{array}$ & Plasma & $\begin{array}{l}\text { c-Fn and MMP-9 were significantly higher in } \\
\text { patients with malignant MCA infarcts } \\
\text { c-Fn }>16.6 \mu \mathrm{g} / \mathrm{mL} \text { predicted malignant } \\
\text { infarction }(90 \% \text { sensitivity; } 100 \% \\
\text { specificity; } 89 \% \mathrm{NPV} ; 100 \% \mathrm{PPV})\end{array}$ \\
\hline $\begin{array}{l}\text { Montaner, } \\
2003\end{array}$ & Pro & $\begin{array}{l}\text { AIS in MCA territory treated } \\
\text { with IV tPA within } 3 \mathrm{~h}\end{array}$ & 41 & MMP9 & Plasma & $\begin{array}{l}\text { Higher baseline (pre-tPA) MMP9 was } \\
\text { associated with hemorrhagic transformation } \\
\text { in dose-dependent fashion } \\
\text { MMP9 was predictive of hemorrhagic } \\
\text { transformation in multivariate model (OR } \\
9.62 \text { ) }\end{array}$ \\
\hline $\begin{array}{l}\text { Montaner, } \\
2001\end{array}$ & Pro & $\begin{array}{l}\text { Cardioembolic AIS in MCA } \\
\text { territory }\end{array}$ & 39 & MMP9 & Plasma & $\begin{array}{l}\text { Elevated baseline MMP9 was associated with } \\
\text { late hemorrhagic transformation in } \\
\text { multivariate regression (OR 9) }\end{array}$ \\
\hline $\begin{array}{l}\text { Castellanos, } \\
2004\end{array}$ & Pro & $\begin{array}{l}\text { AIS treated with IV tPA by } \\
\text { ECASS II criteria }\end{array}$ & 87 & c-Fn & Plasma & $\begin{array}{l}\text { c-Fn was independently associated with } \\
\text { hemorrhagic transformation in multivariate } \\
\text { analysis (OR 2.1). } \\
71 \text { of the patients were treated within } 3 \mathrm{~h} \text { of } \\
\text { AIS onset. Similar results were found in } \\
\text { these patients }\end{array}$ \\
\hline Guo, 2011 & Pro & First onset AIS & $\begin{array}{l}172 \\
\text { AIS } \\
50 \\
\text { CTRL }\end{array}$ & pGSN & Plasma & $\begin{array}{l}\text { Samples from first } 24 \mathrm{~h} \text { of stroke onset } \\
\text { obtained. } \\
\text { pGSN decreased in AIS compared to controls } \\
\text { pGSN was independent predictor for 1-year } \\
\text { mortality } \\
\text { pGSN > }>52 \mathrm{mg} / \mathrm{L} \text { predicted 1-year mortality } \\
\text { ( } 73 \% \text { sensitivity; } 65.2 \% \text { specificity) }\end{array}$ \\
\hline Yin, 2013 & Pro & AIS & $\begin{array}{l}186 \\
\text { AIS } \\
100 \\
\text { CTRL }\end{array}$ & Visfatin & Plasma & $\begin{array}{l}\text { Visfatin was higher in AIS than in controls } \\
\text { Visfatin was independent predictor of 6-month } \\
\text { clinical outcome } \\
\text { Adding visfatin did not improve predictive } \\
\text { performance of NIHSS }\end{array}$ \\
\hline \multicolumn{7}{|c|}{ Other biomarkers } \\
\hline $\begin{array}{l}\text { Haapaniem, } \\
2000\end{array}$ & $\begin{array}{l}\text { Case } \\
\quad \text { control }\end{array}$ & AIS & $\begin{array}{l}101 \\
\text { AIS, } \\
101 \\
\text { CTRL }\end{array}$ & ET-1 & Plasma & $\begin{array}{l}\text { No difference in ET-1 levels between stroke } \\
\text { and controls }\end{array}$ \\
\hline
\end{tabular}




\begin{tabular}{|c|c|c|c|c|c|c|}
\hline Authors/year & $\begin{array}{l}\text { Study } \\
\text { design }\end{array}$ & Population & $N$ & $\begin{array}{l}\text { Bio- } \\
\text { marker }\end{array}$ & $\begin{array}{l}\text { Sample } \\
\text { source }\end{array}$ & Findings \\
\hline Lampl, 1997 & Pro & AIS within $18 \mathrm{~h}$ from onset & 26 & ET-1 & $\begin{array}{l}\text { CSF, } \\
\text { Plasma }\end{array}$ & $\begin{array}{l}\text { CSF ET-1 correlated with volume of the lesion } \\
\text { and higher in cortical infarcts compared to } \\
\text { subcortical infarcts. } \\
\text { Plasma ET-1 was not elevated }\end{array}$ \\
\hline $\begin{array}{l}\text { Chiquete, } \\
2012\end{array}$ & Pro & AIS & 463 & UA & Serum & $\begin{array}{l}\mathrm{UA} \leq 4.5 \mathrm{mg} / \mathrm{dL} \text { at hospital } \\
\text { admission was associated } \\
\text { with very good } 30 \text { day outcome } \\
\text { (OR } 1.76 \text { [1.05-2.95]; } 81.1 \% \\
\mathrm{NPV} \text { ) }\end{array}$ \\
\hline $\begin{array}{l}\text { Matsumoto, } \\
2012\end{array}$ & Retro & $\begin{array}{l}\text { AIS from non-valvular } \\
\text { AF within } 48 \mathrm{~h} \text { of onset }\end{array}$ & 124 & d-dimer & Plasma & $\begin{array}{l}\text { d-dimer level at hospital } \\
\text { admission is independently } \\
\text { associated } \\
\text { with infarct volume } \\
\text { Highest d-dimer tertile group } \\
\text { had worse outcome compared } \\
\text { to middle and lowest } \\
\text { tertiles }\end{array}$ \\
\hline
\end{tabular}

$A F$ atrial fibrillation, $N P V$ negative predictive value, $P P V$ positive predictive value, Pro prospective observational, $R C T$ randomized controlled trial, Retro retrospective, CTRL control subjects, NIHSS NIH stroke scale, OR odds ratio

Biomarkers for intracerebral hemorrhage

\begin{tabular}{|c|c|c|c|c|c|c|}
\hline Authors/Year & $\begin{array}{l}\text { Study } \\
\text { design }\end{array}$ & Population & $N$ & Bio-marker & $\begin{array}{l}\text { Sample } \\
\text { source }\end{array}$ & Findings \\
\hline \multicolumn{7}{|c|}{ Markers of CNS origin } \\
\hline $\mathrm{Hu}, 2012$ & Pro & $\begin{array}{l}\text { Basal ganglia ICH } \\
\text { within } 6 \mathrm{~h} \text { of onset }\end{array}$ & 176 & Tau & Serum & $\begin{array}{l}\text { tau }>91.4 \mathrm{pg} / \mathrm{mL} \text { predicted poor } 3 \text {-month } \\
\text { outcome }(83.6 \% \text { sensitivity; } 75.8 \% \\
\text { specificity) } \\
\text { Addition of tau improved prognostic value of } \\
\text { NIHSS for outcome but not for mortality }\end{array}$ \\
\hline $\mathrm{Hu}, 2010$ & Pro & Basal ganglia ICH & $\begin{array}{c}86 \text { ICH, } 30 \\
\text { CTRL }\end{array}$ & $\mathrm{s} 100 \beta$ & Plasma & $\begin{array}{l}\text { s100 } \beta \text { was significantly associated with IVH, } \\
\text { GCS scores, and ICH volumes } \\
\text { s100 } \beta \text { is independently associated with mortality } \\
\text { at } 1 \text { week (OR } 1.046) \\
\text { s100 } \beta>192.5 \mathrm{pg} / \mathrm{mL} \text { predicted } 1 \text {-week } \\
\text { mortality }(93.8 \% \text { sensitivity; } 70.4 \% \\
\text { specificity) }\end{array}$ \\
\hline Delgado, 2006 & Pro & $\mathrm{ICH}$ & 78 & $\mathrm{~s} 100 \beta$ & Blood & $\begin{array}{l}\text { s100 } \beta \text { was higher in patients who deteriorated } \\
\text { early and in patients with a poor neurological } \\
\text { outcome }\end{array}$ \\
\hline Brea, 2009 & Pro & ICH and AIS & $\begin{array}{l}44 \mathrm{ICH}, 224 \\
\text { AIS }\end{array}$ & NSE & Blood & $\begin{array}{l}\text { NSE elevation at } 24 \mathrm{~h} \text { post ICH was } \\
\text { independently associated with poor outcome } \\
\text { (OR 2.6 [1.9-15.6]) }\end{array}$ \\
\hline James, 2009 & Pro & $\mathrm{ICH}$ & 28 & $\mathrm{~s} 100 \beta, \mathrm{BNP}$ & Blood & $\begin{array}{l}\text { s100 } \beta \text { and BNP levels correlated with outcome } \\
\text { at hospital discharge } \\
\text { Inclusion of biomarkers added little to the } \\
\text { predictive power of ICH score }\end{array}$ \\
\hline Cai, 2013 & $\begin{array}{l}\text { Case } \\
\text { control }\end{array}$ & $\begin{array}{l}\text { Basal ganglia } \\
\text { ICH }\end{array}$ & $\begin{array}{l}112 \mathrm{ICH}, \\
112 \mathrm{CTRL}\end{array}$ & pNF-H & Plasma & $\begin{array}{l}\text { pNF-H is higher in ICH compared to controls } \\
\text { pNF-H is an independent predictor of } 6 \text { month } \\
\text { mortality (OR 1.287), 6-month unfavorable } \\
\text { outcome (OR 1.265), and early neurological } \\
\text { deterioration (OR 1.246) } \\
\text { Addition of pNF-H did not improve predictive } \\
\text { value of NIHSS }\end{array}$ \\
\hline
\end{tabular}




\begin{tabular}{|c|c|c|c|c|c|c|}
\hline Authors/Year & $\begin{array}{l}\text { Study } \\
\text { design }\end{array}$ & Population & $N$ & Bio-marker & $\begin{array}{l}\text { Sample } \\
\text { source }\end{array}$ & Findings \\
\hline \multicolumn{7}{|c|}{ Biomarkers of inflammation } \\
\hline Leira, 2004 & Pro & $\begin{array}{l}\text { ICH within } 12 \mathrm{~h} \text { of } \\
\text { onset }\end{array}$ & 266 & $\begin{array}{l}\text { Neutrophils, } \\
\text { fibrinogen }\end{array}$ & Blood & $\begin{array}{l}\text { Higher neutrophil count (OR 2.1) and } \\
\text { fibrinogen }>523 \mathrm{mg} / \mathrm{dL} \text { (OR 5.6) on } \\
\text { admission were independently associated with } \\
\text { early neurological deterioration }\end{array}$ \\
\hline $\begin{array}{l}\text { Di Napolii, } \\
2011\end{array}$ & Pro & $\mathrm{ICH}$ & 210 & $\begin{array}{l}\text { WBC, CRP, } \\
\text { glucose }\end{array}$ & Blood & $\begin{array}{l}\text { Higher WBC, CRP, and glucose were } \\
\text { significantly related to mortality } \\
\text { Only CRP remained significantly related to } \\
\text { mortality when adjusted for ICH score and the } \\
\text { combination of ICH score and CRP had the } \\
\text { best predictive ability }\end{array}$ \\
\hline $\begin{array}{l}\text { Agnihotri, } \\
2011\end{array}$ & Retro & Spontaneous ICH & 423 & WBC & Blood & $\begin{array}{l}\text { Change in WBC (difference between max WBC } \\
\text { in first } 72 \mathrm{~h} \text { and WBC on admission) } \\
\text { correlated with worse discharge disposition } \\
\text { and decline in modified Barthel index at } \\
3 \text { months }\end{array}$ \\
\hline Zhao, 2013 & Pro & $\begin{array}{l}\text { Basal ganglia ICH } \\
\text { within } 6 \mathrm{~h} \text { of onset }\end{array}$ & $\begin{array}{l}132 \mathrm{ICH}, 68 \\
\text { CTRL }\end{array}$ & pGSN & Plasma & $\begin{array}{l}\text { pGSN was lower in ICH compared to controls } \\
\text { pGSN is an independent predictor of 6-month } \\
\text { mortality and unfavorable outcome in } \\
\text { multivariate analysis } \\
\text { pGSN improved prognostic value of NIHSS for } \\
\text { poor outcome but not for mortality }\end{array}$ \\
\hline Castillo, 2002 & Pro & $\begin{array}{l}\text { ICH within } 24 \mathrm{~h} \text { of } \\
\text { onset }\end{array}$ & 124 & $\begin{array}{l}\text { Glutamate, } \\
\text { TNF } \alpha\end{array}$ & Blood & $\begin{array}{l}\text { Glutamate level was an independent predictor of } \\
\text { poor outcome } \\
\text { TNF } \alpha \text { correlated with volume of peri-hematoma } \\
\text { edema }\end{array}$ \\
\hline Wang, 2011 & $\begin{array}{l}\text { Pro- } \\
\text { posthoc } \\
\text { analysis }\end{array}$ & $\begin{array}{l}\text { ICH within } 24 \mathrm{~h} \text { of } \\
\text { onset }\end{array}$ & 60 & $\begin{array}{l}\text { sICAM-1, } \\
\text { sE- } \\
\text { selectin }\end{array}$ & Plasma & $\begin{array}{l}\text { Higher levels of sICAM-1 and sE-selectin were } \\
\text { found in patients who had a poor outcome at } \\
\text { hospital discharge }\end{array}$ \\
\hline $\mathrm{Li}, 2013$ & Pro & $\begin{array}{l}\text { ICH within } 24 \mathrm{~h} \text { of } \\
\text { onset }\end{array}$ & 59 & $\begin{array}{l}\text { MMP3, } \\
\text { MMP9 }\end{array}$ & Plasma & $\begin{array}{l}\text { Elevated MMP3 was independently associated } \\
\text { with peri-hematoma edema volume } \\
\text { MMP3 }>12.4 \mu \mathrm{g} / \mathrm{L} \text { and MMP9 }>192.4 \mu \mathrm{g} / \mathrm{L} \\
\text { were associated with poor outcome in } \\
\text { multivariate analysis }\end{array}$ \\
\hline $\begin{array}{l}\text { Hernandez- } \\
\text { Guillamon, } \\
2012\end{array}$ & Pro & $\begin{array}{l}\text { ICH within } 48 \mathrm{~h} \text { of } \\
\text { onset }\end{array}$ & $\begin{array}{l}66 \text { ICH, } 58 \\
\text { CTRL }\end{array}$ & $\begin{array}{l}\text { VAP-1/ } \\
\text { SSAO }\end{array}$ & Plasma & $\begin{array}{l}\text { VAP-1/SSAO activity }<2.7 \mathrm{pmol} / \mathrm{min} \mathrm{mg} \text { was } \\
\text { independent predictor of neurological } \\
\text { improvement after } 48 \mathrm{~h}(\mathrm{OR} 6.8)\end{array}$ \\
\hline Fang, 2005 & Pro & $\mathrm{ICH}$ & 43 & IL-11 & Plasma & $\begin{array}{l}\text { Samples collected in first } 4 \text { days of ICH } \\
\text { Plasma IL-11 higher in non-survivors compared } \\
\text { to survivors }\end{array}$ \\
\hline Diedler, 2009 & Retro & Supratentorial ICH & 113 & CRP & Blood & $\begin{array}{l}\mathrm{CRP} \text { is independent predictor of poor long-term } \\
\text { functional outcome }\end{array}$ \\
\hline Gu, 2013 & Pro & $\begin{array}{l}\text { Basal ganglia ICH } \\
\text { within } 6 \mathrm{~h} \text { of onset }\end{array}$ & $\begin{array}{l}85 \mathrm{ICH}, 85 \\
\text { CTRL }\end{array}$ & Visfatin & Plasma & $\begin{array}{l}\text { Visfatin was higher in ICH compared to controls } \\
\text { Visfatin level was independent predictor of } \\
\text { hematoma growth. (OR 1.154 [1.046-3.018]) } \\
\text { and of early neurological deterioration (OR } \\
1.195[1.073-3.516] \text { ) }\end{array}$ \\
\hline Huang, 2013 & $\begin{array}{l}\text { Case } \\
\text { control }\end{array}$ & Basal ganglia ICH & $\begin{array}{l}128 \mathrm{ICH}, \\
128 \mathrm{CTRL}\end{array}$ & Visfatin & Plasma & $\begin{array}{l}\text { ICH patients had higher visfatin compared to } \\
\text { controls } \\
\text { Visfatin correlated with NIHSS and is } \\
\text { independent predictor for 6-month mortality } \\
\text { and unfavorable outcome }\end{array}$ \\
\hline Zhang, 2013 & Pro & Basal ganglia ICH & $\begin{array}{l}92 \mathrm{ICH}, 50 \\
\text { CTRL }\end{array}$ & Leptin & Plasma & $\begin{array}{l}\text { Leptin higher in ICH compared to controls } \\
\text { Leptin on admission is independent predictor of } \\
\text { 6-month mortality and unfavorable outcome }\end{array}$ \\
\hline
\end{tabular}




\begin{tabular}{|c|c|c|c|c|c|c|}
\hline Authors/Year & $\begin{array}{l}\text { Study } \\
\text { design }\end{array}$ & Population & $N$ & Bio-marker & $\begin{array}{l}\text { Sample } \\
\text { source }\end{array}$ & Findings \\
\hline \multicolumn{7}{|l|}{ Other biomarkers } \\
\hline Chiu, 2012 & Pro & $\begin{array}{l}\text { ICH within } 24 \mathrm{~h} \text { of } \\
\text { onset, }>16 \text { years old }\end{array}$ & 170 & d-dimer & Serum & $\begin{array}{l}\text { d-dimer is independently associated with 30-day } \\
\text { mortality (OR 2.72) }\end{array}$ \\
\hline Delgado, 2006 & Pro & $\mathrm{ICH}$ & 98 & d-dimer & Plasma & $\begin{array}{l}\text { d-dimer levels were associated with presence of } \\
\text { IVH or SAH extension } \\
\text { d-dimer }>1,900 \mu \mathrm{g} / \mathrm{L} \text { is independently } \\
\text { associated with early neurological } \\
\text { deterioration (OR 4.5) and with mortality (OR } \\
8.75)\end{array}$ \\
\hline $\begin{array}{l}\text { Rodriguez- } \\
\text { Luna, } 2011\end{array}$ & Pro & $\begin{array}{l}\text { Supratentorial ICH } \\
\text { within } 6 \mathrm{~h} \text { of onset }\end{array}$ & 108 & LDL-C & Serum & $\begin{array}{l}\text { Lower LDL-C levels were associated with } \\
\text { hematoma growth, early neurological } \\
\text { deterioration and 3-month mortality but not } \\
\text { with NIHSS or ICH volume }\end{array}$ \\
\hline $\begin{array}{l}\text { Ramirez- } \\
\text { Moreno, } 2009\end{array}$ & Pro & $\begin{array}{l}\text { ICH within } 12 \mathrm{~h} \text { of } \\
\text { onset }\end{array}$ & 88 & LDL-C & Serum & $\begin{array}{l}\text { Lipid profile measured in first hour after } \\
\text { admission } \\
\text { Low LDL-C levels were independently } \\
\text { associated with death after ICH in multivariate } \\
\text { analysis (HR }=3.07 \text { ) } \\
\text { LDL-C correlated with NIHSS, GCS, and ICH } \\
\text { volume }\end{array}$ \\
\hline Hays, 2006 & Retro & $\mathrm{ICH}$ & 235 & cTn1 & Blood & $\begin{array}{l}\text { Elevated cTn } 1 \text { was independent predictor of in- } \\
\text { hospital mortality }\end{array}$ \\
\hline Chen, 2011 & Pro & $\mathrm{ICH}$ & $\begin{array}{l}64 \mathrm{ICH} \\
114 \\
\text { CTRL }\end{array}$ & $\begin{array}{l}\text { Oxidative } \\
\text { markers }\end{array}$ & Blood & $\begin{array}{l}\text { Blood collected within } 3 \text { days of ICH } \\
\text { Measured 8-OHdG, G6PD, GPx, MDA, vitamin } \\
\text { E, vitamin A } \\
\text { 8-OHdG elevation was independently associated } \\
\text { with } 30 \text {-day lower Barthel index but not with } \\
\text { outcome by mRS }\end{array}$ \\
\hline Wang, 2012 & Pro & $\begin{array}{l}\text { ICH within } 24 \mathrm{~h} \text { of } \\
\text { onset }\end{array}$ & $\begin{array}{l}60 \mathrm{ICH}, 60 \\
\text { CTRL }\end{array}$ & $\begin{array}{r}\text { Nuclear } \\
\text { DNA }\end{array}$ & Plasma & $\begin{array}{l}\text { Nuclear but not mitochondrial DNA correlated } \\
\text { with GCS and ICH volume on presentation } \\
\text { Nuclear DNA }>18.7 \mu \mathrm{g} / \mathrm{L} \text { on presentation was } \\
\text { associated with poor outcome at discharge } \\
\text { ( } 63.6 \% \text { sensitivity; } 71.4 \% \text { specificity) }\end{array}$ \\
\hline Huang, 2009 & Pro & Basal ganglia ICH & $\begin{array}{l}36 \text { ICH, } 10 \\
\text { CTRL }\end{array}$ & MP & $\begin{array}{l}\text { Plasma, } \\
\text { CSF }\end{array}$ & $\begin{array}{l}\text { Plasma and CSF MP levels were associated with } \\
\text { GCS score, ICH volume, IVH, and survival } \\
\text { Controls have suspected SAH }\end{array}$ \\
\hline Zheng, 2012 & $\begin{array}{l}\text { Case } \\
\quad \text { control }\end{array}$ & $\mathrm{ICH}$ & 79 & miRNAs & Blood & $\begin{array}{l}\text { Patients with hematoma expansion had different } \\
\text { expression pattern of miRNAs ( } 19 \text { with } \\
\text { increased expression, } 7 \text { with decreased } \\
\text { expression) }\end{array}$ \\
\hline Zhang, 2012 & Pro & Basal ganglia ICH & $\begin{array}{l}89 \mathrm{ICH}, 50 \\
\text { CTRL }\end{array}$ & Copeptin & Plasma & $\begin{array}{l}\text { Copeptin level is an independent predictor for 1- } \\
\text { year mortality, poor outcome, and early } \\
\text { neurological deterioration } \\
\text { Copeptin did not improve prognostic value of } \\
\text { NIHSS }\end{array}$ \\
\hline
\end{tabular}

Pro prospective observational, $R C T$ randomized controlled trial, Retro retrospective, $C T R L$ control subjects, $O R$ odds ratio 
Biomarkers for traumatic brain injury

\begin{tabular}{|c|c|c|c|c|c|c|}
\hline Authors/year & $\begin{array}{l}\text { Study } \\
\text { design }\end{array}$ & Population & $N$ & Bio-marker & $\begin{array}{l}\text { Sample } \\
\text { source }\end{array}$ & Findings \\
\hline \multicolumn{7}{|c|}{ Markers of CNS origin } \\
\hline $\begin{array}{l}\text { Okonkwo, } \\
2013\end{array}$ & Pro & $\begin{array}{l}\text { Mild, moderate, and } \\
\text { severe TBI }\end{array}$ & 215 & GFAP-BDP & Blood & $\begin{array}{l}\text { Levels of GFAP-BDP were related to number of } \\
\text { CT scan lesions and to neurological recovery } \\
\text { A level of } 0.68 \mu \mathrm{g} / \mathrm{L} \text { was associated with a } 21.61 \\
\text { OR for a positive CT and a } 2.07 \text { OR for failure } \\
\text { to return to pre-injury baseline }\end{array}$ \\
\hline Metting, 2012 & Pro & Mild TBI & 94 & s100ß. GFAP & Blood & $\begin{array}{l}\text { Levels of GFAP but not } s 100 \beta \text { were related to } \\
\text { outcome, but the PPV was not high }(<50 \%)\end{array}$ \\
\hline Vos, 2010 & Pro & $\begin{array}{l}\text { Moderate and severe } \\
\text { TBI }\end{array}$ & 79 & s100 $\beta$, GFAP & Blood & $\begin{array}{l}\text { Levels of } s 100 \beta \text { and GFAP on admission were } \\
\text { associated with poor outcome at } 6 \text { months and } \\
\text { with mortality at } 6 \text { months even after } \\
\text { adjusting for injury severity }\end{array}$ \\
\hline Vos, 2004 & Pro & Severe TBI & 85 & $\begin{array}{l}\text { s100 } \beta, \text { NSE, } \\
\text { GFAP }\end{array}$ & Blood & $\begin{array}{l}\text { s100 } \beta, \text { NSE, and GFAP were all higher in non- } \\
\text { survivors and in those with poor 6-month } \\
\text { outcome } \\
\text { s100 } \beta>1.13 \mu \mathrm{g} / \mathrm{L} \text { predicted death with } 100 \% \\
\text { discrimination }\end{array}$ \\
\hline $\begin{array}{l}\text { Wiesmann, } \\
2009\end{array}$ & Pro & $\begin{array}{l}\text { Mild, moderate, and } \\
\text { severe TBI }\end{array}$ & 60 & s100 $\beta$, GFAP & Blood & $\begin{array}{l}\text { Levels of s100 } \beta \text { and GFAP were correlated with } \\
6 \text { month GOS } \\
\text { Levels of } s 100 \beta \text { at } 24 \text { h post-injury had the } \\
\text { highest correlation }\end{array}$ \\
\hline Pelinka, 2004 & Pro & TBI within $12 \mathrm{~h}$ & 92 & $\mathrm{~s} 100 \beta$, GFAP & Blood & $\begin{array}{l}\text { GFAP and s100 } \beta \text { were higher in non-survivors } \\
\text { and predicted mortality }\end{array}$ \\
\hline Nylen, 2008 & Pro & Severe TBI & 59 & 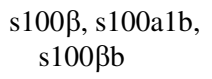 & Blood & $\begin{array}{l}\text { Levels of } s 100 \beta, \mathrm{s} 100 \mathrm{a} 1 \mathrm{~b} \text {, and } \mathrm{s} 100 \beta \mathrm{b} \text { were all } \\
\text { related to } 1 \text { year GOS }\end{array}$ \\
\hline Nylen, 2006 & Pro & Severe TBI & 59 & GFAP & Blood & $\begin{array}{l}\text { Levels of GFAP were independently associated } \\
\text { with 1-year outcome }\end{array}$ \\
\hline $\begin{array}{l}\text { Olivecrona, } \\
2009\end{array}$ & Pro & Severe TBI & 48 & s100ß, NSE & Blood & $\begin{array}{l}\text { Levels of NSE and s100 } \beta \text { were not significantly } \\
\text { related to outcome at } 3 \text { or } 12 \text { months }\end{array}$ \\
\hline $\begin{array}{l}\text { Topolovec- } \\
\text { Vranic, } 2011\end{array}$ & Pro & Mild TBI within $4 \mathrm{~h}$ & 141 & s100 $\beta$, NSE & Blood & $\begin{array}{l}\text { s100 } \beta \text { predicted poor cognitive outcome at } \\
1 \text { week } \\
\text { NSE is independently associated with poor } \\
\text { cognitive outcome at } 6 \text { weeks post-injury }\end{array}$ \\
\hline Rainey, 2009 & Pro & $\begin{array}{l}\text { Severe TBI within } \\
24 \mathrm{~h}\end{array}$ & 100 & $\mathrm{~s} 100 \beta$ & Blood & $\begin{array}{l}\mathrm{s} 100 \beta \text { at } 24 \mathrm{~h} \text { post injury were higher in patients } \\
\text { with unfavorable outcome } \\
\mathrm{s} 100 \beta>0.53 \mu \mathrm{g} / \mathrm{L} \text { predicted poor outcome } \\
\text { ( }>80 \% \text { sensitivity; } 60 \% \text { specificity) }\end{array}$ \\
\hline Thelin, 2013 & Retro & Severe TBI & 265 & $\mathrm{~s} 100 \beta$ & Blood & $\begin{array}{l}\text { Levels of s100 } \beta \text { between } 12 \text { and } 36 \text { h of injury } \\
\text { were correlated with } 6-12 \text { months GOS and } \\
\text { remained significantly related to outcome after } \\
\text { adjustment for injury severity factors }\end{array}$ \\
\hline $\begin{array}{l}\text { Rodriguez- } \\
\text { Rodriguez, } \\
2012\end{array}$ & Pro & Severe TBI & 55 & $\mathrm{~s} 100 \beta$ & $\begin{array}{l}\text { Blood } \\
\text { urine }\end{array}$ & 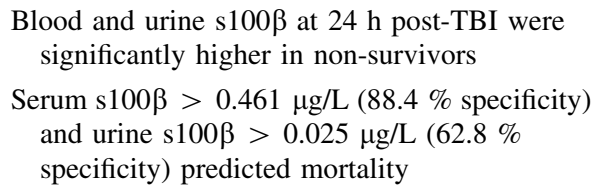 \\
\hline Kay, 2003 & $\begin{array}{l}\text { Case } \\
\quad \text { control }\end{array}$ & $\begin{array}{l}\text { TBI with } \\
\text { GCS }<8\end{array}$ & $\begin{array}{l}27 \text { TBI, } 28 \\
\text { CTRL }\end{array}$ & ApoE, s100 $\beta$ & CSF & $\begin{array}{l}\text { s100 } \beta \text { is elevated and ApoE is decreased in TBI } \\
\text { compared with controls }\end{array}$ \\
\hline Mondello, 2012 & $\begin{array}{l}\text { Case } \\
\quad \text { control }\end{array}$ & Severe TBI & 95 & UCH-L1 & $\begin{array}{l}\text { Blood, } \\
\text { CSF }\end{array}$ & $\begin{array}{l}\text { Blood and CSF levels of UCH-L1 were higher in } \\
\text { patients with lower GCS, in patients who died, } \\
\text { and in patients with unfavorable outcome. } \\
\text { Levels at } 6 \mathrm{~h} \text { had the highest correlation } \\
\text { Cumulative serum UCH-L1 }>5.22 \mu \mathrm{g} / \mathrm{L} \\
\text { predicted death with OR } 4.8\end{array}$ \\
\hline
\end{tabular}




\begin{tabular}{|c|c|c|c|c|c|c|}
\hline Authors/year & $\begin{array}{l}\text { Study } \\
\text { design }\end{array}$ & Population & $N$ & Bio-marker & $\begin{array}{l}\text { Sample } \\
\text { source }\end{array}$ & Findings \\
\hline Brophy, 2011 & Pro & $\begin{array}{l}\text { Severe TBI } \\
\text { GCS } \leq 8\end{array}$ & $\begin{array}{l}86 \text { (blood) } \\
59 \text { (CSF) }\end{array}$ & UCH-L1 & $\begin{array}{l}\text { Blood, } \\
\text { CSF }\end{array}$ & $\begin{array}{l}\text { Non-survivors had higher median serum and } \\
\text { CSF UCH-L1 levels in the first } 24 \mathrm{~h}\end{array}$ \\
\hline Papa, 2010 & Pro & $\begin{array}{l}\text { TBI GCS } \leq 8 \text { with } \\
\text { EVD }\end{array}$ & $\begin{array}{l}41 \text { TBI, } 25 \\
\text { CTRL }\end{array}$ & UCH-L1 & CSF & $\begin{array}{l}\text { UCH-L1 was higher in TBI compared with } \\
\text { controls at all time points up to } 168 \mathrm{~h} \\
\text { Levels of UCH-L1 were higher in patients with a } \\
\text { lower GCS at } 24 \mathrm{~h} \text {, post-injury complications, } \\
\text { in those died within } 6 \text { weeks, and in those with } \\
\text { poor outcome at } 6 \text { months }\end{array}$ \\
\hline Papa, 2012 & Pro & $\begin{array}{l}\text { Mild and moderate } \\
\text { TBI GCS 9-15 }\end{array}$ & $\begin{array}{l}96 \text { TBI, } 199 \\
\text { CTRL }\end{array}$ & UCH-L1 & Blood & $\begin{array}{l}\text { UCH-L1 within } 4 \mathrm{~h} \text { of injury distinguished TBI } \\
\text { from uninjured controls (AUC }=0.87[0.82- \\
0.92] \text { ) } \\
\text { UCH-L1 was associated with severity of injury } \\
\text { in TBI }\end{array}$ \\
\hline Liliang, 2010 & Pro & Severe TBI & 34 & Tau & Blood & $\begin{array}{l}\text { Tau levels were significantly higher in patients } \\
\text { with a poor outcome } \\
\text { Remained significant when adjusted for injury } \\
\text { severity factors }\end{array}$ \\
\hline Pineda, 2007 & Pro & Severe TBI & 41 & $\begin{array}{l}\text { SBDP145, } \\
\text { SBDP150 }\end{array}$ & CSF & $\begin{array}{l}\text { SBDP145 and } 150 \text { levels were significantly } \\
\text { related to outcome at } 6 \text { months }\end{array}$ \\
\hline Brophy, 2009 & $\begin{array}{l}\text { Case } \\
\quad \text { control }\end{array}$ & Severe TBI & 38 & $\begin{array}{l}\text { SBDP145, } \\
\text { SBDP150 }\end{array}$ & CSF & $\begin{array}{l}\text { SBDP145 and } 150 \text { levels were higher in patients } \\
\text { with worse GCS and longer ICP elevation }\end{array}$ \\
\hline Mondello, 2010 & Pro & Severe TBI & $\begin{array}{c}40 \text { TBI, } 24 \\
\text { CTRL }\end{array}$ & $\begin{array}{l}\text { SBDP145, } \\
\text { SBDP120 }\end{array}$ & CSF & $\begin{array}{l}\text { SBDP145 }>6 \mu \mathrm{g} / \mathrm{L} \text { (OR 5.9) and SBDP } \\
120>17.55 \mu \mathrm{g} / \mathrm{L} \text { (OR 18.34) predicted } \\
\text { death } \\
\text { SBDP145 within } 24 \text { h of injury correlated with } \\
\text { GCS score }\end{array}$ \\
\hline \multicolumn{7}{|c|}{ Inflammatory markers } \\
\hline $\begin{array}{l}\text { Schneider } \\
\text { Soares, } 2012\end{array}$ & Pro & $\begin{array}{l}\text { Mild, moderate, } \\
\text { and severe TBI }\end{array}$ & 127 & IL-10, TNF $\alpha$ & Blood & $\begin{array}{l}\text { Levels of IL-10 but not TNF } \alpha \text { were related to } \\
\text { mortality, even when adjusted for injury } \\
\text { severity characteristics }\end{array}$ \\
\hline Stein, 2012 & Pro & Severe TBI & 68 & IL-8, TNF $\alpha$ & Serum & $\begin{array}{l}\text { High levels of both IL- } 8 \text { and TNF } \alpha \text { predicted } \\
\text { subsequent development of intracranial } \\
\text { hypertension (specificity was high but } \\
\text { sensitivity was low) }\end{array}$ \\
\hline Tasci, 2003 & Pro & $\begin{array}{l}\text { Mild, moderate, and } \\
\text { severe TBI }\end{array}$ & 48 & IL-1 & Blood & $\begin{array}{l}\text { IL-1 levels within } 6 \text { h correlated with the initial } \\
\text { injury severity (GCS) and with GOS, but } \\
\text { timing of the GOS is not described }\end{array}$ \\
\hline Antunes, 2010 & Pro & $\begin{array}{l}\text { TBI with } \\
\text { hemorrhagic } \\
\text { contusions }\end{array}$ & 30 & IL-6 & Blood & $\begin{array}{l}\text { IL-6 levels at } 6 \mathrm{~h} \text { were higher in patients who } \\
\text { would subsequently clinically deteriorate due } \\
\text { to evolving contusions }\end{array}$ \\
\hline \multicolumn{7}{|c|}{ Combinations of markers } \\
\hline $\begin{array}{l}\text { Diaz-Arrastia, } \\
2013\end{array}$ & Pro & $\begin{array}{l}\text { Mild, moderate, and } \\
\text { severe TBI }\end{array}$ & 206 & $\begin{array}{l}\text { UCH-L1, } \\
\text { GFAP }\end{array}$ & Blood & $\begin{array}{l}\text { Levels of UCH-L1 were higher with moderate- } \\
\text { severe than with mild TBI } \\
\text { UCH-L1 levels were poorly predictive of } \\
\text { complete recovery but better at predicting } \\
\text { poor outcome } \\
\text { For predicting complete recovery, UCH-L1 in } \\
\text { combination with GFAP was not better than } \\
\text { GFAP alone. For predicting favorable versus } \\
\text { unfavorable outcome, UCH-L1 is marginally } \\
\text { better than GFAP and both together are better } \\
\text { than either alone }\end{array}$ \\
\hline
\end{tabular}




\begin{tabular}{|c|c|c|c|c|c|c|}
\hline Authors/year & $\begin{array}{l}\text { Study } \\
\text { design }\end{array}$ & Population & $N$ & Bio-marker & $\begin{array}{l}\text { Sample } \\
\text { source }\end{array}$ & Findings \\
\hline \multirow[t]{3}{*}{ Czeiter, 2012} & Pro & Severe TBI & 45 & $\begin{array}{l}\text { GFAP, UCH- } \\
\text { L1, } \\
\text { SBDP145 }\end{array}$ & $\begin{array}{r}\text { Serum, } \\
\text { CSF }\end{array}$ & $\begin{array}{l}\text { GFAP, UCH-L1, and SBDP145 all had at least } \\
\text { one measure that was significantly related to } \\
\text { unfavorable outcome }\end{array}$ \\
\hline & & & & & & $\begin{array}{l}\text { When included in a model with IMPACT } \\
\text { predictors of outcome, serum GFAP during } \\
\text { first } 24 \mathrm{~h} \text { and the first CSF UCH-L1 value } \\
\text { obtained were significantly related to mortality } \\
\text { and only serum GFAP during first } 24 \mathrm{~h} \text { was } \\
\text { significantly related to unfavorable outcome }\end{array}$ \\
\hline & & & & & & $\begin{array}{l}\text { In combination, the IMPACT core model with } \\
\text { the first CSF GFAP value, the first serum } \\
\text { GFAP value, and the first CSF SBDP145 } \\
\text { value performed the best }\end{array}$ \\
\hline
\end{tabular}

Pro prospective, $P P V$ positive predictive value, Retro retrospective, $C T R L$ control subjects, GOS Glasgow outcome scale, $O R$ odds ratio, $P P V$ positive predictive value

\section{ICU Processes of Care and Quality Assurance}

Evidence summary for specialized neurocritical care

\begin{tabular}{|c|c|c|c|c|}
\hline Study & Design & $N$ & Population & Findings \\
\hline Warme, 1991 [15] & Retrospective & 121 & TBI & $\begin{array}{l}\text { Care in neuro-ICU resulted in decreased mortality and higher GOS } \\
\text { scores }\end{array}$ \\
\hline Diringer, 2001 [22] & $\begin{array}{l}\text { Analysis of prospective } \\
\text { registry data }\end{array}$ & 1,038 & $\mathrm{ICH}$ & $\begin{array}{l}\text { ICH patients in neurological or neurosurgical ICU had lower } \\
\text { hospital mortality rate than ICH patients in general ICU; } \\
\text { presence of full time intensivist associated with lower mortality } \\
\text { rate }\end{array}$ \\
\hline Mirski, 2001 [14] & Retrospective & 128 & $\mathrm{ICH}$ & $\begin{array}{l}\text { ICH patients in neuroscience ICU had lower mortality, and } \\
\text { improved discharge disposition than ICH patients in general } \\
\text { ICU. Neuroscience ICU patients had shorter hospital length of } \\
\text { stay and lower costs than national benchmarks }\end{array}$ \\
\hline Elf, 2002 [19] & Retrospective & 226 & TBI & $\begin{array}{l}\text { Care in neuro-ICU resulted in decreased mortality and improved } \\
\text { functional outcome, measured by GOS scores }\end{array}$ \\
\hline Patel, 2002 [20] & Retrospective & 285 & TBI & $\begin{array}{l}\text { Specialized neurointensive care resulted in decreased mortality and } \\
\text { higher incidence of favorable outcome }\end{array}$ \\
\hline Suarez, 2004 [16] & $\begin{array}{l}\text { Analysis of prospective } \\
\text { registry data }\end{array}$ & 2,381 & $\begin{array}{l}\text { Critically ill } \\
\text { neuroscience } \\
\text { patients }\end{array}$ & $\begin{array}{l}\text { Decreased hospital mortality, shorter hospital and ICU length of } \\
\text { stay after neurocritical care team was introduced }\end{array}$ \\
\hline Varelas, 2004 [13] & $\begin{array}{l}\text { Observational cohort } \\
\text { with historical } \\
\text { controls }\end{array}$ & 2,366 & All NICU admissions & $\begin{array}{l}\text { Decrease in mortality and length of stay, and improved discharge } \\
\text { disposition after implementation of neurointensivist-led team }\end{array}$ \\
\hline Varelas, 2006 [25] & Retrospective & 592 & TBI & $\begin{array}{l}\text { Decreased mortality and hospital length of stay, increased odds of } \\
\text { discharge to home or rehabilitation after neurointensivist } \\
\text { appointed }\end{array}$ \\
\hline Lerch, 2006 [18] & Retrospective & 59 & Aneurysmal SAH & $\begin{array}{l}\text { Specialized neurocritical care associated with higher incidence of } \\
\text { favorable outcome, measured by GOS }\end{array}$ \\
\hline Bershad, 2008 [26] & Retrospective & 400 & Acute ischemic stroke & $\begin{array}{l}\text { Neurointensive care team associated with decreased ICU and } \\
\text { hospital length of stay, and increased proportion of discharges } \\
\text { home }\end{array}$ \\
\hline Lott, 2009 [23] & $\begin{array}{l}\text { Prospective, } \\
\text { multi-site }\end{array}$ & 16,415 & $\begin{array}{l}\text { Intracranial } \\
\text { hemorrhage, } \\
\text { ischemic stroke }\end{array}$ & $\begin{array}{l}\text { Lower mortality and higher incidence of favorable outcome among } \\
\text { units with neuro-specialized care }\end{array}$ \\
\hline Josephson, 2010 [12] & Retrospective & 512 & SAH & $\begin{array}{l}\text { Neuro-intensivist co-management associated with decreased } \\
\text { mortality }\end{array}$ \\
\hline Palminteri, 2010 [21] & Retrospective & 287 & $\mathrm{ICH}$ & $\begin{array}{l}\text { No difference in mortality with neurointensivist; higher proportion } \\
\text { of favorable outcome with neurointensivist-managed care }\end{array}$ \\
\hline
\end{tabular}




\begin{tabular}{|c|c|c|c|c|}
\hline Study & Design & $N$ & Population & Findings \\
\hline Samuels, 2011 [17] & Retrospective & 703 & $\begin{array}{l}\text { Aneurysmal } \\
\text { subarachnoid } \\
\text { hemorrhage }\end{array}$ & $\begin{array}{l}\text { Patients treated by neurocritical care team more likely to receive } \\
\text { definitive aneurysm treatment and be discharged home }\end{array}$ \\
\hline Knopf, 2012 [29] & Retrospective & 2,096 & $\begin{array}{l}\text { AIS, ICH, aneurysmal } \\
\text { SAH }\end{array}$ & $\begin{array}{l}\text { Compared data prior to, during, and after departure of a } \\
\text { neurointensivist (NI). For AIS, departure of the NI resulted in } \\
\text { decreased functional outcome; for ICH, there was no effect of a } \\
\text { NI, but shorter length of stay for patients in specialized } \\
\text { neurocritical care unit, compared to a general ICU. } \\
\text { For SAH, NI resulted in longer ICU LOS, but improved discharge } \\
\text { disposition and mortality }\end{array}$ \\
\hline Burns, 2013 [30] & Retrospective & 74 & $\mathrm{ICH}$ & $\begin{array}{l}\text { Introduction of a neurocritical care consult service resulted in more } \\
\text { timely and sustained SBP control, and more dysphagia screens } \\
\text { prior to initiation of oral feeding. }\end{array}$ \\
\hline
\end{tabular}

Evidence summary for protocol-directed care

\begin{tabular}{|c|c|c|c|c|}
\hline Study & Design & $N$ & Population & Findings \\
\hline Elf, 2002 [19] & Retrospective & 154 & TBI & $\begin{array}{l}\text { Organized secondary insult management protocol and neurointensive care improved } \\
\text { mortality rates and percentage of favorable outcome using GOS scores after } 6 \text { months }\end{array}$ \\
\hline Patel, 2002 [20] & Retrospective & 285 & TBI & $\begin{array}{l}\text { Patients with severe head injury treated by ICP/CPP targeted protocol and neurocritical } \\
\text { care specialists had higher percentage of favorable outcome measured by GOS scores } \\
6 \text { months post-injury }\end{array}$ \\
\hline Arabi, 2010 [40] & $\begin{array}{r}\text { Retrospective/ } \\
\text { prospective }\end{array}$ & 434 & TBI & $\begin{array}{l}\text { Implementation of protocol management based on BTF guidelines was associated with } \\
\text { reduction in hospital and ICU mortality }\end{array}$ \\
\hline Eker, 1998 [41] & Prospective & 91 & TBI & $\begin{array}{l}\text { Protocol targeting brain volume regulation and microcirculation reduced mortality and } \\
\text { improved percentage of favorable outcome measured by GOS } 6 \text { months post-injury }\end{array}$ \\
\hline McKinley, 1999 [42] & $\begin{array}{r}\text { Retrospective/ } \\
\text { prospective }\end{array}$ & 24 & TBI & $\begin{array}{l}\text { ICP management protocol resulted in more consistent and improved ICP control, and less } \\
\text { variation in CPP }\end{array}$ \\
\hline Vukic, 1999 [43] & Retrospective & 39 & TBI & $\begin{array}{l}\text { Protocol based on BTF guidelines for ICP management resulted in decreased mortality } \\
\text { and improved percentage of favorable GOS scale scores }\end{array}$ \\
\hline McIlvoy, 2001 [44] & $\begin{array}{r}\text { Retrospective/ } \\
\text { prospective }\end{array}$ & 125 & TBI & $\begin{array}{l}\text { BTF guidelines used to develop 4-phase protocol for ICP/CPP management, resulting in } \\
\text { decreased hospital and ICU length of stay, decreased number of ventilator days and } \\
\text { incidence of pneumonia, and earlier tracheostomy }\end{array}$ \\
\hline Palmer, 2001 [45] & $\begin{array}{r}\text { Retrospective/ } \\
\text { prospective }\end{array}$ & 93 & TBI & $\begin{array}{l}\text { BTF guideline implementation improved odds of good outcome, measured by GOS at } \\
6 \text { months }\end{array}$ \\
\hline Vitaz, 2001 [46] & $\begin{array}{r}\text { Retrospective/ } \\
\text { prospective }\end{array}$ & 162 & TBI & $\begin{array}{l}\text { Standardized clinical pathway for ICP/CPP management resulted in decreased hospital } \\
\text { and unit length of stay and decreased ventilator days }\end{array}$ \\
\hline Clayton, 2004 [47] & Retrospective & 669 & TBI & $\begin{array}{l}\text { CPP management protocol decreased ICU and hospital mortality, but had no effect on } \\
\text { length of stay }\end{array}$ \\
\hline Fakhry, 2004 [48] & $\begin{array}{r}\text { Retrospective/ } \\
\text { prospective }\end{array}$ & 830 & TBI & $\begin{array}{l}\text { Protocol developed from BTF guidelines decreased hospital length of stay and costs, and } \\
\text { demonstrated a decreased trend in mortality and improved functional recovery }\end{array}$ \\
\hline Cremer, 2005 [49] & $\begin{array}{r}\text { Retrospective/ } \\
\text { prospective }\end{array}$ & 333 & TBI & $\begin{array}{l}\text { ICP/CPP targeted algorithm resulted in increased number of ventilator days and therapy } \\
\text { intensity, with no difference in mortality when compared to supportive care control } \\
\text { group }\end{array}$ \\
\hline Talving, 2013 [50] & Prospective & 216 & TBI & $\begin{array}{l}\text { Observational study comparing patients managed with ICP monitoring versus no } \\
\text { monitoring and compliance with BTF guidelines. In hospital mortality higher in } \\
\text { patients with no ICP monitoring. ICP monitoring group had longer ICU and hospital } \\
\text { length of stay. BTF guideline compliance was } 46.8 \%\end{array}$ \\
\hline Biersteker, 2012 [51] & $\begin{array}{l}\text { Observational } \\
\text { multi-site }\end{array}$ & 265 & TBI & $\begin{array}{l}\text { Investigated compliance and outcomes of BTF guidelines for ICP monitoring. Guideline } \\
\text { compliance was } 46 \% \text {. Guideline compliance was not associated with mortality or } \\
\text { unfavorable outcome when controlling for baseline and clinical characteristics }\end{array}$ \\
\hline Meretoja, 2010 [52] & $\begin{array}{l}\text { Observational, } \\
\text { multi-registry }\end{array}$ & 61,685 & AIS & $\begin{array}{l}\text { Compared data from } 333 \text { hospitals classified as comprehensive stroke centers, primary } \\
\text { stroke centers, and general hospitals. Mortality rates lower in stroke centers for up to } \\
9 \text { years }\end{array}$ \\
\hline Smith, 2010 [53] & $\begin{array}{l}\text { Longitudinal } \\
\text { cohort registry }\end{array}$ & 6,223 & AIS & $\begin{array}{l}\text { Organized stroke care resulted in decreased } 30 \text { day mortality for each ischemic stroke } \\
\text { subtype }\end{array}$ \\
\hline Schwamm, 2009 [54] & $\begin{array}{l}\text { Prospective } \\
\quad \text { quality initiative }\end{array}$ & 322,847 & AIS, TIA & $\begin{array}{l}\text { Centers that participated in Get with the Guidelines-Stroke reported higher compliance } \\
\text { with all stroke performance measures }\end{array}$ \\
\hline Gropen, 2006 [55] & $\begin{array}{l}\text { Retrospective } \\
\text { quality initiative }\end{array}$ & 1,442 & AIS & $\begin{array}{l}\text { Designated stroke centers utilizing Brain Attack Coalition guidelines experienced shorter } \\
\text { door to MD contact, CT scan time, and t-PA administration time. }\end{array}$ \\
\hline
\end{tabular}




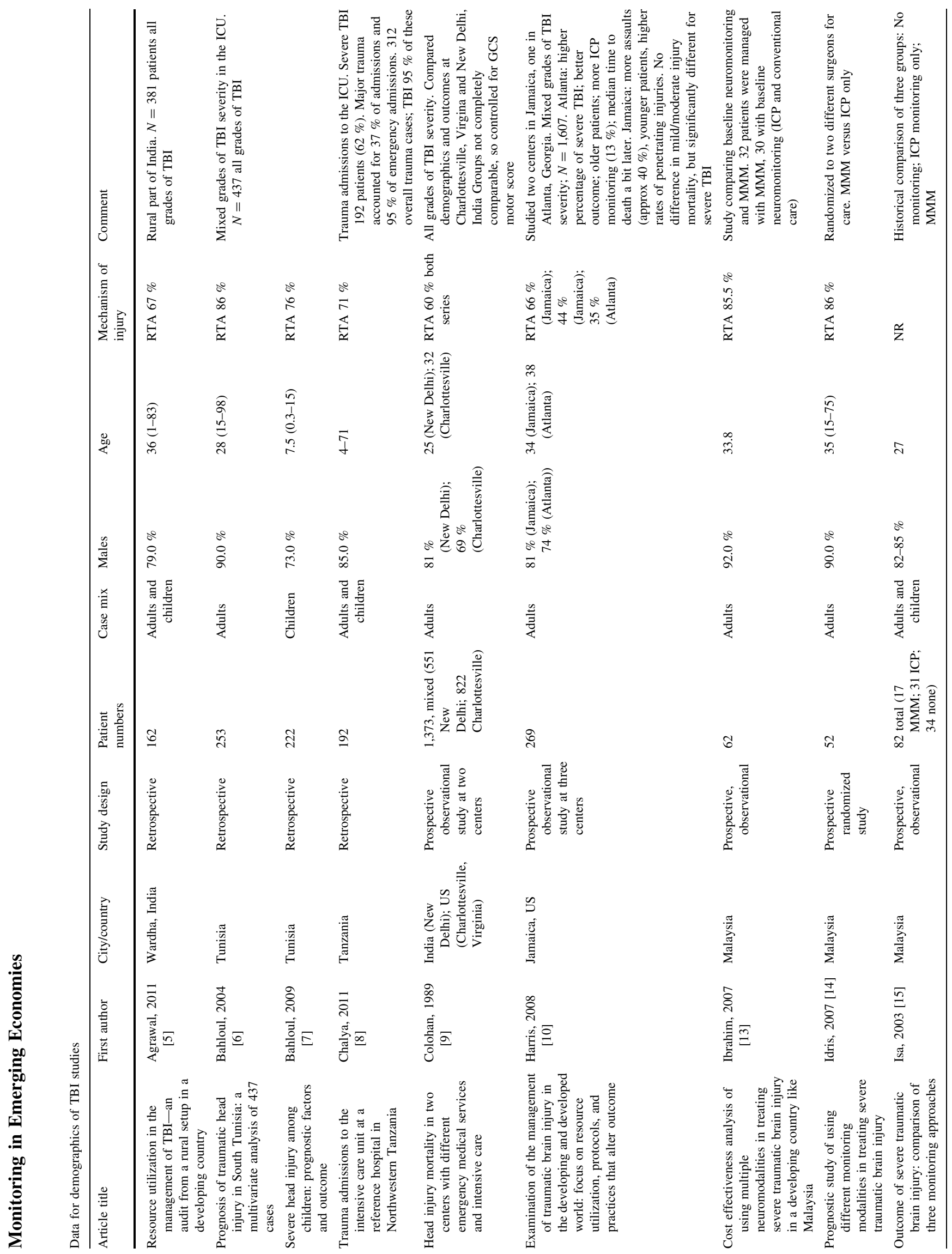




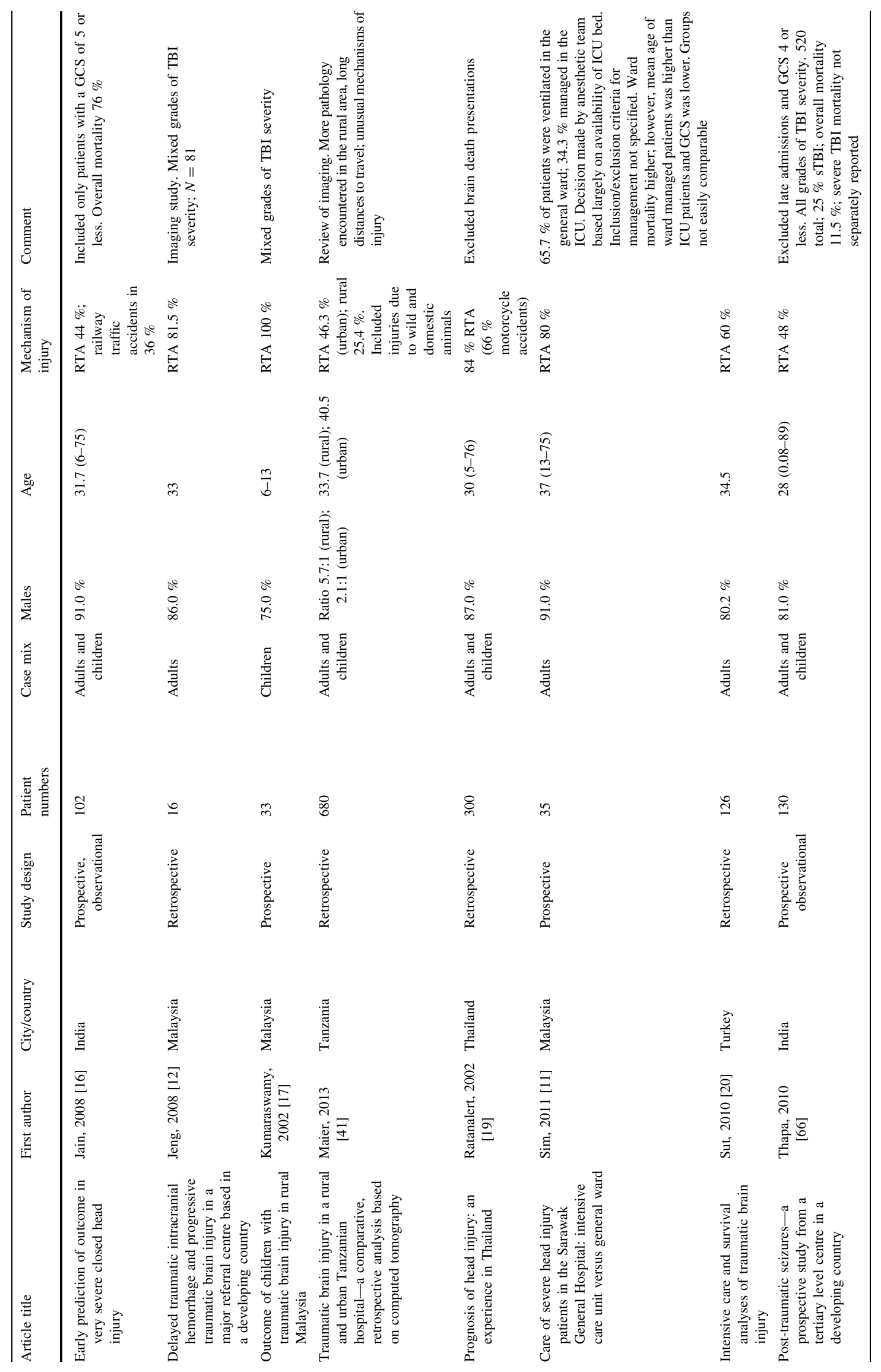




\begin{tabular}{|c|c|c|c|c|c|c|c|c|c|c|}
\hline $\begin{array}{l}\overrightarrow{\overline{0}} \\
\text { 言 } \\
\text { ठे }\end{array}$ & 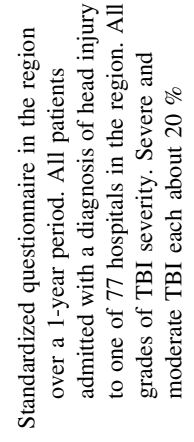 & 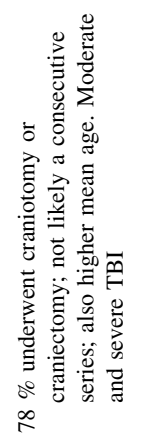 & 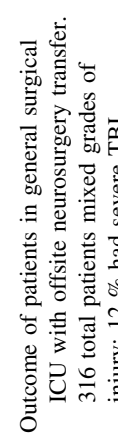 & & & & & & & \\
\hline 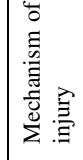 & $\begin{array}{l}8 \\
\sigma \\
\mathbb{6}\end{array}$ & $\begin{array}{l}\stackrel{\circ}{0} \\
\overleftarrow{E}\end{array}$ & $\frac{a}{z}$ & 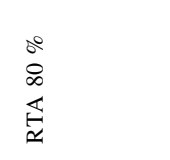 & 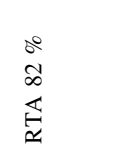 & $\frac{a}{z}$ & $\begin{array}{l}\frac{b}{2} \\
i \\
\mathbb{E} \\
\simeq\end{array}$ & 兑 & $\frac{a}{z}$ & 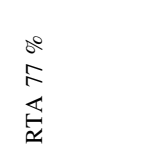 \\
\hline 总 & $\begin{array}{l}\widehat{\infty} \\
\hat{d} \\
\hat{e} \\
\text { के }\end{array}$ & f & $\begin{array}{l}\widehat{\Phi} \\
d \\
\stackrel{d}{=} \\
\vec{m}\end{array}$ & 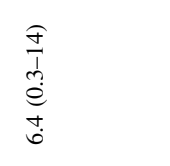 & 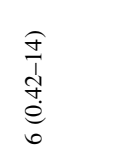 & $\begin{array}{l}\hat{\overline{1}} \\
\underline{1} \\
\hat{\infty} \\
\infty \\
\infty \\
i\end{array}$ & 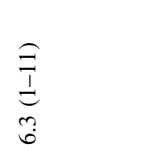 & $\begin{array}{l}\widehat{a} \\
\underline{1} \\
\hat{a} \\
\hat{e} \\
\dot{i}\end{array}$ & $\begin{array}{l}\frac{f}{f} \\
\frac{1}{2} \\
\hat{0} \\
n \\
0\end{array}$ & 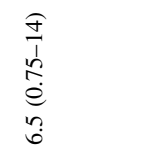 \\
\hline$\frac{\mathscr{s}}{\pi}$ & $\begin{array}{l}\stackrel{0}{0} \\
\stackrel{8}{1}\end{array}$ & $\begin{array}{l}\circ \\
\infty \\
\infty \\
i\end{array}$ & $\begin{array}{l}\stackrel{0}{0} \\
\stackrel{\infty}{\infty}\end{array}$ & $\begin{array}{l}\therefore 0 \\
\ddot{b} \\
\ddot{b}\end{array}$ & $\begin{array}{l}\dot{0} \\
\dot{8} \\
\dot{0}\end{array}$ & 芫 & $\begin{array}{l}\stackrel{0}{0} \\
\stackrel{\infty}{\infty}\end{array}$ & 艺 & 兑 & $\begin{array}{l}\stackrel{\circ}{0} \\
\stackrel{5}{\circ}\end{array}$ \\
\hline 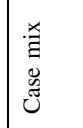 & 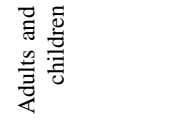 & $\frac{2}{\frac{z}{z}}$ & $\frac{\mathscr{n}}{\frac{z}{z}}$ & 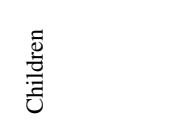 & 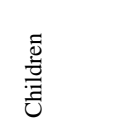 & $\begin{array}{l}\frac{\overline{\tilde{D}}}{\overline{\frac{\pi}{\pi}}} \\
\end{array}$ & 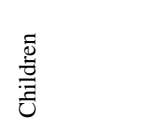 & 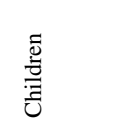 & $\frac{\overline{\underline{D}}}{\frac{\bar{g}}{E}}$ & 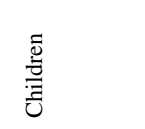 \\
\hline 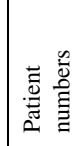 & $\begin{array}{l}\infty \\
\stackrel{i}{i}\end{array}$ & 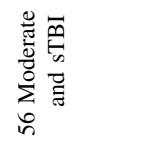 & q & $n$ & $\stackrel{d}{\stackrel{ \pm}{*}}$ & $\stackrel{\infty}{\sim}$ & $\underset{\sim}{\sim}$ & $=$ & 黑 & $\approx$ \\
\hline 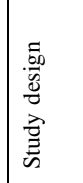 & 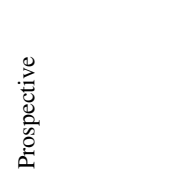 & 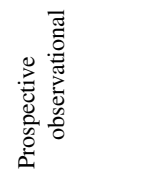 & 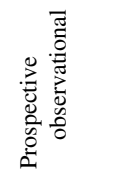 & 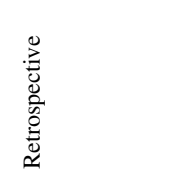 & 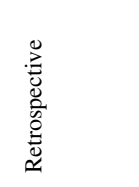 & 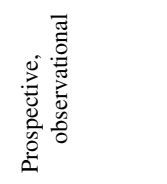 & 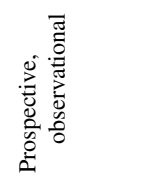 & 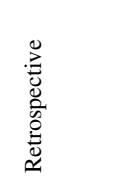 & 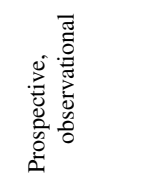 & 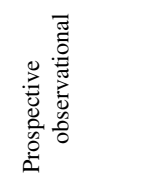 \\
\hline 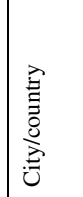 & 节 & 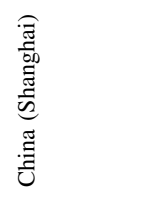 & 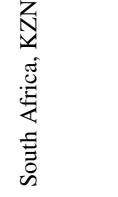 & 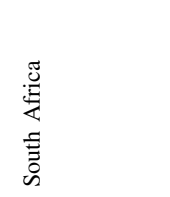 & 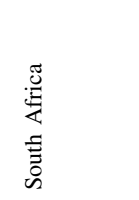 & 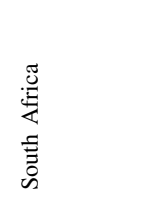 & 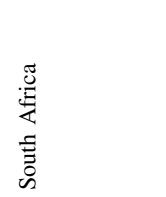 & 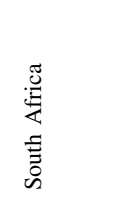 & 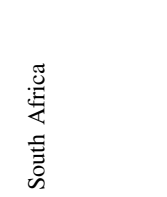 & 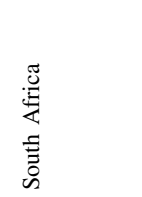 \\
\hline 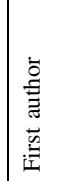 & 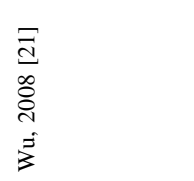 & 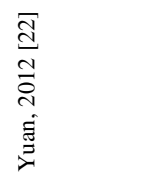 & 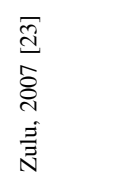 & 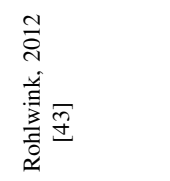 & 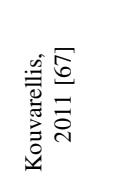 & 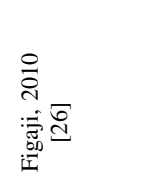 & 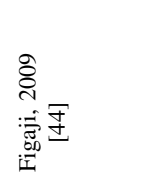 & 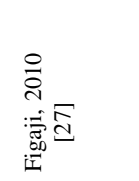 & 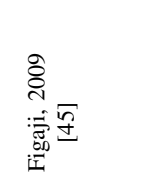 & 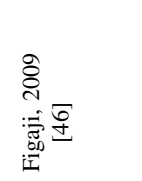 \\
\hline $\begin{array}{l}\stackrel{\varrho}{\Xi} \\
\stackrel{\Xi}{\Xi}\end{array}$ & 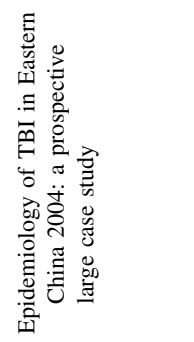 & 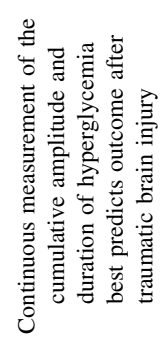 & 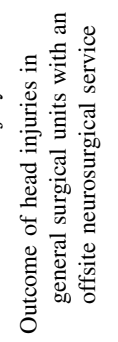 & 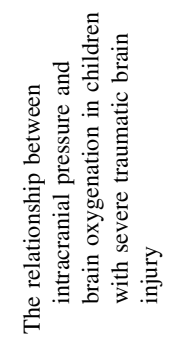 & 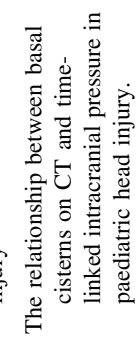 & 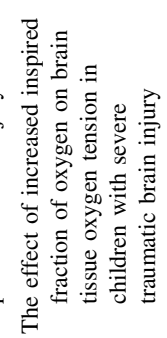 & 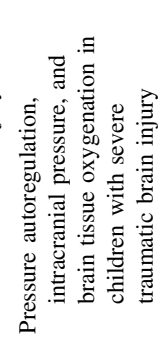 & 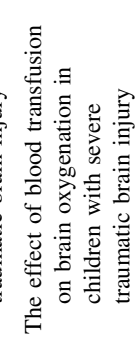 & 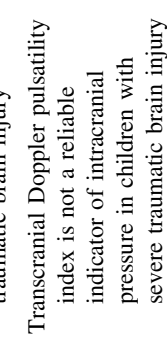 & 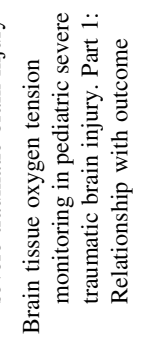 \\
\hline
\end{tabular}




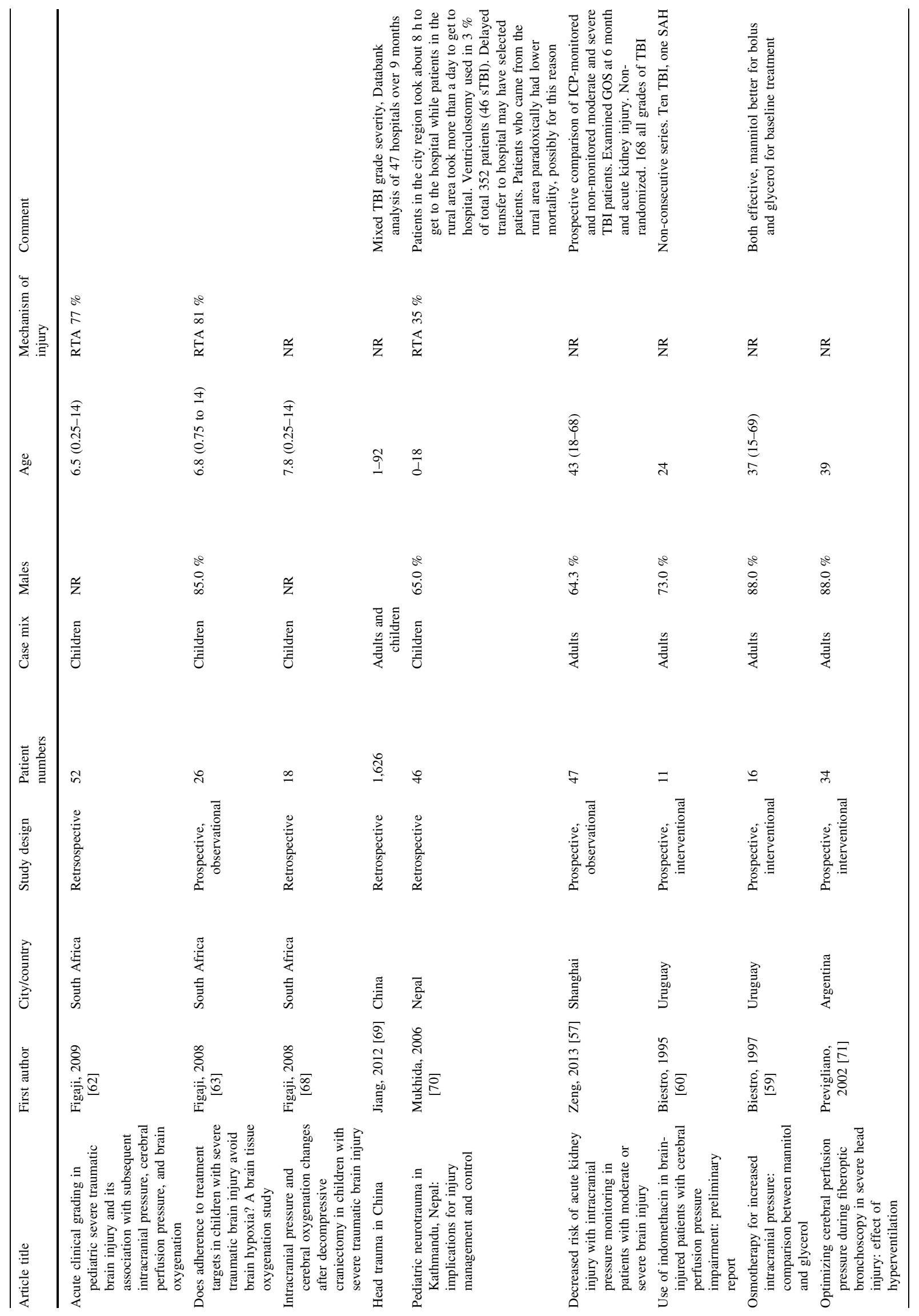




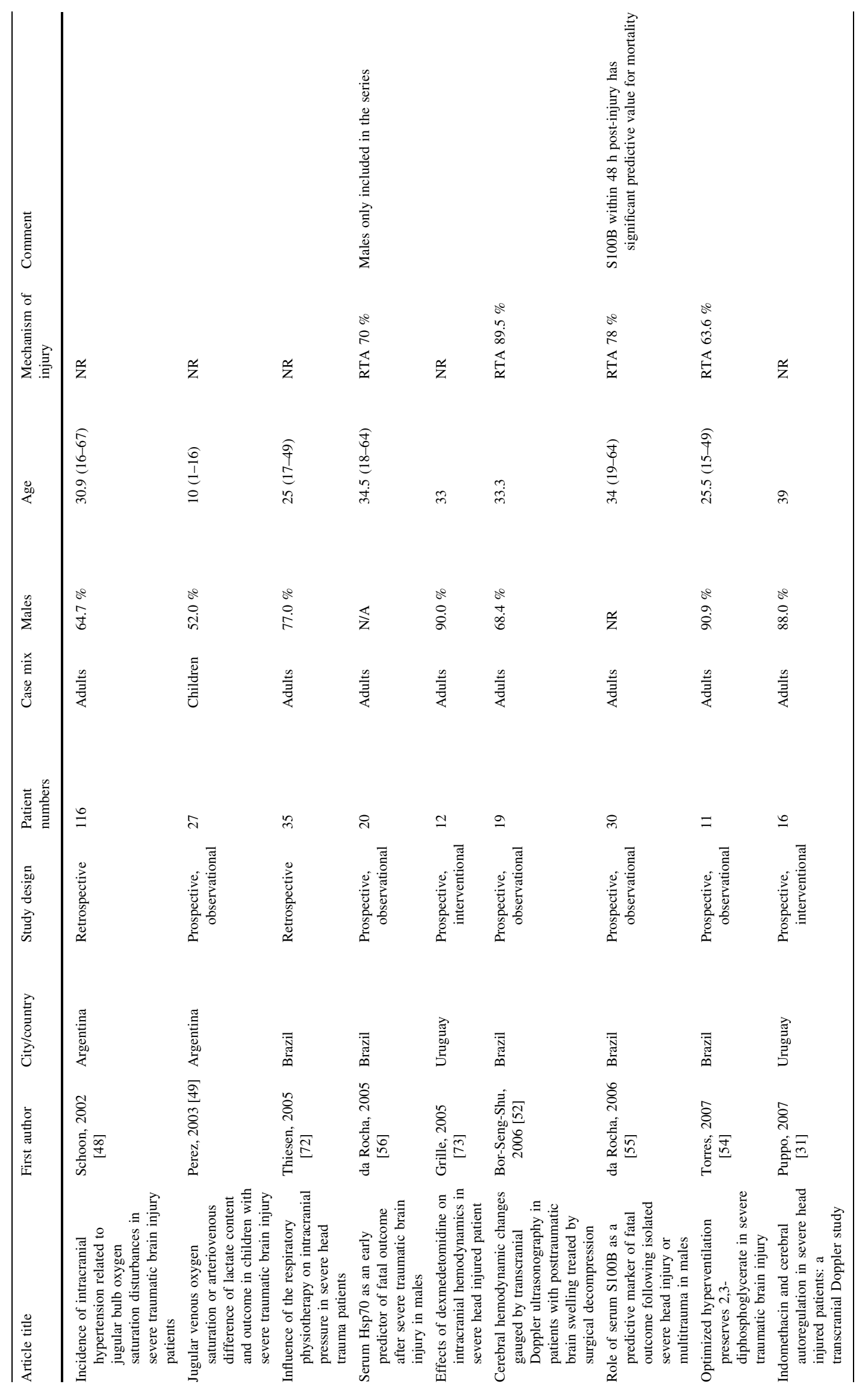




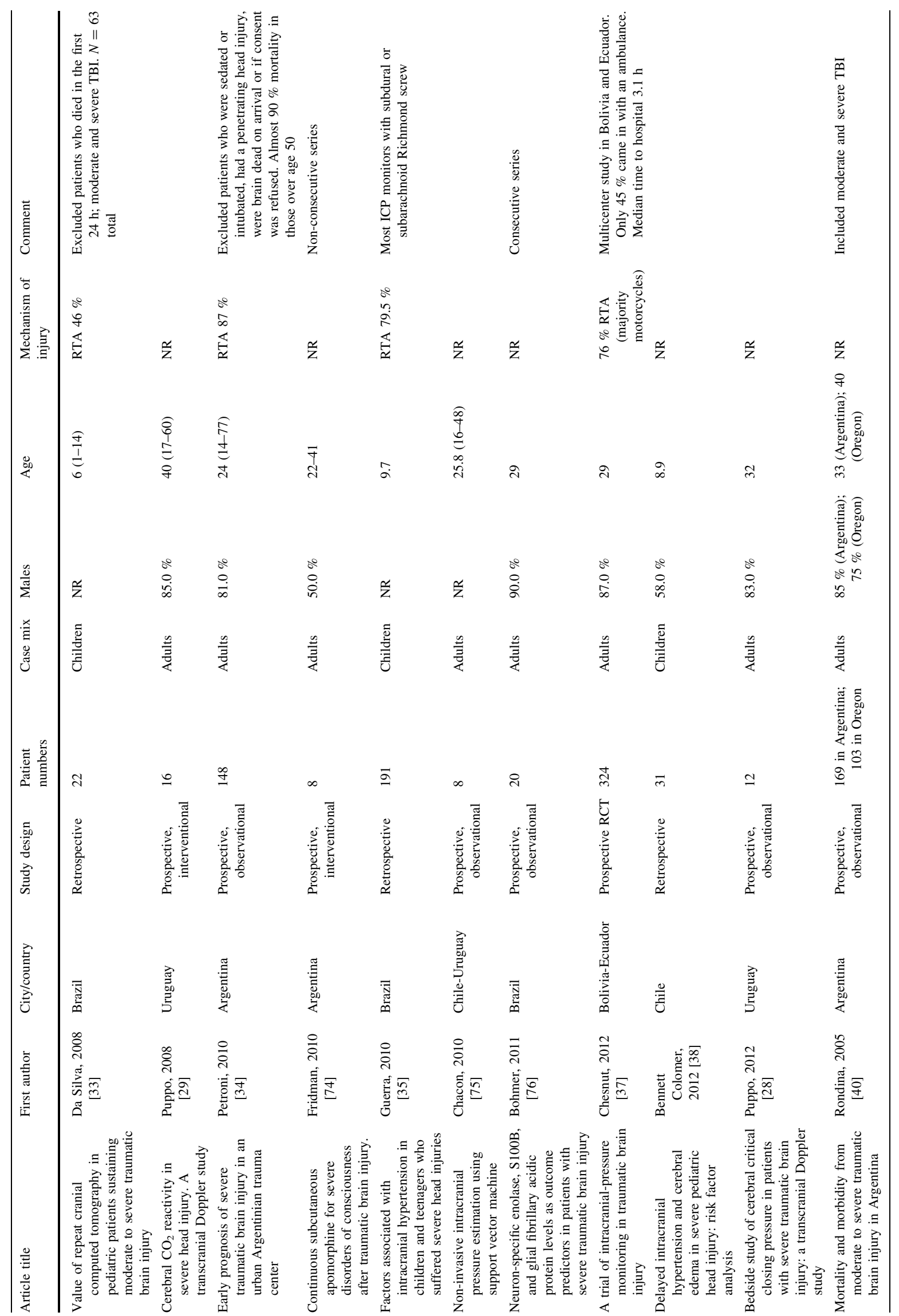




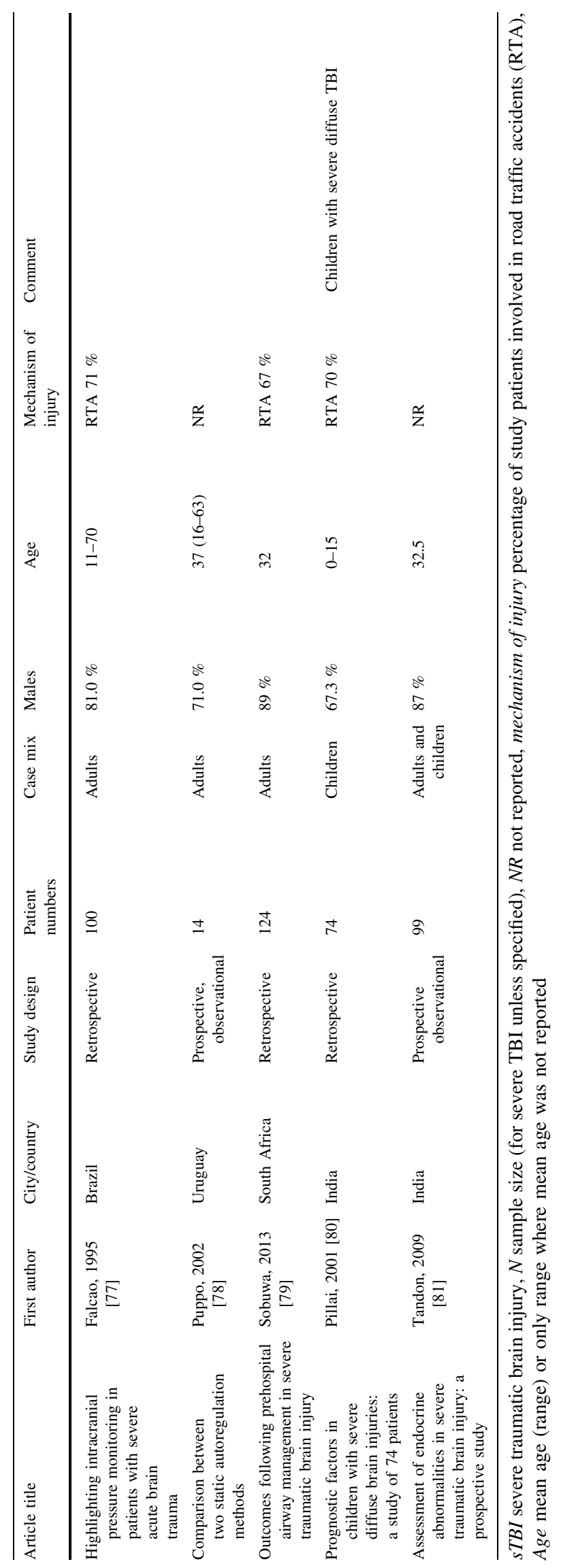




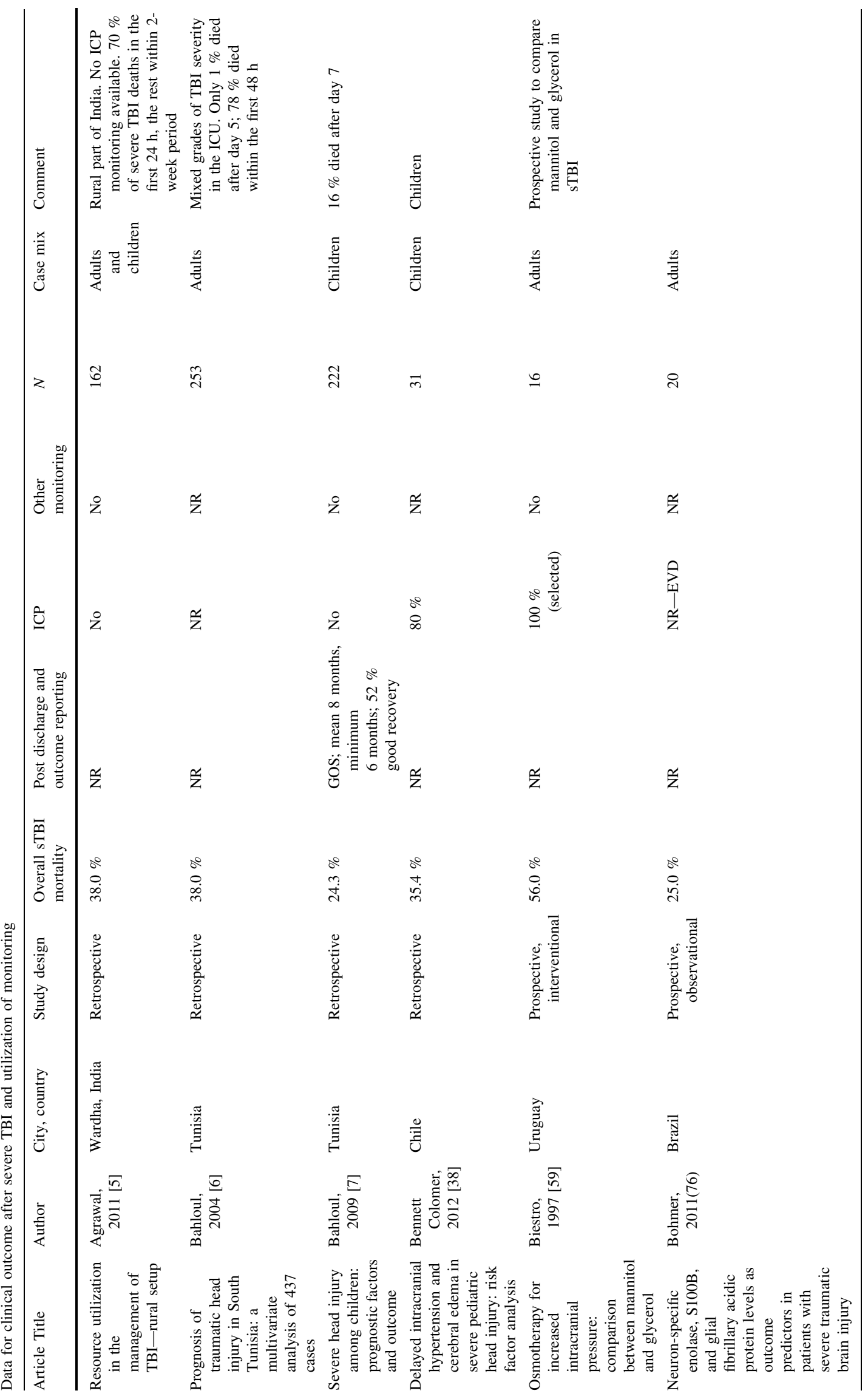




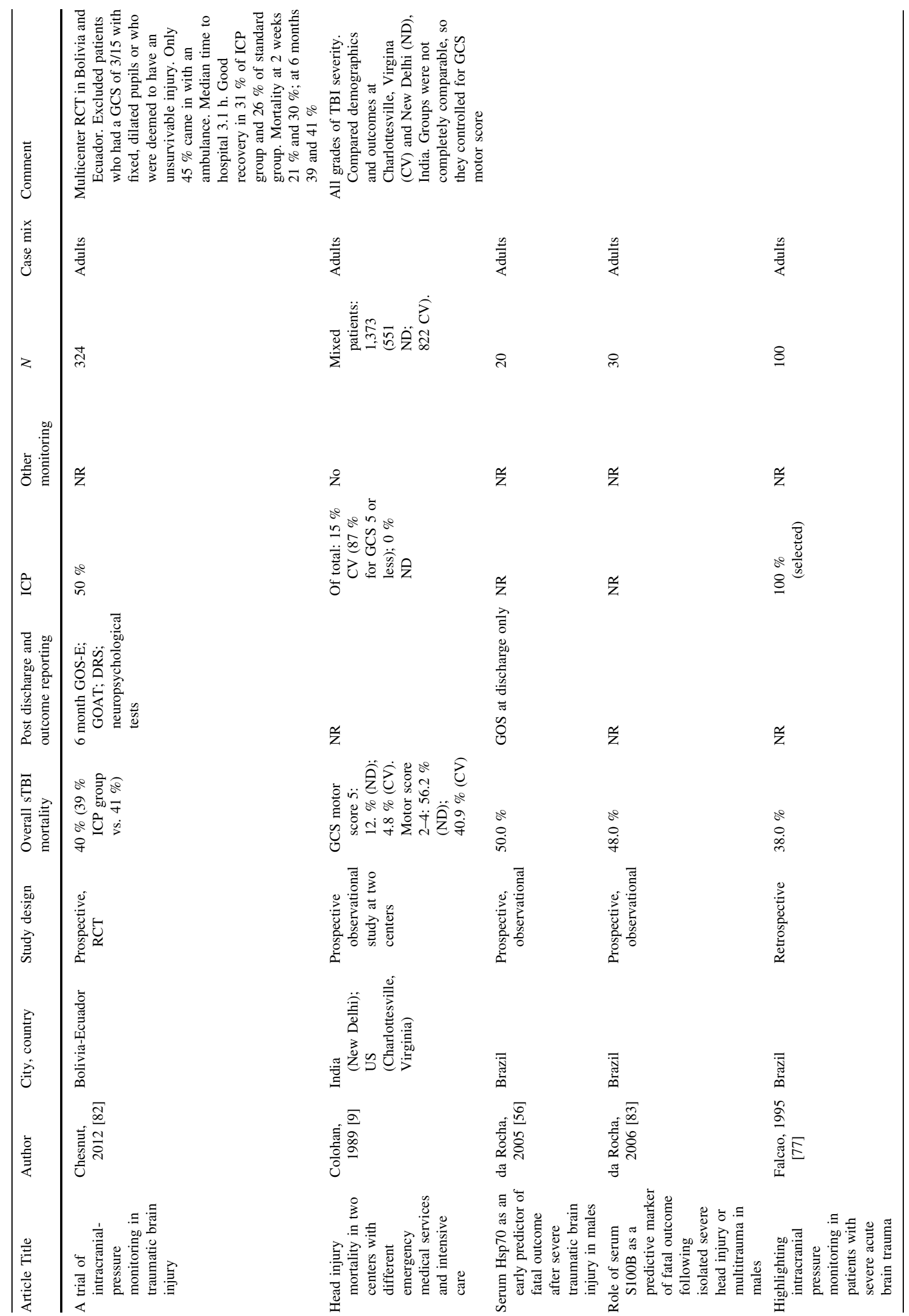




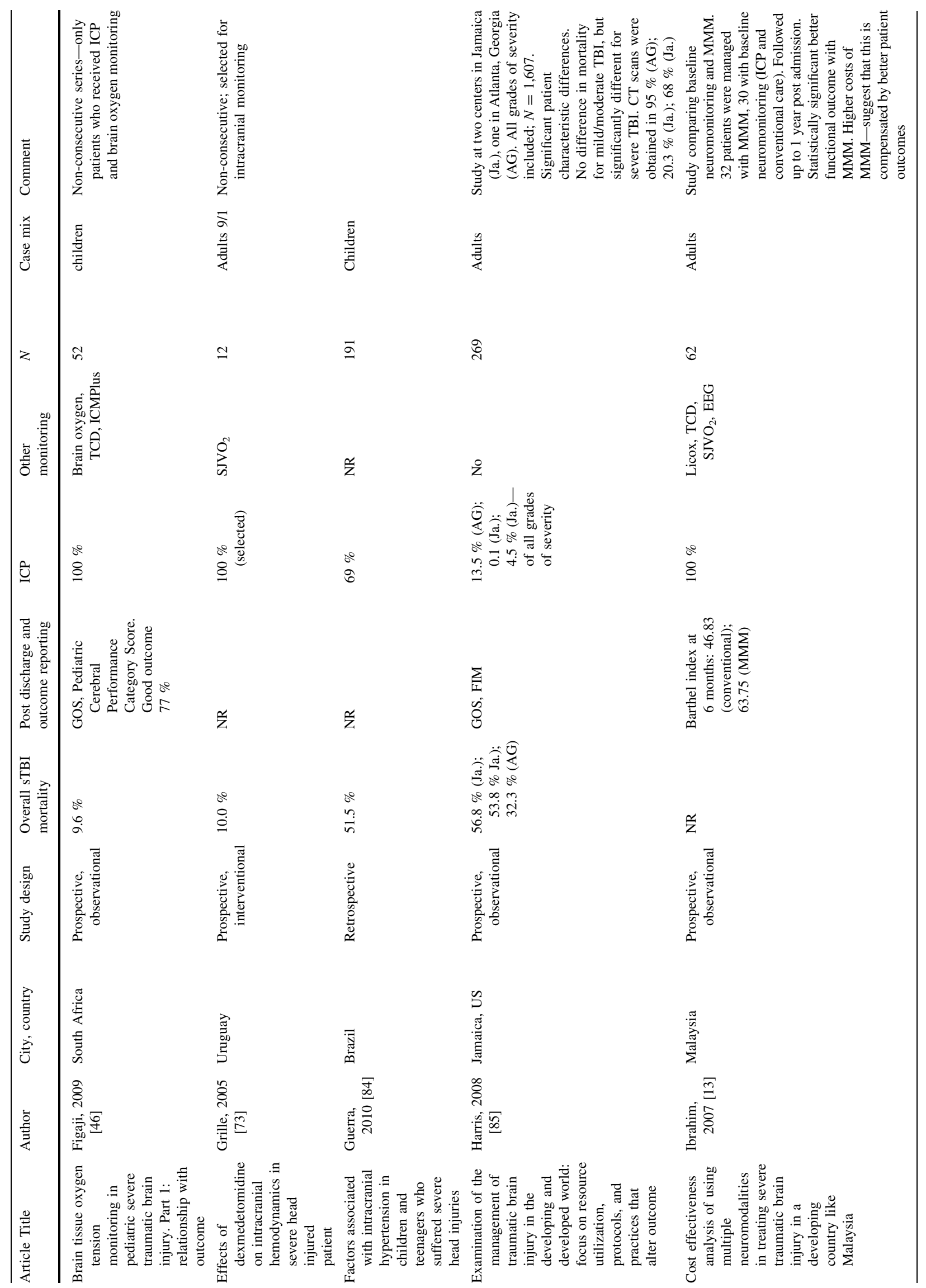




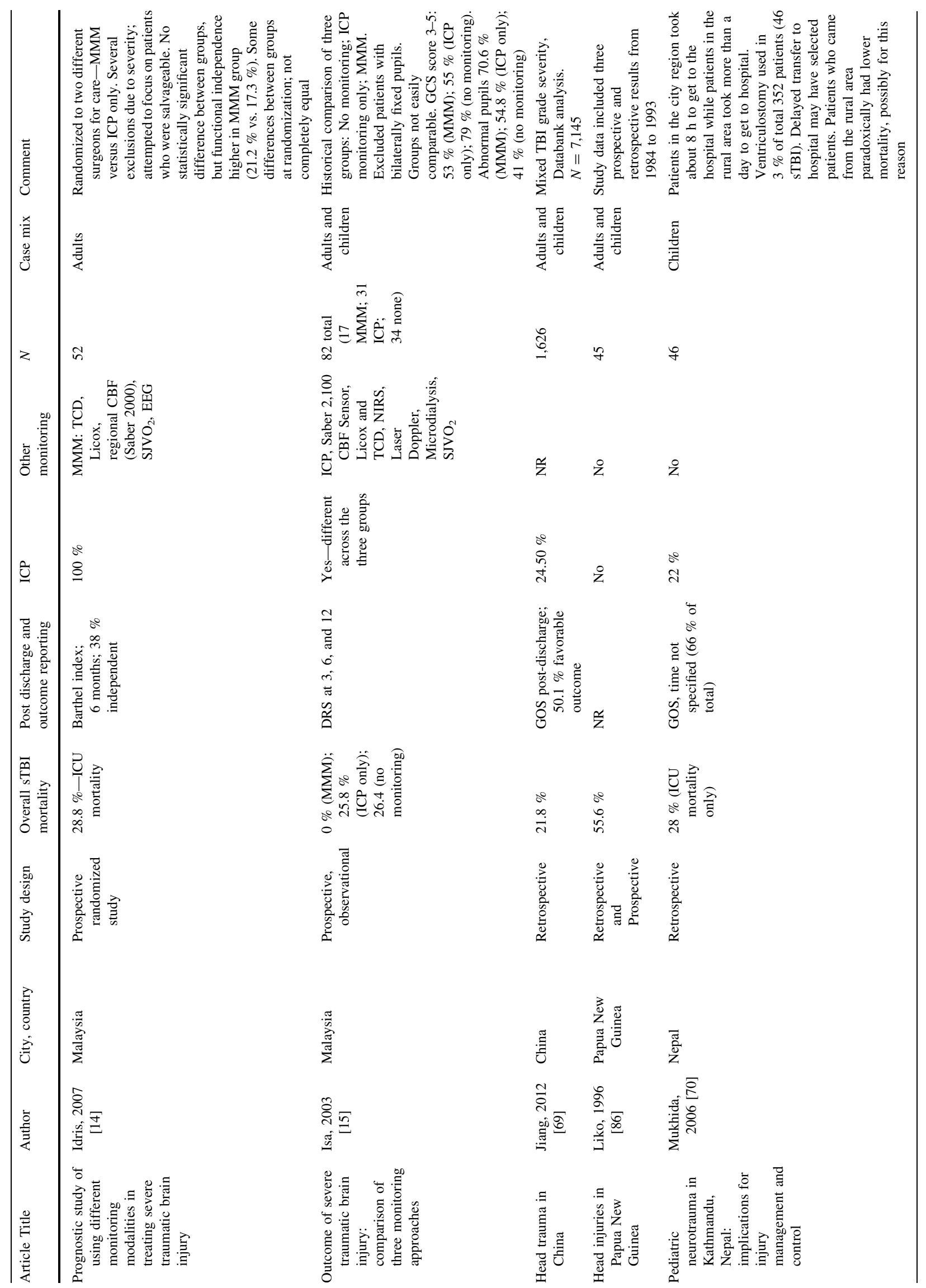




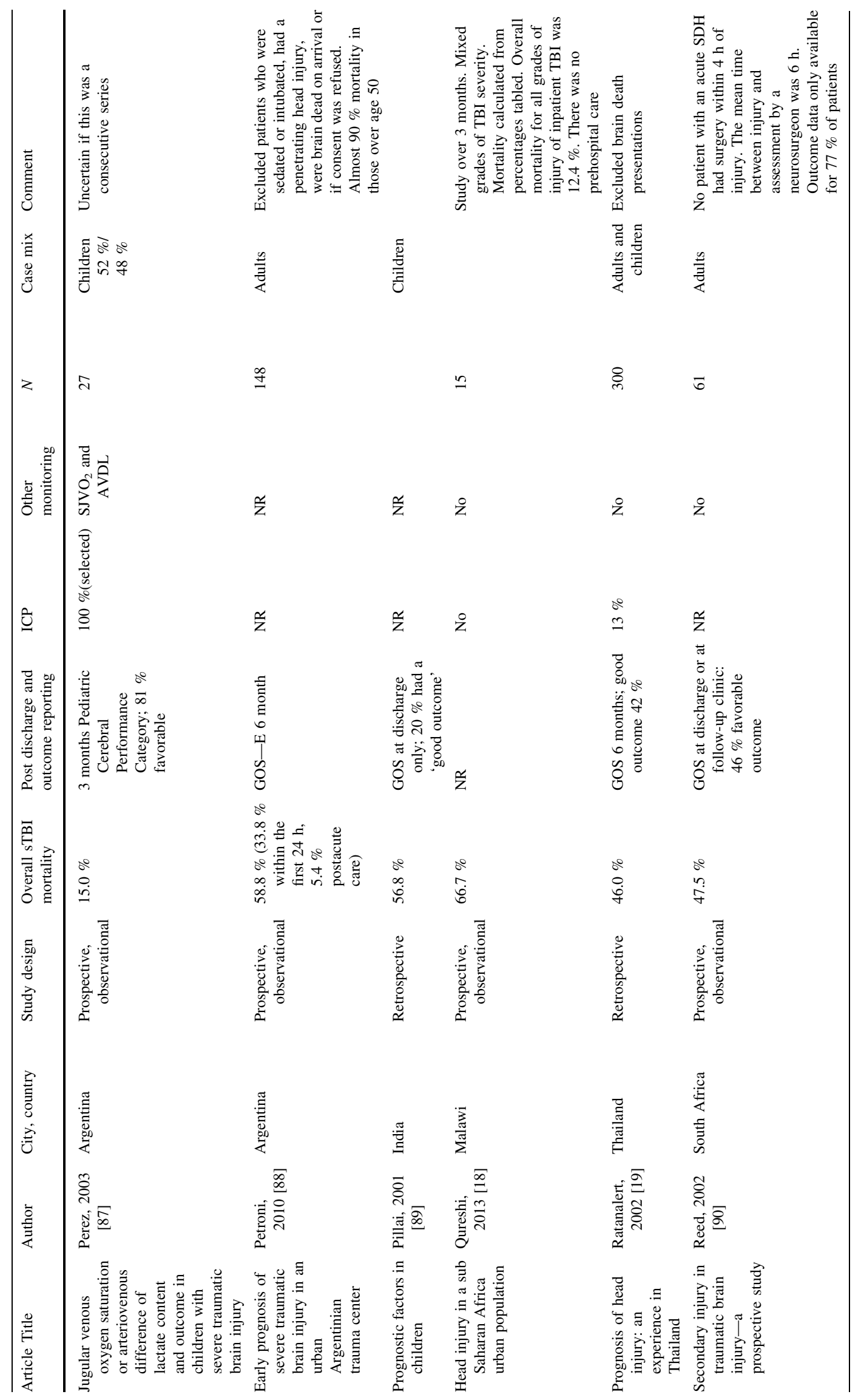




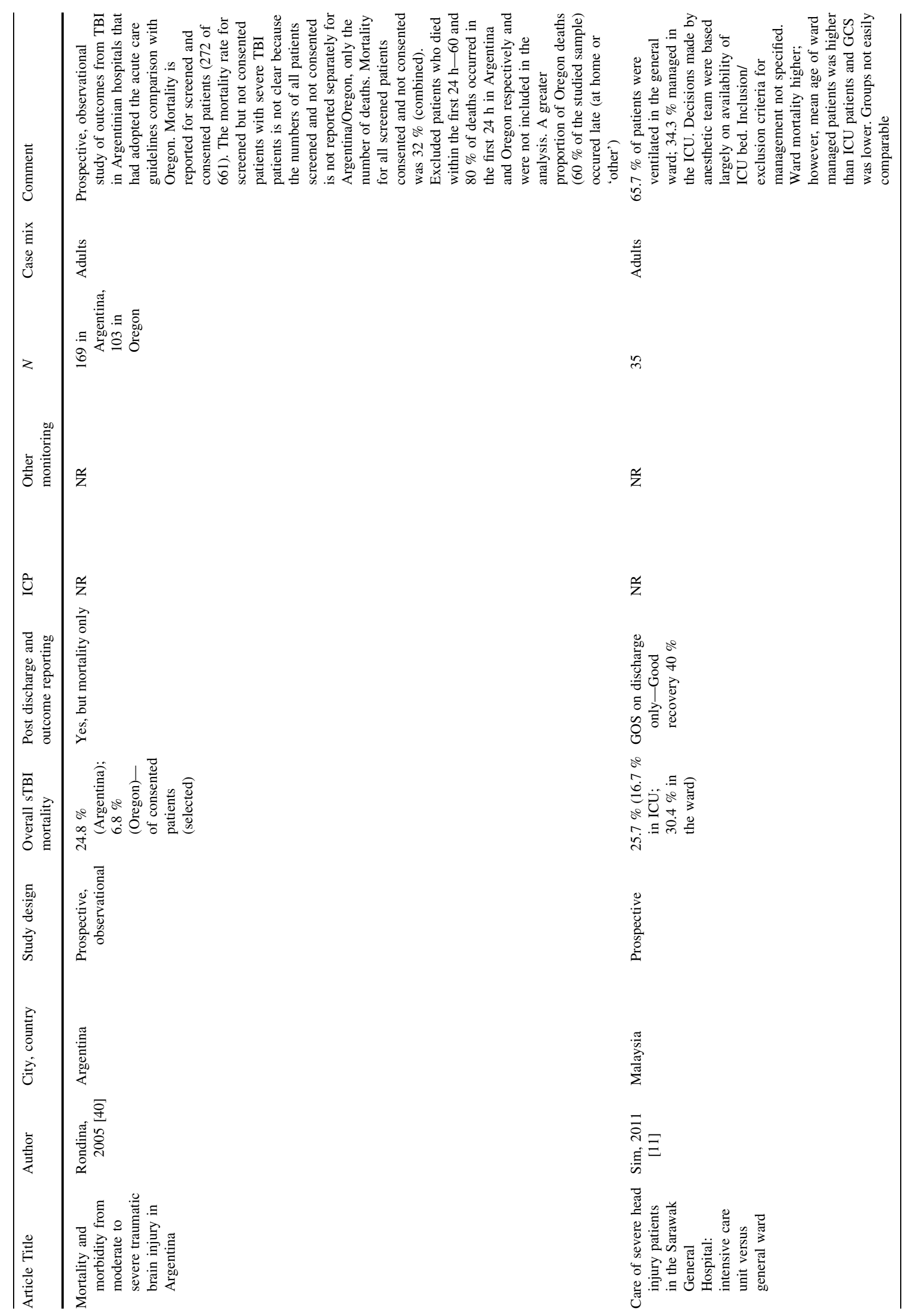




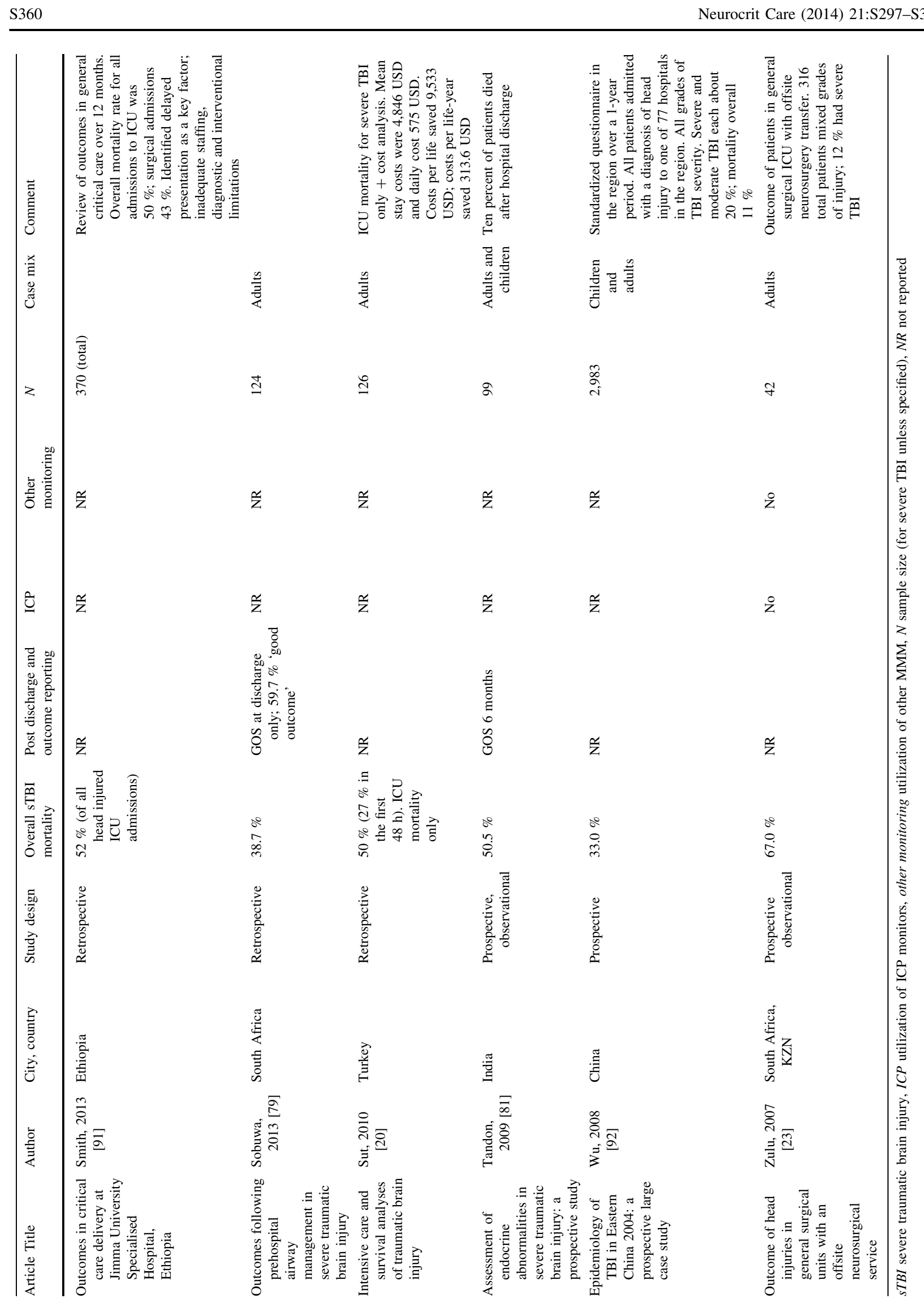

Springer 


\section{References}

1. Le Roux P, Menon DK, Citerio G, Vespa P, Bader MK, Brophy GM, Diringer MN, Stocchetti N, Videtta W, Armonda R, Badjatia N, Böesel J, Chesnut R, Chou S, Claassen J, Czosnyka M, De Georgia M, Figaji A, Fugate J, Helbok R, Horowitz D, Hutchinson P, Kumar M, McNett M, Miller C, Naidech A, Oddo M, Olson D, O'Phelan K, Provencio JJ, Puppo C, Riker R, Robertson C, Schmidt M, Taccone F. Consensus summary statement of the International Multidisciplinary Consensus Conference on Multimodality Monitoring in Neurocritical Care : a statement for healthcare professionals from the Neurocritical Care Society and the European Society of Intensive Care Medicine. Neurocrit Care. 2014; [Epub ahead of print].
2. Moher D, Liberati A, Tetzlaff J, Altman DG, PRISMA Group. Preferred reporting items for systematic reviews and metaanalyses: the PRISMA statement. BMJ. 2009;339:b2535.

3. Jaeschke R, Guyatt GH, Dellinger P, et al. Use of GRADE grid to reach decisions on clinical practice guidelines when consensus is elusive. BMJ. 2008;337:a744.

4. Rochwerg B, Alhazzani W, Jaeschke R. Clinical meaning of the GRADE rules. Intensive Care Med. 2014;40:877-9.

5. Andrews JC, Schünemann HJ, Oxman AD, Pottie K, Meerpohl JJ, Coello PA, Rind D, Montori VM, Brito JP, Norris S, Elbarbary M, Post P, Nasser M, Shukla V, Jaeschke R, Brozek J, Djulbegovic B, Guyatt G. GRADE guidelines: 15. Going from evidence to recommendation-determinants of a recommendation's direction and strength. J Clin Epidemiol. 2013;66(7):726-35. 